Article

\title{
Techno-Economic Optimization Analysis of an Autonomous Photovoltaic Power System for a Shoreline Electrode Station of HVDC Link: Case Study of an Electrode Station on the Small Island of Stachtoroi for the Attica-Crete Interconnection
}

\author{
Panagiota M. Deligianni ${ }^{1}$, George J. Tsekouras ${ }^{1,2, *}$, Costas D. Tsirekis ${ }^{1,3}$, \\ Vassiliki T. Kontargyri ${ }^{2}$, , Fotis D. Kanellos ${ }^{4}$ and Panagiotis A. Kontaxis ${ }^{1,2}(\mathbb{D}$ \\ 1 Department of Electrical and Electronics Engineering, University of West Attica, 250 Thivon Str., \\ 12241 Athens, Greece; mscres-23@uniwa.gr (P.M.D.); ktsirek@uniwa.gr (C.D.T.); pkont@uniwa.gr (P.A.K.) \\ 2 School of Electrical and Computer Engineering, National Technical University of Athens, \\ Heroon Polytechniou 9, 15780 Athens, Greece; vkont@power.ece.ntua.gr \\ 3 Hellenic Independent Power Transmission Operator, Dyrrachiou 89 \& Kifissou, 10443 Athens, Greece \\ 4 School of Electrical and Computer Engineering, Technical University of Crete, University Campus, Akrotiri, \\ 73100 Chania, Greece; kanellos@ece.tuc.gr \\ * Correspondence: gtsekouras@uniwa.gr; Tel.: +30-21-0538-1750
}

Received: 22 August 2020; Accepted: 7 October 2020; Published: 23 October 2020

\begin{abstract}
A lot of autonomous power systems have been designed and operated with different power levels and with special requirements for climatic conditions, availability, operation/maintenance cost, fuel consumption, environmental impacts, etc. In this paper a novel design of an autonomous power system with photovoltaic panels and electrochemical batteries for a shoreline electrode station is analyzed. This station will be constructed on the small island of Stachtoroi for the new high voltage direct current (HVDC) link of Attica-Crete in Greece. The general guidelines of the International Council on Large Electric Systems (CIGRE) and of the International Electrotechnical Committee (IEC) for the power system of lighting and auxiliary loads for these HVDC stations are supplied from the medium voltage or the low voltage distribution network, whereas they do not take into account the criticality of this interconnection, which will practically be the unique power facility of Crete island. The significance of Crete power system interconnection demands an increased reliability level for the power sources, similar to military installations and hospital surgeries. In this research a basic electrical installation design methodology is presented. First, the autonomous photovoltaic power system with the energy storage system (ESS) consisting of electrochemical batteries is preliminary designed according to the relative bibliography. The station power and energy consumption are analytically determined taking into consideration the daily temperature variation annually. Afterwards, a techno-economic optimization process based on a sensitivity analysis is formed modifying the size/power of photovoltaic panels (PVs), the type and the energy capacity of the batteries taking into consideration the operation cycle of PVs-batteries charge and discharge and the battery ageing based on the relationship between battery cycles-the depth of discharge, the daily solar variation per month, the installation cost of PVs and batteries, the respective maintenance cost, etc., while the reliability criteria of expected loss of load power and of load energy are satisfied. Using the proposed methodology the respective results are significantly improved in comparison with the preliminary autonomous power system design or the connection with the distribution power system.
\end{abstract}

Keywords: autonomous power system; battery; photovoltaic panels; electrode station; HVDC link 


\section{Introduction}

During the last three decades many renewable isolated power systems have been installed powering a small electric machine, i.e., air conditioner [1] or a house [2] of a few kilowatts to an autonomous power system for a community [3] or an island [4] of megawatts (MW). The photovoltaic plants with energy storage systems can serve various purposes, i.e., avoiding transmission network expansion [5], transforming traditional load customers into active consumers [6], and providing reserve services to distribution network [7].

However, the main research effort focuses on the sizing and efficient operation of the autonomous photovoltaic (PV) system, the principal limitations of high capital investment for PV panels (PVs) and energy storage systems (ESSs) of low reliability and the satisfaction of electrical load requirements [8]. More specifically it deals with:

- The optimization methods for the sizing of PVs and energy storage items, which can be:

$>\quad$ Simplified for preliminary studies based on a typical daily electric load demand and meteorological data (solar irradiation and ambient temperature) [9-11],

$>$ Numerical iterative, which simulate several combinations of stand-alone photovoltaic (SAPV) components size based on the electric load demand and meteorological data of a typical year in the hourly or daily time step, with one or more objective functions and conditions, as technical (i.e., loss of load probability, loss of energy expected, and PV panel tilt angle), economic (i.e., annualized life cost, net present value, levelized cost of energy, life cycle cost, and life cost unit cost), environmental (i.e., life cycle assessment, embodied energy, and $\mathrm{CO}_{2}$ emissions), and social (i.e., job creation) [2,12-14],

$>$ Analytical optimization methods with one or more objective functions and conditions that represent the components of technical and economic specifications with mathematical equations having the additional difficulty of coefficients determination $[1,3,8]$,

> Non-conventional including a stochastic [15], artificial neural network [16], hybrid with the Pareto method and hierarchy process [17].

In any case the separating limits between the methods are not always clear, as a great number of methods, indicators, constraints, and data are involved [18-26]. Additional methods for off-grid hybrid power systems [27-30] and for energy storage systems [31,32] can be also found in the literature.

- The configuration of PVs and ESSs, where the connection can be through either a DC bus for small electric load demand installation (smaller than $3 \mathrm{~kW}$ [10]) using DC-DC converters and energy storage chargers, or an AC bus for bigger electric load demand installation (bigger than $3 \mathrm{~kW}$ [10]) using rectifiers, inverters, and energy storage charger/de-chargers. The ESSs are:

> Usually batteries, i.e., lead acid, absorbed glass mat (AGM), lithium-ion [8], nickel-cadmium [10], etc.,

> More rarely hydrogen storage tanks with an electrolyzer and fuel cells [33,34],

$>$ Combination of hydrogen storage tanks and batteries [35,36],

> More rarely a pumped-storage hydroelectric plant [13,37],

> More rarely compressed air energy storage [13,38],

$>$ Combination of hydrogen storage tanks, a pumped-storage hydroelectric plant, and batteries [39].

In the case of energy storage combination the batteries are used for short-term operation, while the other storage systems for long-term operation. The addition of other sources beyond the PV one, such as wind turbine [21,38], diesel generators [36], hydro plants [21], biogas and biomass 
generators [4,21], fuel cells without an electrolyzer and storage tank [21], and forms of the hybrid autonomous power system instead of SAPV.

- The design principles of SAPV for specific installations, as:

$>\quad$ Special electrical equipment, i.e., an air conditioner [1], pumping system [40], and milk chiller [41],

> Households [2,3,12,39], school [3], health center [3], islands [4,37], and communities [36],

$>$ Electric vehicles [19],

$>$ Electrochemical reforming of ethanol-water solutions [33], the chemical industrial process [34], and the desalination system [42],

$>\quad$ Stratospheric airship for long duration missions [43].

In this paper the design principles of SAPV for the off-grid power supply of the lighting and auxiliary loads for the shoreline electrode station of a high voltage direct current (HVDC) link is presented. Furthermore, the type and the optimum size of PVs and ESSs are determined by the proper numerical iterative sensitivity analysis method. The idea has arisen by the design of the electrode station on the small island of Stachtoroi for the new HVDC link of Attica-Crete in Greece [44]. The design procedure has shown the shortages of the International Council on Large Electric Systems (CIGRE) [45] and International Electrotechnical Committee (IEC) [46] general guidelines for the power system of HVDC stations being supplied by a medium or low voltage distribution network and not by an autonomous system. Additionally, these guidelines do not take into account the criticality of such interconnections, as HVDC links are usually supplementary supplies of backcountry areas, and the specific link will be practically the unique power facility of Crete Island. These define new requirements for the respective autonomous system, as will be explained in Section 2. In Section 3, the SAPV design methodology is presented including the electric power and energy consumption, taking into consideration the daily temperature variation as well as the proposed type of PVs and ESSs [47] and the configuration of the electrical installation. In Section 4, the main techno-economic optimization process is formed modifying the size/power of PVs and the type and the energy capacity of the batteries based on sensitivity analysis. Moreover, different issues are taken into consideration such as: (1) the operation cycle of PVs-batteries, (2) the battery ageing based on the relation between battery cycles and the depth of discharge, (3) the daily solar variation, 4) the installation cost of PVs and batteries, (5) the respective maintenance cost, etc. At the same time the expected loss of load power and energy should be zero in case of a null forced outage rate for all SAPV elements. In Section 5, the results and the discussion for the respective case study of a SAPV power system for the shoreline electrode station of the small island of Stachtoroi is presented. The adopted dimensioning method is compared with the respective classical dimensioning SAPV methods [10-12]. Finally, general conclusions are drawn and discussed in Section 6. The major contributions of this paper are:

- The definition of the electrical and architectural design principles of SAPV configuration for the off-grid power supply of the load demand for the shoreline electrode station of a HVDC link with very high requirements of availability,

- The proposed techno-economic optimization process, which can jointly determine the type and the size of PVs and batteries from real technical data directly based on the equivalent annual total cost minimization taking into account all possible combinations iteratively. Even if this numerical method looks simple, it should overcome a large number of problems, i.e., the calculation of the capital cost for different PV configurations, which can include various converters, roof expanding, etc. In other relative research works $[3,4,8-17]$ the discrete cost of the converters, roof expanding, etc., are ignored using typical capital cost functions for PVs panels, batteries, etc.

- The proposed sensitivity analysis, which is based on the variation of the equivalent annual total cost with respect to (a) the size of the PVs and of the batteries for every possible type combination of 
PVs and batteries and (b) the interest rate without inflation. The parametric interest rate allows the evaluation of the stability of the configuration of PVs and batteries for different financial scenarios.

- The mathematical formulation of PV power production, where the available solar irradiation for a time period of a specific day is calculated by the proposed solar radiation modification factor based on the respective available mean monthly irradiation. In this way different timescales for available data (i.e., temperature and solar radiation, which influence the load demand and the power production respectively) are bridged.

- The estimation of the economic lifetime of the battery, which takes into consideration (a) the battery capacity degradation and (b) the operation failure of the SAPV due to energy deficiency of the PVs-batteries system. The energy deficiency avoidance ensures high reliability in the operation of the SAPV system from the energy supply capacity point of view.

\section{Design Principles for an Electrode Station of the HVDC Link: The Case of the Small Island of Stachtoroi for the Attica-Crete Interconnection}

\subsection{General Issues of the HVDC Attica-Crete Inteconnection, Greece}

The main target is securing the electric power supply of Crete Island in Greece by the continental Greek power system, while the thermal diesel oil units are shut down for environmental reasons, especially with regard to $\mathrm{CO}_{2}$ emissions nullification in the city of Heraklion. The mean demand load of Crete is about $340 \mathrm{MW}$ with a peak load of $600 \mathrm{MW}$ approximately with increment trends because of the growth of tourism and the industrialization of agriculture. Additionally, wind parks and photovoltaic parks of $2 \mathrm{GW}$ can be installed in the island, which can cover the load demand whilst the excess power should be stored in long-term operation energy storage system, i.e., hydro-pumped plants, and be transmitted to the continental system of Greece. These reasons have led to the design and construction of two interconnections, as shown in Figure 1:

- Interconnection Peloponnese-Crete: 2 three-phase $132 \mathrm{~km}$ transmission lines with a cross-linked polyethylene (XLPE) cable technology at a maximum depth of $980 \mathrm{~m}$ with nominal apparent power $2 \times 200 \mathrm{MVA}$, at a nominal voltage of $150 \mathrm{kV}$, with a frequency of $50 \mathrm{~Hz}$ and high voltage gas insulated substations (GIS).

- Interconnection Attica-Crete: a $380 \mathrm{~km}$ bi-directional HVDC link with a bipolar heteropolar configuration with ground return beyond the sea, with a mass impregnated non-drain (MIND) or XLPE cable technology at a maximum depth of $1250 \mathrm{~m}$ with a nominal power of $2 \times 500 \mathrm{MW}$, at a nominal voltage of $\pm 500 \mathrm{kV}$ DC and voltage source converters.

The last connection will be the main one and it could be an integral part of the EuroAsia power interconnection between Greece-Cyprus-Israel [44], while the interconnection Peloponnese-Crete has a supplementary role, as it cannot supply the total island load demand with its renewable energy sources (REs) without the thermal units operation or the HVDC interconnection for power adequacy and stability issues [48].

Using the sea as a "return" cable in the Attica-Crete interconnection, there is a saving of $200 \mathrm{M€}$, while the total budget is $1200 \mathrm{M} €$. The cost of the construction of the two shoreline/pond electrode stations in Korakia, Crete and in Stachtoroi island, Attica [44] ranges from 2 to $5 \mathrm{M€}$. 


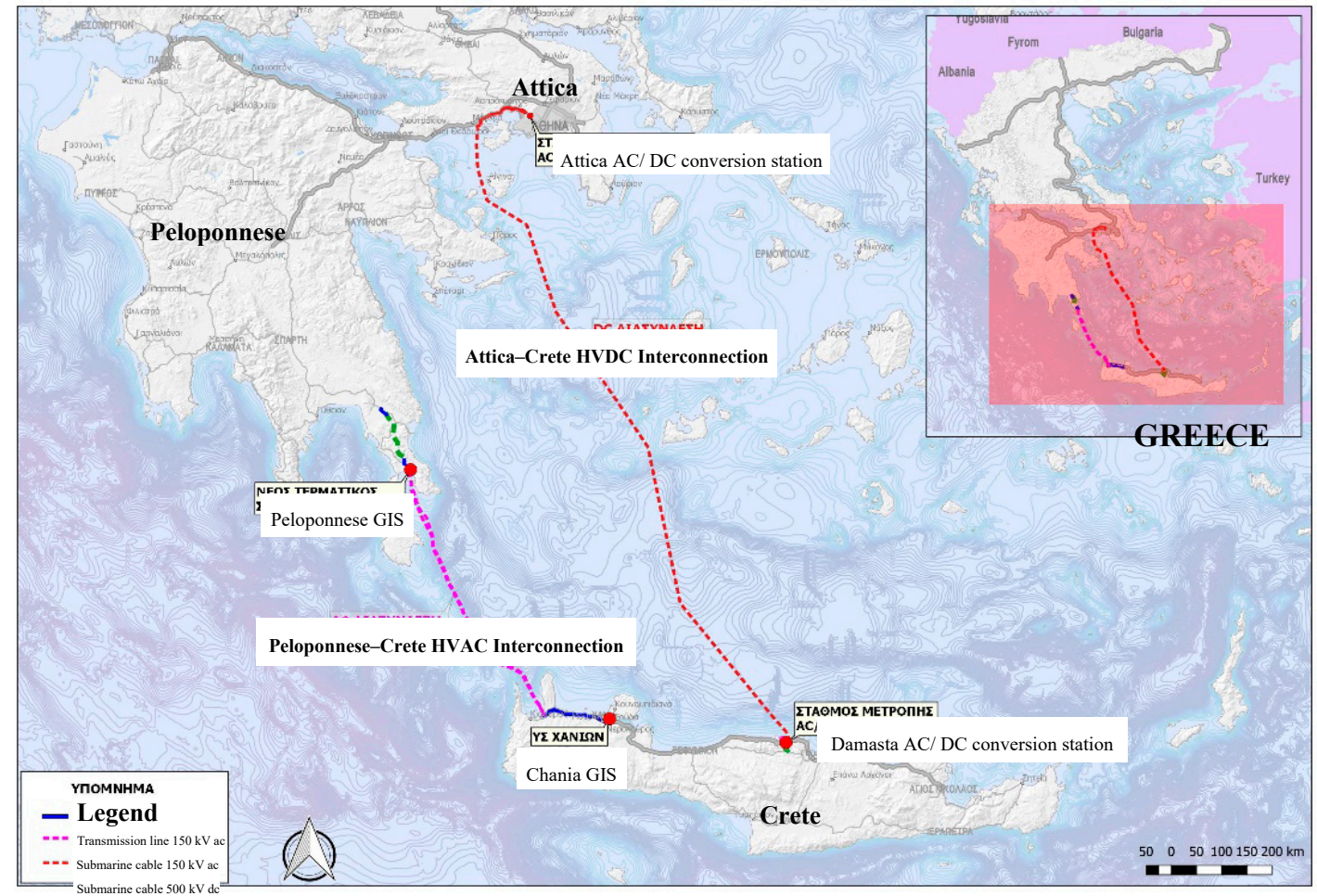

Figure 1. Geographical map of interconnections between Crete and the continental Greece power systems.

\subsection{General Guidelines by CIGRE and IEC for the Design of the Power Supply for the HVDC Eletrode Station}

The general guidelines for HVDC electrode design by CIGRE [45] and IEC [46] are focused on the:

- Electrode type selection, which is influenced by the distance between the converter station and the prospective electrode site, the soil resistivity in the area of the converter station, the operational duties of electrode operation and its limitations, the operation and maintenance processes, the expected cost, the land use limitations, the safety at the electrode site, and the possible adverse affections at the infrastructure elements.

- Site selection, which is influenced by the site exclusion for environmental reasons and neighboring electromechanical infrastructures, human settlements, culturally sensitive areas, etc., the technical, economic, geophysical, geological, and hydrological aspects.

- Local and remote impacts of electrodes operation, which includes corrosion of infrastructures, saturations of electrical transformers, potential rise and surface potential gradient at the land-sea infrastructures and the safety risks for humans, plants, animal, and marine life, soil or water overheating and the respective chemical reactions, etc.

On the contrary the instructions for connection between the electrode station and converter station for electrode stations are limited. More specifically, the guidelines of CIGRE ([45], chapter 7) for the design of the electrode of HVDC stations are limited to the requirements for electrode site monitoring, station AC and DC services, and communication links to the HVDC station or to central supervisory facility. However, the guidelines do not take into consideration the type of the electrode, the number and type of monitoring systems required at the site for facilitating HVDC scheme operation, the electrode line monitoring scheme, and the utility or owners operational and maintenance practices. The respective proposed solution for the power supply of a shoreline electrode station for the Greek distribution network would be a low voltage feeder of 230/400 V, which can cover a demand lower than $150 \mathrm{kVA}$ sufficiently. The off-site service will be typically a medium voltage (MV) feeder of $20 \mathrm{kV}$. A typical single line diagram for the station service of a site with a building and back-up diesel 
generator according to ([45], paragraph 7.2) is shown in Figure 2 satisfying the reliability criterion of " $n+1$ " power sources.

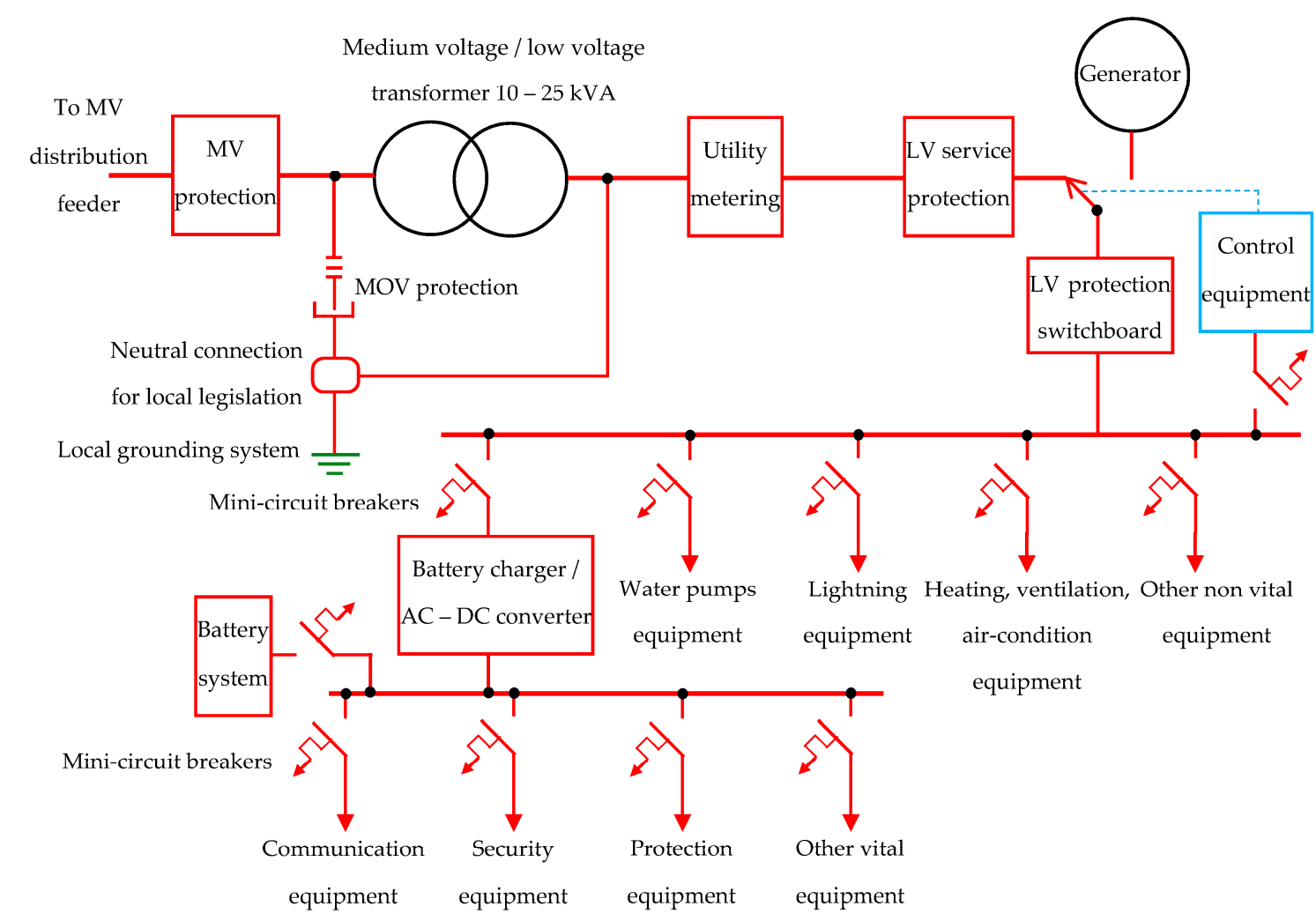

Figure 2. Typical single line diagram of the auxiliary power IT (isolated or impedance-earthed neutral) system supplied by the medium voltage distribution system according to International Council on Large Electric Systems (CIGRE; [45], similar to Figure 7.1).

Typically, non-availability of the auxiliary power system should not impact the performance of the grounding electrode negatively, and the HVDC link should operate in a degraded mode reliably without the auxiliary systems available with little or no operator intervention ([45], paragraph 7.1). However, in the HVDC link between Attica and the island of Crete the reliability level should not be decreased, because in the final operation stage the Hellenic Independent Power Transmission Operator (H-IPTSO) requires the thermal power plants in Crete to be shut down, while the HVAC Peloponnese-Crete interconnection cannot handle the load demand alone. So, another design is necessary based on the reliability criterion of " $2 \times \mathrm{n}$ " power sources, which is used in navy ships [49], hospital operation rooms, and intensive care units [50]. Additionally, the shoreline electrode station in Stachtoroi Island is isolated and cannot be easily connected with the medium or low voltage distribution network.

\subsection{Proposed Special Guidelines for the Design of the Power Supply for the HVDC Eletrode Station}

Taking into consideration the aforementioned issues of the last paragraph the respective guidelines should be improved in two axes:

1. HVDC interconnection with high reliability levels: The power supplies for normal and emergency operation are duplicated, which means that it will be two network feeders and two back-up sources, i.e., one generator and one big energy storage system or two generators. The vital loads for the HVDC interconnection, such as the control system, communication system, heating-ventilation-air condition (HVAc), etc., should be duplicated. For example, the programmable logic controller (PLC) system for the HVDC electrodes switchgear control 
is constructed by two similar units, which operate in the master-slave mode and their power supply is realized by two different power sources. Similarly the HVAc system for the main electrode station room consists of two units, where each one can cover the heating/cooling load completely. The essential loads, i.e., water pumps, can be supplied by two sources, while the non-essential loads, i.e., sockets for cleaning/maintenance purposes, can be divided to the two sources. Additionally, the proper circuit breaker between AC buses or DC buses must exist for alternative supply of essential and non-vital loads. The basic idea is presented in Figure 3.

2. Isolated/off-grid power supply for electrode stations: The connection, with the distribution network or the formation of an autonomous power system, should be decided based on minimization of the total construction, operation and maintenance cost taking into consideration technical limitations, i.e., the loss of load probability, economic, i.e., construction capital limitation, environmental, i.e., $\mathrm{CO}_{2}$ emissions reduction, etc., optimizing the selection of the type and of the size of the REs and ESSs. It is noted that the alternative autonomous system can be formed by classic thermal units, especially diesel oil generators between 10 and $25 \mathrm{kVA}$, which is the most common power plant for this power supply, or by REs, especially wind turbines and PVs, combined with ESSs, i.e., batteries or more rarely hydrogen tanks with fuel cells and electrolyzer modules, and a hydro-pumped storage power plant.

Additionally, some complicated conditions should be ensured, such as:

$>$ A remote control for the autonomous power system,

$>$ A dedicated electrode station building design, which includes:

- The limitation of the energy consumption beyond the respective regulation requirements, i.e., category A [51] reducing the autonomous power size (ideally zero energy building),

- No use of structural steel and metallic mechanical settlements because of the danger for electrochemical corrosion of metallic structures by the direct current flow between electrode stations [45] (i.e., concrete with glass fiber reinforced polymers can be suitable).

- Protection with the highest significance factor against environmental dangers, i.e., floods, earthquakes, etc.,

- Proper building orientation for PV production maximization,

- Proper foundation insulation material, i.e., asphalt, as damp proofing against humidity and electrical insulator against direct current flow between electrode stations and step voltage [45], etc.

$>$ Reduction of fire risk. This can be succeeded by:

- The increment of fire-resistance because of ESSs existence and electrode station isolation,

- The supplementary of the autonomous fire-fighting system, specialized in the presence of high voltage and active electric circuits [52], with energy storage systems [53] and crucial computer/control systems [54]. The use of dedicated fire-fighting agents, as inert gas (i.e., FM200, Novec 1230) [55,56] and special equipment, such as sprinklers [57] and impulse fire-fighting guns [58], are necessary.

It is noted that fire-protection codes do take into account the usual urban and suburban environment, but not the isolated and unapproachable area of the electrode station. So, the architecture design should proceed beyond the respective codes and may require the separation between energy storage systems, the main electrode station, the engine room, the control room, etc. 


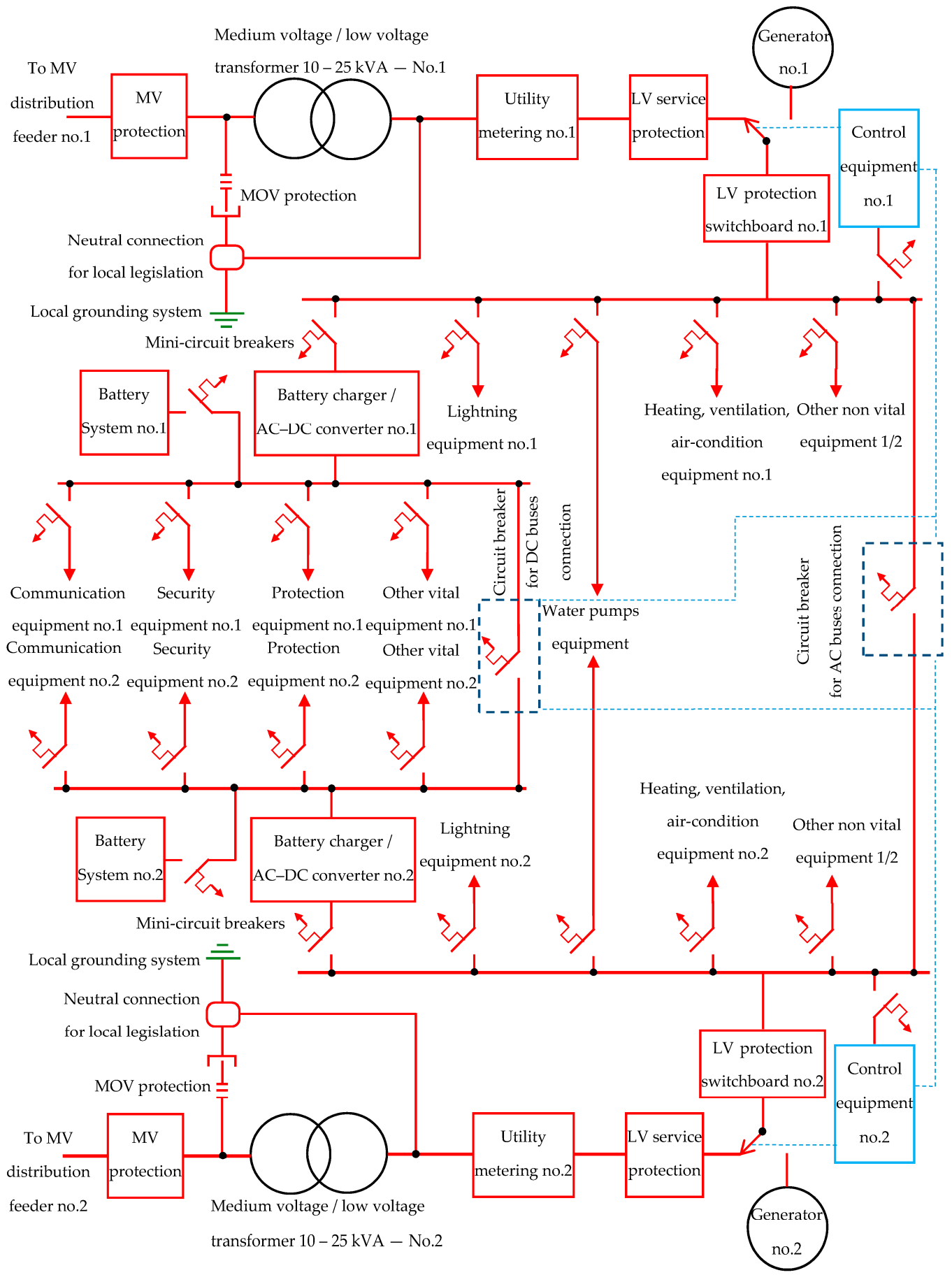

Figure 3. Proposed typical single line diagram of the auxiliary power IT system supplied by the medium voltage distribution system with high reliability requirements.

Generally, the following steps for the design of the electrode station building can be proposed:

1. Preliminary architecture design of the electrode station building based on engineers' experience for similar buildings taking into account concrete, antiseismic, energy saving legislation, etc., and rules for electrical-mechanical equipment and distribution, etc.

2. Optimum minimization of the total cost function with respect to technical, environmental, economic limitations, formatting the connection of distribution network, or the autonomous power system including the type and the size of their main elements. 
3. Examination of whether the selected power supply and supplementary settlements are satisfied by the preliminary architecture design, go to the next step, otherwise go to the first step to correct the architecture design.

4. Examination of economic viability through feasibility studies, taking into account interest rate, life cycle, construction and maintenance cost, etc.

5. Selection of the optimum architecture design.

Here, the second step for the design methodology of the electrode station building will be analyzed in the next sections for the SAPV system.

\subsection{Special Conditions for the Small Island of Stachtoroi for the Attica-Crete Interoconnection}

The electrode station of Attica has been placed on the island of Stachtoroi in the Saronic Golf, because of its adjacency to the Koumoundorou converter station in Eleusis, Attica. Simultaneously, it is quite far from residential and industrial settlements for the avoidance of electrochemical corrosion of metallic structures by the direct current flow between electrode stations [44]. The distance between this uninhabited small island with no settlements and the nearest residential area (Aegina) is $7.8 \mathrm{~km}$, as it can be seen in Figure 4.

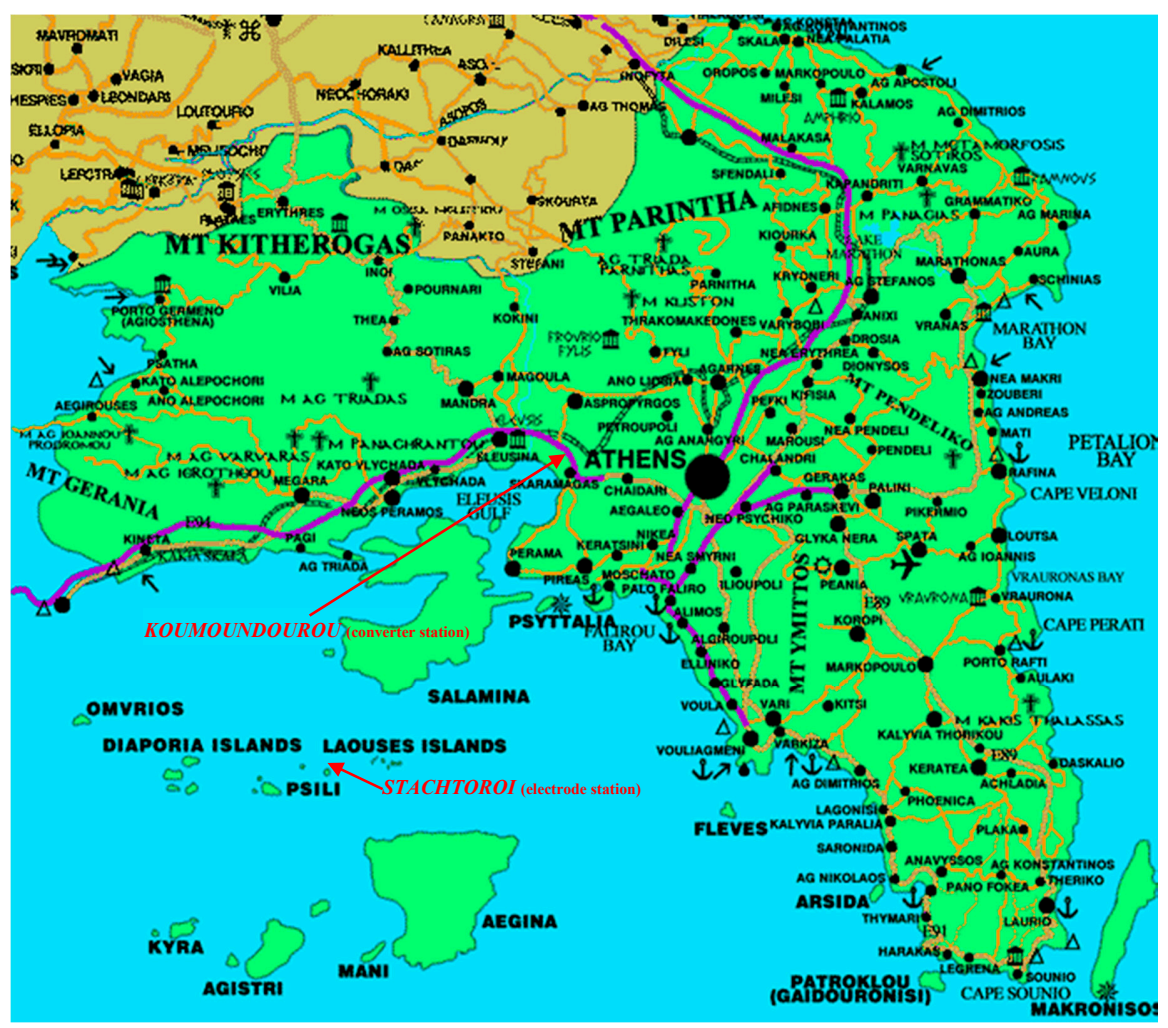

Figure 4. Geographical map of Attica mentioning the electrode station and converter station [59].

Taking into consideration the aforementioned circumstances the electrode station can be supplied either by a medium voltage three phase cable from Aegina through a step down transformer and having a back-up diesel generator power plant and a proper back-up energy storage system of at least for $48 \mathrm{~h}$, or by an autonomous power system. The first solution requires the architectural design of Figure 5, which includes the main electrode station room, the Hellenic Electricity Distribution Network Operator's (H-EDNO) medium voltage switchboard room, the electrode station medium voltage switchboard room, a transformer room, a low voltage switchboard room, a control/accommodation room, a battery room, a back-up diesel generator room, a storage room, a water and pump room, a 
water closet (W.C.), etc. The sheltered solution for the distribution connection equipment has been chosen for sea salinity protection.

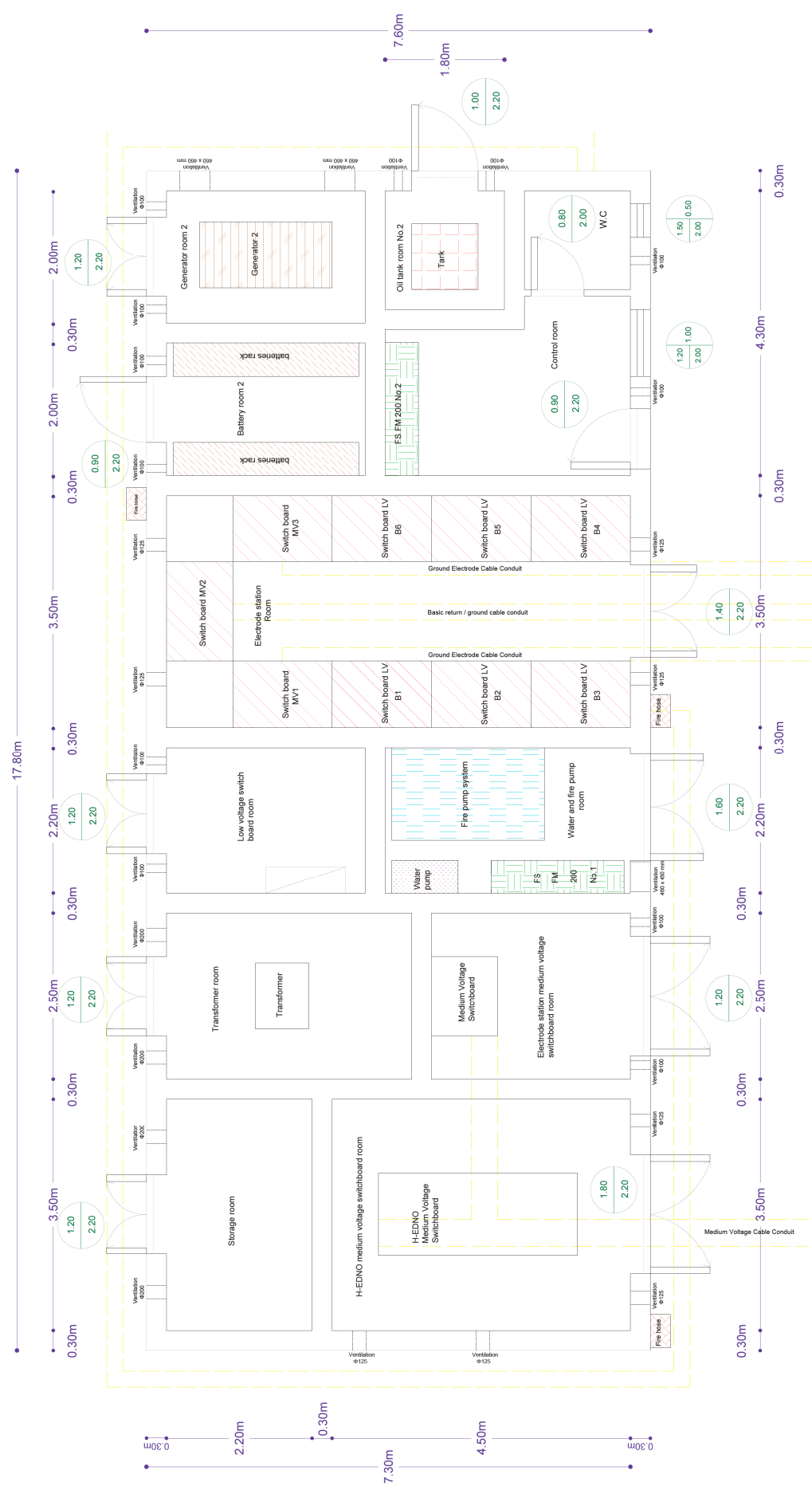

Figure 5. Layout of the electrode station building in Stachtoroi, Saronic Gulf, Attica in case of connection with the distribution network.

Alternatively, the autonomous system can involve PVs, two batteries subsections and two back-up diesel generators according to the reliability criterion of " $2 \times \mathrm{n}$ " power sources (see Section 2.2). Wind generators cannot be used, because Stachtoroi is a protected sanctuary for seagulls. The PVs should be suitable for marine applications because they are put near to the seaside (5-10 $\mathrm{m}$ from the shore). The batteries can be valve regulated lead acid (VRLA) ones or AGM ones, but not classical flooded 
lead acid ones because of the maintenance issues or lithium-ion ones because of serious difficulties in the case of fire, which is why the National Fire Protection Association (NFPA) rules propose a small capacity of $50 \mathrm{kWh}$ per fire protective segment [53]. For the same fire risk reasons, solutions as hydrogen tanks are not proposed, while a hydro-pumped storage plant cannot be placed because of a small height difference in the island. The respective architecture solution is presented in Figure 6, which includes the main electrode station room, the control/accommodation room, two battery rooms, two back-up diesel generator rooms, a storage room, a water and pump room, a W.C., etc.

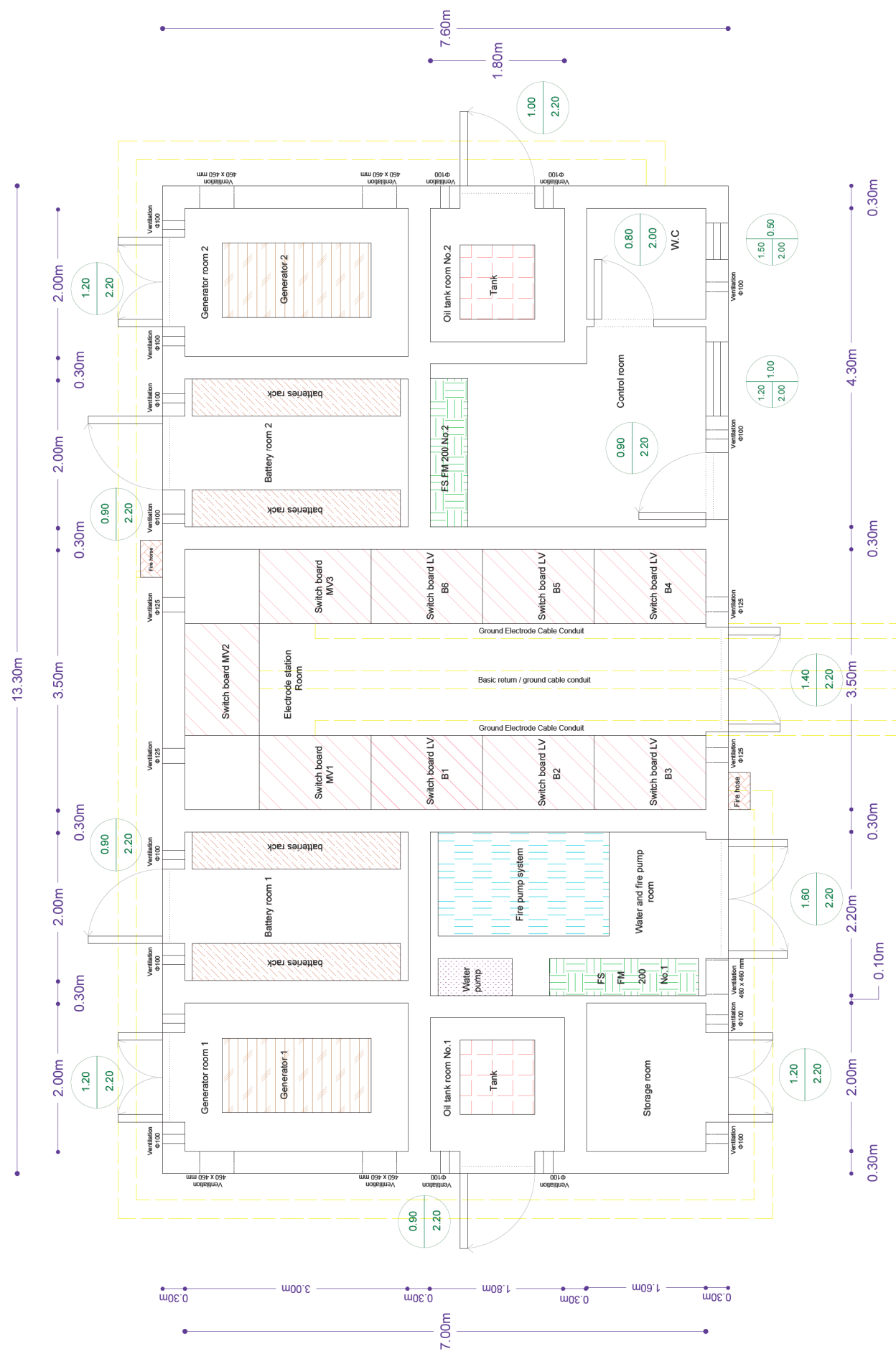

Figure 6. Layout of the electrode station building in Stachtoroi, Saronic Gulf, Attica in case of the stand-alone photovoltaic (SAPV) system with back-up diesel generators. 
The occupied area of the second architecture design is smaller by $15 \%$ than the respective area of the first one. In both cases additional special requirements have been included beyond the respective ones of Sections 2.3 and 2.4 because of the shoreline position of the electrode station:

- A small breakwater and port facility is formed because of building protection from sea waves and to allow for ships calling at the installation and maintenance.

- All rooms have proper ventilation and dehumidifier equipment.

- External lighting is necessary, including one aviation obstruction light buoy, according to International Aviation Organization (ICAO) guidelines because of adjacency to a Hellenic Navy practice field.

- Three $40 \mathrm{~m}^{3}$ underground tanks are constructed for firefighting and water cleanness reasons, as well as a small underground $2 \mathrm{~m}^{3}$ sewage water tank on the opposite site.

Especially for the SAPV solution, the following is also needed:

- The building has southern exposure for the better PVs operation.

- The PVs inclination is put at $3^{\circ}$ for rain/water follow out, adapted to the roof, without any frame, obstructing seagulls constructing nests.

\section{Classical Design Methodology for Stand Alone Photovoltaic Panels with Batteries}

\subsection{Basic Steps of the Classical Design Methodology}

The basic steps for the sizing of the power system with PVs and batteries are:

- Daily electric energy consumption: The power system total daily peak load $P_{A}$ and the daily energy $E_{d a y}$ are calculated as:

$$
\begin{gathered}
P_{\text {install }-i}=N_{i} \times C_{\text {install }-i} \\
P_{A-i}=P_{\text {install }-i} \times \zeta_{i} \times \sigma_{i} \\
P_{A-i}^{\prime}=P_{A-i} / r_{i} \\
E_{i}=m_{i} \times P_{A-i} \times T \\
P_{A}=\sum_{i=1}^{N} P_{A-i}^{\prime} \\
E_{\text {day }}=\sum_{i=1}^{N} E_{i}
\end{gathered}
$$

where $C_{\text {install-i }}$ is the installed power of the ith electric consumer, $N_{i}$ the consumer population, $P_{\text {install }-i}$ the total install power of the ith consumer type, $\zeta_{i}$ the demand factor, $\sigma_{i}$ the coincidence factor per consumer category, $P_{A-i}$ the peak load per consumer category, $r_{i}$ the participation factor at the power system total peak load, $m_{i}$ the mean load factor for time period under study $T(=24 \mathrm{~h})$, $P^{\prime}{ }_{A-i}$ the partition peak load per consumer category at the power system total peak load, and $E_{i}$ the energy demand per consumer category.

- Optimized selection of the inclination angle/slope $a$ for PVs based on the time period optimized operation and PVs azimuth angle: The slope $a$ is connected with latitude $\varphi$ and daily solar radiation with no-linear process:

Solar declination $\delta$ calculation for the current day of the year for the calculation of daily solar irradiation (DoY; i.e., DoY $=1$ for 1 January):

$$
\delta^{\circ}=23.45^{\circ} \times \sin \left(\frac{360^{\circ}}{365} \times(\text { DoY }-81)\right)
$$


$>\quad$ Total mean solar irradiation $H_{m}$ at the horizontal level in the Earth surface determination either by an experimental process, or by a bibliography for the specific area in $\mathrm{kWh} / \mathrm{m}^{2}$ per month [11].

$>\quad$ Time sunset $\omega_{s}$ calculation:

$$
\omega_{s}=\cos ^{-1}(-\tan \delta \times \tan \varphi)
$$

Mean monthly extraterrestrial solar irradiation $H_{o m}$ at the horizontal level without the Earth atmosphere in $\mathrm{kWh} / \mathrm{m}^{2}$ per month [11]:

$$
\begin{aligned}
& H_{o m}=\frac{M_{m} \times 24 \times I_{o}}{\pi} \times\left(1+0.0333 \times \cos \left(\frac{360^{\circ}}{365} \times \operatorname{DoY}\right)\right) \times\left(\cos \varphi \times \cos \delta \times \sin \omega_{s}+\sin \varphi \times \sin \delta \times\right. \\
& \left.\frac{\pi \cdot \omega_{s}}{180^{\circ}}\right)
\end{aligned}
$$

where $M_{m}$ is the population of days of the $\mathrm{m}^{\text {th }}$ month and $I_{o}$ the solar constant or otherwise the long-term average extraterrestrial total solar irradiance equal to $1367 \mathrm{~W} / \mathrm{m}^{2}$ [10].

Lucidity $K_{m}$ calculation as the ratio between the mean monthly solar irradiation $H_{m}$ at the horizontal level in the Earth surface and respective extraterrestrial solar irradiation $H_{o m}$ at the same level:

$$
K_{m}=\frac{H_{m}}{H_{o m}}
$$

$>\quad$ Determination of the ratio between diffused solar irradiation $H_{m d}$ at the horizontal level in the Earth surface and the respective total solar irradiation $H_{m}$ based on Lala's function ([11], Equation (2.48)):

$$
\frac{H_{m d}}{H_{m}}=1446-2965 \times K_{m}+1727 \times K_{m}^{2}
$$

$>\quad$ Calculation of correction factor $R_{B}$ of the total direct mean monthly solar irradiation for the south-facing PVs with slope $a$ with respect to the total mean monthly solar irradiation for horizontal PVs:

$$
R_{B}=\frac{\cos (\varphi-a) \times \cos \delta \times \sin \omega_{s}^{\prime}+\sin (\varphi-a) \times \sin \delta \times \frac{\pi}{180^{\circ}} \times \omega_{s}^{\prime}}{\cos \varphi \times \cos \delta \times \sin \omega_{s}+\sin \varphi \times \sin \delta \times \frac{\pi}{180^{\circ}} \times \omega_{s}}
$$

where $\omega_{s}^{\prime}$ is the hourly sunset angle for the day DoY for the south-facing PVs with slope $a$ :

$$
\omega_{s}^{\prime}=\min \left\{\omega_{s}, \cos ^{-1}(-\tan \delta \times \tan (\varphi-a))\right\}
$$

Calculation of correction factor $R_{M}$ of the total mean monthly solar irradiation for the south-facing PVs with slope $a$ with respect to the total mean monthly solar irradiation for horizontal PVs ([11], Equation (2.47)):

$$
R_{M}=\left(1-\frac{H_{m d}}{H_{m}}\right) \times R_{B}+\frac{H_{m d}}{H_{m}} \times \frac{1+\cos a}{2}+\rho \times \frac{1-\cos a}{2}
$$

where $\rho$ is the solar radiation reflection factor with a typical value of 0.2 for land use, 0.05 for asphalt, sea, dark-colored rocks, etc., and 0.60 for light-colored rocks, etc.

Calculation of total mean solar irradiation $H_{m \text {-panel }}$ for the south-facing PVs with slope $a$ in the Earth surface ([11], Equation (2.51)):

$$
H_{m-\text { panel }}=R_{M} \times H_{m}
$$


According to the previous subsection, PVs inclination has been adapted to the roof, without any frame, so the respective angle of the obstacles' shadow is null and the total mean solar irradiation has not been modified according to ([10], p. 264, eq. (35), [11], Equation (2.47), [11], and Equation (2.51)).

Calculation of total mean solar irradiation $H_{m-\text { panel-Tp }}$ for the time period under optimized $>$ operation $T_{p}$ :

$$
H_{m-\text { panel }-T_{p}}=\sum_{m \in T_{p}} M_{m} \times H_{m-\text { panel }}
$$

For different combinations of slope $a$ with the null shadow angle, the maximum total mean solar radiation for the time period optimized operation is selected.

It is noted that Equation (7) to Equation (16) can be used either for the monthly solar irradiation, or the daily one or another time period. In the case of the month of study, a typical DoY is equal to 15,46 , $74,105,135,166,196,227,258,288,319$, and 349 for January, February, ... , and December respectively.

- Calculation of the daily available solar irradiation/energy $H_{m \text {-panel-day }}$ for the selected slope $a$ with the null shadow angle:

$$
H_{m-\text { panel-day }}=\frac{H_{m-\text { panel }}}{M_{m}}
$$

- Calculation of the population of PVs with nominal power $P_{n o m P V}$, nominal voltage $V_{n o m P V}$, and nominal $I_{\text {nomPV }}$ at standard test conditions (STC: $1.5 \mathrm{AM}, P_{S T C}=1000 \mathrm{~W} / \mathrm{m}^{2}, 25^{\circ} \mathrm{C}$ ): The essential power supply $P_{\alpha_{-} m o n}$ by the PVs is given by:

$$
P_{a_{-} \text {mon }}=\sigma_{\text {in_Eday }} \times \frac{E_{\text {day }} \times P_{\text {STC }}}{\sigma_{\text {TotLoss } P V} \times \sigma_{\text {Tran_el_losses }} \times H_{m-\text { panel-day }}^{\prime}} \times \frac{M_{m}}{M_{m}-n}
$$

where the autonomy population of days $n$ varies from 5 to 10 (for critical settlements), the PV daily energy increment factor $\sigma_{\text {in_Eday }}$ with typical values range from $115 \%$ up to $125 \%$ depending on the accuracy of the estimation for the daily electrical energy consumption, the PV transmission electrical losses correction factor $\sigma_{\text {Tran_el_losses }}$ with typical values range from $75 \%$ up to $99 \%$ depending on the existence of DC or AC buses, converters-inverters batteries ([10], p. 406, Table 9), the factor of the total loss of PVs $\sigma_{\text {TotLossPV }}$ is given by:

$$
\sigma_{\text {TotLossPV }}=\sigma_{\text {pollution }} \times \sigma_{\text {ageing }} \times \sigma_{\text {blocking_diode }} \times \sigma_{\text {no_homogeneity }} \times \sigma_{\text {cable }} \times \sigma_{\text {Temp }}
$$

where the PV pollution correction factor $\sigma_{\text {pollution }}$ with typical values range from $80 \%$ up to $95 \%$, the PV ageing correction factor $\sigma_{\text {ageing }}$ with a typical annual degradation $1 \%$, the blocking diode losses correction factor $\sigma_{\text {blocking_diode }}$ with a typical value of $99 \%$, the PV lack of homogeneity factor $\sigma_{\text {no_homogeneity }}$ with a typical value of $98 \%$, the PV cables losses factor $\sigma_{\text {cables }}$ with typical values range from $97 \%$ up to $99 \%$, the PV temperature correction factor $\sigma_{\text {Temp }}$ is given by the mean monthly temperature $T_{\text {month }}$ when the temperature difference between the environment and PVs is $D T_{e n-P V}$, the environment temperature $T_{r e f-e n}$, and the typical power decrease factor $f_{d_{-} T e m p}$ [10]:

$$
\sigma_{\text {Temp }}=1-\left(T_{\text {month }}+D T_{e n-P V}-T_{\text {ref-en }}\right) \times f_{d_{-} \text {Temp }}
$$

The necessary population of PVs $N_{\text {panel }}$ is calculated by:

$$
N_{\text {panel }}=\left\lceil\frac{P_{a \_m o n}}{P_{\text {nomPV }}}\right\rceil
$$


- Capacity calculation of the battery storage system based on autonomy population of days $n$ and battery depth of discharge DoD: The essential battery capacity $C_{n o m}$ of the ESSs with operation nominal voltage $V_{\text {nomESS }}$ is given by:

$$
C_{\text {nom }}=\frac{1}{k_{\text {Temp }}} \times \sigma_{\text {in_EEday_ESS }} \times \frac{E_{\text {day }} \times\left(n+\ell_{D}\right)}{\sigma_{\text {ageing_ESS }} \times \sigma_{\text {Tran_el_losses_ESS }} \times D o D \times V_{\text {nomESS }}}
$$

where the indirect PV service of the electric consumption factor $\ell_{D}$ with typical values range from $0 \%$ up to $100 \%$ (typical value $80 \%$ in case that PVs supply the $20 \%$ from electrical load consumption directly), the battery daily energy increment factor $\sigma_{\text {in_Eday_ESS }}$ with typical values range from $115 \%$ up to $125 \%$ depending on the accuracy of the estimation for the daily electrical energy consumption, the battery transmission electrical losses correction factor $\sigma_{\text {Tran_el_losses_ESS }}$ with typical values range from $90 \%$ up to $97 \%$ depending on the existence of DC or AC buses, converters-inverters ([10], p. 417), the battery ageing correction factor $\sigma_{\text {ageing_ESS }}$ with a typical value of $80 \%$ for lead acid batteries ([10], p. 415), the battery temperature correction factor $k_{\text {Temp }}$ is given with respect to the annual temperature $T_{\text {year }}$ :

$$
k_{\text {Temp }}= \begin{cases}1, & T_{\text {year }} \geq 20^{\circ} \mathrm{C} \\ 1-\frac{20^{\circ} \mathrm{C}-T_{\text {year }}}{160^{\circ} \mathrm{C}}, & T_{\text {year }}<20^{\circ} \mathrm{C}\end{cases}
$$

- Calculation of electrical installation elements: The configuration and the number of battery elements and of PVs, the dimensions of cables, converters, battery chargers, and control systems are determined taking into consideration the electroscience principles, i.e., the cable dimensions include the insulation level based on maximum operation voltage, the conductor cross section based on the maximum thermal operation current, maximum short circuit current, voltage drop, protection system design, etc. [50].

\subsection{Daily Electric Energy Consumption for the Electrode Station of Stachtoroi Island}

In case of a SAPV system, each electric consumption of the electrode station should be studied during different seasons (winter, summer, and autumn-spring) and different operational modes (stand alone mode and maintenance mode). At the maintenance mode the electrode station is inhabited by H-IPTSO personnel for a few hours per month, while the operation of back-up diesel-electric generators is necessary for the generators maintenance. The heating and cooling split units operate for keeping the temperature between 10 and $30^{\circ} \mathrm{C}$ in battery rooms and the electrode station room for all modes, and between 20 and $26^{\circ} \mathrm{C}$ in the accommodation room during the maintenance mode. The extreme external temperature is $0^{\circ} \mathrm{C}$ for the winter and $40^{\circ} \mathrm{C}$ for the summer season. Lighting, heating, cooling, ventilation, and dehumidifier loads are estimated per each room based on its dimensions of Figure 6 and the respective electric consumer is formed. In Tables 1-3 the respective consumers per room with area $A$ and the respective power and energy demand are presented. The total daily peak load and the daily energy were calculated by Equation (1) to Equation (6). 
Table 1. Daily peak power and energy consumption for the electrode station in Stachtoroi Island, Attica.

\begin{tabular}{|c|c|c|c|c|c|c|c|c|c|c|c|c|c|}
\hline \multirow[b]{2}{*}{ Room/A } & \multirow[b]{2}{*}{$\begin{array}{c}\text { Electric } \\
\text { Consumption }\end{array}$} & \multirow[b]{2}{*}{$C_{i n s t a l l-i}$} & \multirow[b]{2}{*}{$N_{i \ldots}$} & \multirow[b]{2}{*}{ nstall- $i$} & \multirow[b]{2}{*}{$\zeta_{i}$} & \multicolumn{4}{|c|}{ Normal Mode with PVs and Batteries } & \multicolumn{4}{|c|}{$\begin{array}{l}\text { Maintenance Mode with Diesel-Electric } \\
\text { Units in Operation }\end{array}$} \\
\hline & & & & & & $\sigma_{i}$ & $m_{i}$ & $P_{A-i}$ & $E_{i}$ & $\sigma_{i}$ & $m_{i}$ & $P_{A-i}$ & $E_{i}$ \\
\hline$\left(\mathrm{m}^{2}\right)$ & $(-)$ & (W) & $(-)$ & $(\mathrm{W})$ & $(-)$ & $(-)$ & $(-)$ & $(W)$ & (Wh) & $(-)$ & $(-)$ & $(W)$ & (Wh) \\
\hline \multirow{5}{*}{ Generator 1 or $2 / 6.00$} & Lighting & 16 & 2 & 32 & 1.0 & 0.0 & 0.0 & 0.0 & 0.0 & 1.0 & 0.5 & 32 & 384 \\
\hline & Ventilation $^{1}$ & 13 & 1 & 13 & 1.0 & 1.0 & 1.0 & 13 & 312 & 1.0 & 0.49 & 13 & 153 \\
\hline & Ventilation $^{2}$ & 110 & 2 & 220 & 1.0 & 0.0 & 0.0 & 0.0 & 0.0 & 1.0 & 0.51 & 220 & 2693 \\
\hline & Sockets & 3500 & 1 & 3500 & 1.0 & 0.0 & 0.0 & 0.0 & 0.0 & 0.3 & 0.01 & 1050 & 252 \\
\hline & Dehumidifier & 22.5 & 1 & 22.5 & 1.0 & 1.0 & 0.6 & 22.5 & 324 & 1.0 & 0.5 & 22.5 & 270 \\
\hline \multirow{5}{*}{ Tank 1 or $2 / 3.24$} & Lighting & 16 & 1 & 16 & 1.0 & 0.0 & 0.0 & 0.0 & 0.0 & 1.0 & 0.05 & 16 & 19.2 \\
\hline & Ventilation & 13 & 1 & 13 & 1.0 & 1.0 & 0.4 & 13 & 124.8 & 1.0 & 0.4 & 13 & 124.8 \\
\hline & Motors & 9 & 1 & 9 & 1.0 & 0.0 & 0.0 & 0.0 & 0.0 & 1.0 & 0.06 & 9.0 & 12.96 \\
\hline & Sockets & 3500 & 1 & 3500 & 1.0 & 0.0 & 0.0 & 0.0 & 0.0 & 0.3 & 0.005 & 1050 & 126 \\
\hline & Dehumidifier & 22.5 & 1 & 22.5 & 1.0 & 1.0 & 0.33 & 22.5 & 178.2 & 1.0 & 0.33 & 22.5 & 178.2 \\
\hline \multirow{5}{*}{ Storage/3.20 } & Lighting & 16 & 1 & 16 & 1.0 & 0.0 & 0.0 & 0.0 & 0.0 & 1.0 & 0.05 & 16 & 19.2 \\
\hline & Ventilation & 13 & 1 & 13 & 1.0 & 1.0 & 0.4 & 13 & 124.8 & 1.0 & 0.4 & 13 & 124.8 \\
\hline & Motors & 1900 & 1 & 1900 & 1.0 & 0.0 & 0.0 & 0.0 & 0.0 & 1.0 & 0.005 & 1900 & 228 \\
\hline & Sockets & 3500 & 1 & 3500 & 1.0 & 0.0 & 0.0 & 0.0 & 0.0 & 0.3 & 0.005 & 1050 & 126 \\
\hline & Dehumidifier & 22.5 & 1 & 22.5 & 1.0 & 1.0 & 0.32 & 22.5 & 172.8 & 1.0 & 0.32 & 22.5 & 172.8 \\
\hline \multirow{8}{*}{$\begin{array}{l}\text { Water and fire } \\
\text { pump/8.14 }\end{array}$} & Lighting & 16 & 4 & 64 & 1.0 & 0.0 & 0.0 & 0.0 & 0.0 & 1.0 & 0.05 & 64 & 76.8 \\
\hline & Ventilation $^{1}$ & 13 & 1 & 13 & 1.0 & 1.0 & 1.0 & 13 & 312 & 1.0 & 0.99 & 13 & 309 \\
\hline & Ventilation $^{2}$ & 245 & 2 & 220 & 1.0 & 0.0 & 0.0 & 0.0 & 0.0 & 1.0 & 0.01 & 490 & 117.6 \\
\hline & Water pump & 1000 & 2 & 2000 & 0.5 & 1.0 & 0.01 & 1000 & 240 & 1.0 & 0.02 & 1000 & 480 \\
\hline & Jockey fire pump & 1000 & 1 & 1000 & 1.0 & 1.0 & 0.001 & 1000 & 24 & 1.0 & 0.001 & 1000 & 24 \\
\hline & Air-compressor & 2000 & 1 & 2000 & 1.0 & 1.0 & 0.001 & 2000 & 48 & 1.0 & 0.001 & 2000 & 48 \\
\hline & FM200 fire station 1 & 100 & 1 & 100 & 1.0 & 1.0 & 0.10 & 100 & 240 & 1.0 & 0.10 & 100 & 240 \\
\hline & Sockets & 3500 & 1 & 3500 & 1.0 & 0.0 & 0.0 & 0.0 & 0.0 & 0.3 & 0.005 & 1050 & 126 \\
\hline
\end{tabular}

${ }^{1}$ Ventilation without any diesel engine operation. ${ }^{2}$ Cooling and air combustion ventilation during diesel engine operation. 
Table 2. Daily peak power and energy consumption for the electrode station in Stachtoroi Island, Attica.

\begin{tabular}{|c|c|c|c|c|c|c|c|c|c|c|c|c|c|}
\hline \multirow[b]{2}{*}{ Room/A } & \multirow[b]{2}{*}{$\begin{array}{c}\text { Electric } \\
\text { Consumption }\end{array}$} & \multirow[b]{2}{*}{$C_{\text {install-i }}$} & \multirow[b]{2}{*}{$N_{i \ldots}$} & \multirow[b]{2}{*}{ nstall- $i$} & \multirow[b]{2}{*}{$\zeta_{i}$} & \multicolumn{4}{|c|}{ Normal Mode with PVs and Batteries } & \multicolumn{4}{|c|}{$\begin{array}{l}\text { Maintenance Mode with Diesel-Electric } \\
\text { Units in Operation }\end{array}$} \\
\hline & & & & & & $\sigma_{i}$ & $m_{i}$ & $P_{A-i}$ & $E_{i}$ & $\sigma_{i}$ & $m_{i}$ & $P_{A-i}$ & $E_{i}$ \\
\hline$\left(\mathrm{m}^{2}\right)$ & $(-)$ & (W) & $(-)$ & (W) & $(-)$ & $(-)$ & $(-)$ & $(W)$ & (Wh) & $(-)$ & $(-)$ & $(W)$ & (Wh) \\
\hline \multirow{5}{*}{ Battery 1 or $2 / 6.00$} & Lighting & 16 & 2 & 32 & 1.0 & 0.0 & 0.0 & 0.0 & 0.0 & 1.0 & 0.5 & 32 & 384 \\
\hline & Ventilation & 13 & 1 & 13 & 1.0 & 1.0 & 1.0 & 13 & 312 & 1.0 & 1.0 & 13 & 312 \\
\hline & Sockets & 3500 & 1 & 3500 & 1.0 & 0.0 & 0.0 & 0.0 & 0.0 & 0.3 & 0.005 & 1050 & 126 \\
\hline & Split unit Summer & 1240 & 1 & 1240 & 1.0 & 1.0 & 0.22 & 1240 & 6547 & 1.0 & 0.22 & 1240 & 6547 \\
\hline & Split unit ${ }^{\text {Winter }}$ & 1200 & 1 & 1200 & 1.0 & 1.0 & 0.20 & 1200 & 5760 & 1.0 & 0.20 & 1200 & 5760 \\
\hline \multirow{7}{*}{ Electrode station/24.5 } & Lighting & 16 & 8 & 128 & 1.0 & 0.0 & 0.0 & 0.0 & 0.0 & 1.0 & 0.3 & 128 & 921.6 \\
\hline & Ventilation & 30 & 1 & 30 & 1.0 & 1.0 & 1.0 & 30 & 720 & 1.0 & 1.0 & 30 & 720 \\
\hline & PLC System & 100 & 2 & 100 & 1.0 & 1.0 & 0.5 & 200 & 2400 & 1.0 & 0.5 & 100 & 2400 \\
\hline & Control system & 100 & 1 & 100 & 1.0 & 1.0 & 0.8 & 100 & 1920 & 1.0 & 0.5 & 100 & 1920 \\
\hline & Sockets & 3500 & 1 & 3500 & 1.0 & 0.0 & 0.0 & 0.0 & 0.0 & 0.3 & 0.1 & 1050 & 2520 \\
\hline & Split unit ${ }^{\text {Summer }}$ & 1240 & 1 & 1240 & 1.0 & 1.0 & 0.76 & 1240 & 22,618 & 1.0 & 0.76 & 1240 & 22,618 \\
\hline & Split unit ${ }^{\text {Winter }}$ & 1200 & 1 & 1200 & 1.0 & 1.0 & 0.58 & 1200 & 16,704 & 1.0 & 0.58 & 1200 & 16,704 \\
\hline \multirow{9}{*}{ Control-accommodation/11.5 } & Lighting & 16 & 4 & 64 & 1.0 & 0.0 & 0.0 & 0.0 & 0.0 & 1.0 & 0.3 & 64 & 460.8 \\
\hline & Ventilation & 25 & 1 & 25 & 1.0 & 1.0 & 1.0 & 25 & 600 & 1.0 & 1.0 & 25 & 600 \\
\hline & FM200 fire station 2 & 50 & 1 & 50 & 1.0 & 1.0 & 0.10 & 50 & 120 & 1.0 & 0.10 & 50 & 120 \\
\hline & Small cooker & 3000 & 1 & 3000 & 1.0 & 0.0 & 0.0 & 0.0 & 0.0 & 1.0 & 0.04 & 3000 & 2880 \\
\hline & Heater & 4000 & 1 & 4000 & 1.0 & 0.0 & 0.0 & 0.0 & 0.0 & 1.0 & 0.04 & 4000 & 3840 \\
\hline & Sockets & 3500 & 1 & 3500 & 1.0 & 0.0 & 0.0 & 0.0 & 0.0 & 0.3 & 0.1 & 1050 & 2520 \\
\hline & Dehumidifier & 22.5 & 1 & 22.5 & 1.0 & 1.0 & 1.0 & 22.5 & 540 & 1.0 & 1.0 & 22.5 & 540 \\
\hline & Split unit ${ }^{\text {Summer }}$ & 1240 & 1 & 1240 & 1.0 & 0.0 & 0.0 & 0.0 & 0.0 & 1.0 & 0.95 & 1240 & 28,272 \\
\hline & Split unit ${ }^{\text {Winter }}$ & 1200 & 1 & 1200 & 1.0 & 0.0 & 0.0 & 0.0 & 0.0 & 1.0 & 0.60 & 1200 & 17,280 \\
\hline
\end{tabular}


Table 3. Daily peak power and energy consumption for the electrode station in Stachtoroi Island, Attica.

\begin{tabular}{|c|c|c|c|c|c|c|c|c|c|c|c|c|c|}
\hline \multirow[b]{2}{*}{ Room/A } & \multirow[b]{2}{*}{ Electric Consumption } & \multirow[b]{2}{*}{$C_{\text {install-i }}$} & \multirow[b]{2}{*}{$N_{i \ldots}$} & \multirow[b]{2}{*}{$n s t a l l-i$} & \multirow[b]{2}{*}{$\zeta_{i}$} & \multicolumn{4}{|c|}{$\begin{array}{c}\text { Normal Mode with PVs } \\
\text { and Batteries }\end{array}$} & \multicolumn{4}{|c|}{$\begin{array}{c}\text { Maintenance Mode with } \\
\text { Diesel-Electric Units in Operation }\end{array}$} \\
\hline & & & & & & $\sigma_{i}$ & $m_{i}$ & $P_{A-i}$ & $E_{i}$ & $\sigma_{i}$ & $m_{i}$ & $P_{A-i}$ & $E_{i}$ \\
\hline$\left(\mathrm{m}^{2}\right)$ & $(-)$ & $(W)$ & $(-)$ & $(W)$ & $(-)$ & $(-)$ & $(-)$ & $(W)$ & (Wh) & $(-)$ & $(-)$ & (W) & (Wh) \\
\hline \multirow{5}{*}{ Surrounding } & Aviation obstruction light buoy & 10 & 10 & 10 & 1.0 & 1.0 & 1.0 & 10 & 240 & 1.0 & 1.0 & 10 & 240 \\
\hline & Lighting & 13 & 10 & 130 & 1.0 & 0.0 & 0.0 & 0.0 & 0.0 & 1.0 & 0.5 & 130 & 1560 \\
\hline & Sockets & 3500 & 1 & 3500 & 1.0 & 0.0 & 0.0 & 0.0 & 0.0 & 0.3 & 0.005 & 1050 & 126 \\
\hline & \multirow[t]{2}{*}{ Season } & \multicolumn{4}{|c|}{ Summer maximum } & \multirow{2}{*}{\multicolumn{2}{|c|}{ Total }} & 8564 & 47,644 & \multirow{2}{*}{\multicolumn{2}{|c|}{ Total }} & 22,250 & 98,474 \\
\hline & & \multicolumn{4}{|c|}{ Winter maximum } & & & 8444 & 40,156 & & & 22,090 & 79,994 \\
\hline
\end{tabular}


It is noted that the participation factor at the power system total peak load $r_{i}$ was equal to 1 because of a lack of experimental data, so in this case the peak load $P_{A-i}$ per ith consumer was equal to the partition peak load $P^{\prime}{ }_{A-i}$. The only exception involves sockets, where it is acceptable that 2 sockets lines can be in operation at peak load from a total of 11 lines at the maintenance mode, which means that the respective factor was equal to 5.5. From the respective results the following remarks could be mentioned:

- For the normal operation mode the total daily peak load was $4.8 \mathrm{~kW}$ during spring-autumn without split units in operation, $8.44 \mathrm{~kW}$ during winter with split units in maximum heating operation and $8.5 \mathrm{~kW}$ during summer with split units in maximum cooling operation, whereas the maximum daily energy load consumption was $11.93,40.16$, and $47.64 \mathrm{kWh}$ respectively.

- For the maintenance mode with diesel-electric generators in operation the total daily peak load was $17.3 \mathrm{~kW}$ during spring-autumn, $22.02 \mathrm{~kW}$ during winter and $22.25 \mathrm{~kW}$ during summer, whereas the maximum daily energy load consumption was $34.44,79.99$, and $98.47 \mathrm{kWh}$ respectively, even if its practical value was limited to the fuel oil tank dimensions because of only a few hours of operation.

In this case the maximum peak load was $22.25 \mathrm{~kW}$ with typically an inductive power factor of 0.8 , the respective maximum apparent power was $27.8 \mathrm{kVA}$, which means that one back-up $25 \mathrm{kVA}$ diesel engine electric generator power unit with $10 \%$ overload capability for small time periods should be used. The respective engine room can receive the power unit. Otherwise, H-EDNO should give a three-phase typical power supply of $25 \mathrm{kVA}$.

\subsection{Preliminary Study of Stand-Alone Photovoltaic with Batteries for the Electrode Station of Stachtoroi Island}

After the calculation of the daily electric energy consumption (Section 3.2), the total monthly mean solar irradiation $H_{m-\text { panel }}$ for the south-facing PVs with slope $a$ in the Earth surface can be realized by Equation (7) to Equation (16) with a reflection factor equal to 0.2 because of the mixed environment (sea, light-colored earth) without the shadow angle in Stachtoroi Island, Attica (longitude $-23.361770^{\circ}$, latitude $37.815199^{\circ}$ ). In this case the PVs slope was set at $3^{\circ}$ for rain/water run-off, adapted to the roof, without any frame, with a null shadow angle, obstructing seagulls to construct nests causing mediocre solar radiation for the winter months (see $H_{m-p a n e l}$ in Table 4 ). It is noted that the best slope was $28^{\circ}$ annually, whilst for the summer period the slope should be small and for the winter period big at $60^{\circ}$. 
Table 4. Calculation of the essential photovoltaic panels (PVs) power supply of the population of PVs and of the battery capacity with respect to mean monthly solar radiation with an angle inclination of $3^{\circ}$ and null shadow angle in Stachtoroi Island, Attica.

\begin{tabular}{|c|c|c|c|c|c|c|c|c|c|c|}
\hline & $M_{m}$ & $E_{\text {day }}$ & $H_{m-p a n e l}$ & $H^{\prime}{ }_{m-p a n e l-d a y}$ & $T_{\text {month }}$ & $\sigma_{T e m p}$ & $\sigma_{\text {TotLossPV }}$ & $P_{\alpha \_m o n}$ & $N_{\text {panel }}$ & $C_{\text {nom }}$ \\
\hline Month & $(-)$ & (kWh/d) & $\left(\mathrm{kWh} /\left(\mathrm{m}^{2} \cdot \mathrm{month}\right)\right)$ & $\left(\mathrm{kWh} /\left(\mathrm{m}^{2} \cdot \mathrm{d}\right)\right)$ & $\left({ }^{\circ} \mathrm{C}\right)$ & $(-)$ & $(-)$ & (W) & $(-)$ & (A.h) \\
\hline January & 31 & 16.079 & 67.88 & 2.190 & 10.03 & 0.9429 & 0.8068 & 18,177 & 119 & 3724 \\
\hline February & 28 & 15.911 & 75.89 & 2.710 & 10.24 & 0.9421 & 0.8062 & 15,326 & 100 & 3685 \\
\hline March & 31 & 14.438 & 123.28 & 3.977 & 11.61 & 0.9369 & 0.8017 & 9044 & 59 & 3344 \\
\hline April & 30 & 12.178 & 160.02 & 5.334 & 15.54 & 0.9219 & 0.7889 & 5873 & 39 & 2821 \\
\hline May & 31 & 11.968 & 196.43 & 6.336 & 19.66 & 0.9063 & 0.7755 & 4864 & 32 & 2772 \\
\hline June & 30 & 12.470 & 214.36 & 7.145 & 24.90 & 0.8864 & 0.7585 & 4669 & 31 & 2888 \\
\hline July & 31 & 14.224 & 218.81 & 7.058 & 27.83 & 0.8753 & 0.7490 & 5374 & 35 & 3294 \\
\hline August & 31 & 14.165 & 198.69 & 6.409 & 27.80 & 0.8754 & 0.7491 & 5893 & 39 & 3281 \\
\hline September & 30 & 12.174 & 159.83 & 5.328 & 24.13 & 0.8893 & 0.7610 & 6094 & 40 & 2820 \\
\hline October & 31 & 11.965 & 110.3 & 3.558 & 19.07 & 0.9085 & 0.7774 & 8639 & 57 & 2771 \\
\hline November & 30 & 12.512 & 68.45 & 2.282 & 14.49 & 0.9259 & 0.7923 & 14,046 & 92 & 2898 \\
\hline December & 31 & 14.751 & 58.42 & 1.885 & 11.39 & 0.9377 & 0.8024 & 19,483 & 127 & 3417 \\
\hline
\end{tabular}


Next, the photovoltaic panel Sxp154Q or Sxp154L by Solbian [60] was chosen, which is suitable for marine applications with $P_{\text {nomPV }}=154 \mathrm{~W}, V_{\text {nomPV }}=18.2 \mathrm{~V}, I_{\text {nomPV }}=8.5 \mathrm{~A}$ at STC, open circuit voltage $V_{o c}=23.0 \mathrm{~V}$, short circuit current $I_{s c}=9.1 \mathrm{~A}, D T_{e n-P V}=30{ }^{\circ} \mathrm{C}, T_{r e f-e n}=25{ }^{\circ} \mathrm{C}, f_{d_{-} \text {Temp }}=0.38 \% /{ }^{\circ} \mathrm{C}$, and dimensions $1046 \mathrm{~mm} \times 996 \mathrm{~mm} \times 2 \mathrm{~mm}$ or $1523 \mathrm{~mm} \times 683 \mathrm{~mm} \times 2 \mathrm{~mm}$, respectively [60]. The autonomy population of days $n$ was equal to 10 because of the critical settlements, the PV daily energy increment factor $\sigma_{i n_{-} E d a y}$ was $115 \%$ and the battery daily energy increment factor $\sigma_{\text {in_Eday_ESS }}$ was $115 \%$ because of the high accuracy of the estimation for the daily electrical energy consumption estimation, the PV transmission electrical losses correction factor $\sigma_{\text {Tran_el_losses }}$ was $85 \%$ and the battery transmission electrical losses correction factor for energy storage system $\sigma_{\text {Tran_el_losses_ESS }}$ was $91 \%$ because of the existence of AC bus with inverters batteries, etc., the PV pollution correction factor $\sigma_{\text {pollution }}$ was $90 \%$ because of the small inclination and of the use of cleanliness water sprinkler system, the PV old age correction factor $\sigma_{\text {old_age }}$ was $90 \%$ because of a typical marine PVs time life of 10 years, while the rest factors had typical values ( $\sigma_{\text {blocking_diode }}=99 \%, \sigma_{\text {no_homogeneity }}=98 \%, \sigma_{\text {cables }}=98 \%, \sigma_{\text {Temp }}$ by Equation (20), $\sigma_{\text {old_age_ESS }}=80 \%, \ell_{D}=80 \%$, and $k_{\text {Temp }}$ by Equation (23)). The battery nominal voltage $V_{\text {nomESS }}$ was $110 \mathrm{~V}$, because of the H-IPTO battery system standardization reasons, while the available depth of discharge $D o D$ was $70 \%$ for $7-10$ autonomy days ([10], p. 416, Table 16). The respective population of PVs was calculated by Equation (18) to Equation (21), while the battery capacity by Equation (22) and the results are presented in Table 4, where daily energy $E_{\text {day }}$ per month varied, because the heating-cooling electric load of split units was modified linearly with respect to the monthly mean temperature $T_{\text {month }}$.

From the respective results the PV nominal power should be $19.48 \mathrm{~kW}$, which means 128 panels Sxp154Q practically in 4 parallel branches with 32 panels in series succeeding a maximum open circuit voltage of $864.4 \mathrm{~V}$ with the $115 \%$ safety factor, maximum short circuit current of $11.38 \mathrm{~A}$ per branch with the $125 \%$ safety factor, nominal operation voltage of $582.4 \mathrm{~V}$ at maximum power, maximum nominal operation current of $10.63 \mathrm{~A}$ at maximum power for cables dimensions, etc. The nominal power per branch was $4928 \mathrm{~kW}$ and the maximum one $6.16 \mathrm{~kW}$ (+25\% for solar radiation superabundance). So, if each inverter serves two branches, its nominal power should be $12.4 \mathrm{~kW}$ at $400 \mathrm{~V} \mathrm{AC} / 50 \mathrm{~Hz}$ and two inverters is needed typically. Each inverter with two branches forms a PV power plant, as it is shown in Figure 7. The building roof should be also expanded by $1.0 \mathrm{~m}$ per each dimension so as to be $14.30 \mathrm{~m} \times 8.60 \mathrm{~m}$, as it is presented in Figure 8. Other PV formations need more area.

For the battery system a capacity of 3724 Ah at $110 \mathrm{~V}$ should be formed. If the $12 \mathrm{~V} 100$ Ah AGM VRLA battery element is chosen by Narada Company [61], 342 VLRA elements will be needed-38 parallel branches with 9 elements in series. So, two battery storage systems are formed with 17 parallel branches $\times 9$ elements in series. Alternatively, if the $2 \mathrm{~V} 1360$ Ah gel form RES 8 SOPzV 1360 battery element is chosen by Sunlight Company [62], 165 elements will be needed-3 parallel branches with 55 elements in series forming three battery storage systems, respectively. The division of PVs and energy storage system in parts improves reliability behavior generally. In case of failure of one battery system the remaining ones should cover the total load demand, i.e., if two ESSs exist, their chargers/dechargers nominal power can be equal to the peak load or if three ESSs exist, their chargers/dechargers nominal power can be equal to the half of the peak load.

Additionally, two back-up diesel-engine generator sets of $25 \mathrm{kVA}$ are put in with a fuel oil tank of $1000 \mathrm{~L}$ for each one, for reliability reasons. They are going to serve the load demand rarely, either in the maintenance mode or in case of a total failure of the autonomous system operation. The respective interconnections between AC buses or DC buses are presented in Figure 7.

However, this preliminary design does not ensure that the proposed system is the optimized one with technical-economic criterions, while crucial elements have been ignored or simplified such as the PVs and battery lifetime, degradation of the battery capacity based on the depth of discharge, battery self-discharge, PV power production variation because of seasonal and daily solar radiation variance, load demand variation because of seasonal and daily temperature variance, etc. In the next section the proposed methodology will confront these issues. 


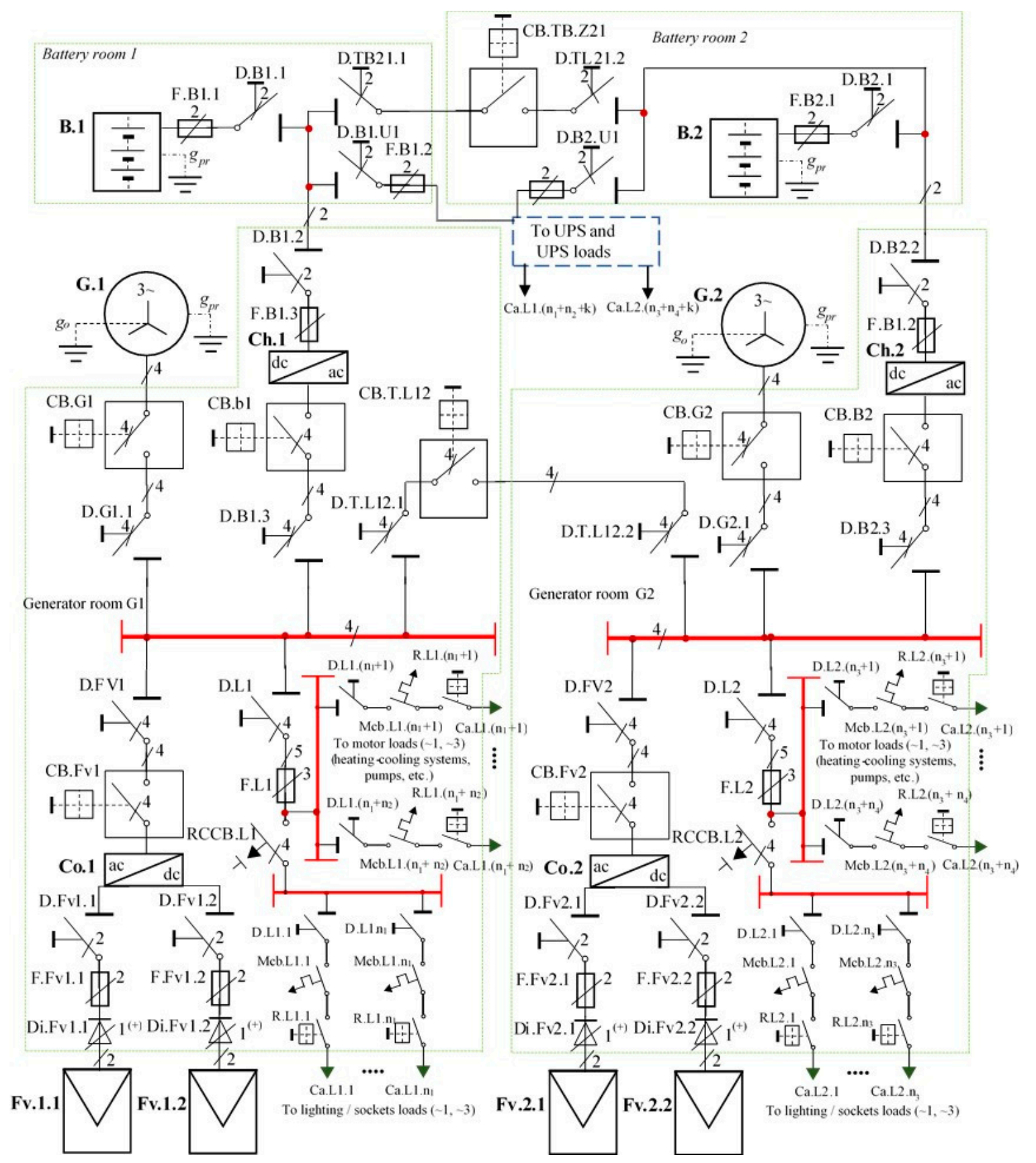

Figure 7. Typical single line diagram of an autonomous power system (back-up diesel engine electric generator- $\mathrm{G}$, photovoltaic panels $-\mathrm{FV}$, and battery storage system-B) for the electrode station building in Stachtoroi, Attica. (D: disconnector, F: fuse, CB: circuit breaker, Di: blocking diode, Mcb: mini circuit breaker, RCCB: residual current circuit breaker, R: relay switch, Ca: cable, Co: converter, Ch: charger, Fv: photovoltaic panel branch, B: battery, L: line, and T = interconnection). 


\begin{tabular}{|c|c|c|c|c|c|c|c|c|c|c|c|c|c|c|c|}
\hline 1.1 & 1.2 & 1.3 & 1.4 & 1.5 & 1.6 & 1.7 & 1.8 & 1.9 & 1.10 & 1.11 & 1.12 & 1.13 & 1.14 & 1.15 & 1.16 \\
\hline 2.1 & 2.2 & 2.3 & 2.4 & 2.5 & 2.6 & 2.7 & 2.8 & 2.9 & 2.10 & 2.11 & 2.12 & 2.13 & 2.14 & 2.15 & 2.16 \\
\hline \multicolumn{16}{|c|}{ 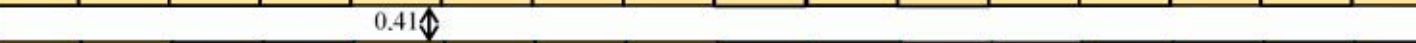 } \\
\hline 3.1 & 3.2 & 3.3 & 3.4 & 3.5 & 3.6 & 3.7 & 3.8 & 3.9 & 3.10 & 3.11 & 3.12 & 3.13 & 3.14 & 3.15 & 3.16 \\
\hline 4.1 & 4.2 & 4.3 & 4.4 & 4.5 & 4.6 & 4.7 & 4.8 & 4.9 & 4.10 & 4.11 & 4.12 & 4.13 & 4.14 & 4.15 & 4.16 \\
\hline \multicolumn{16}{|c|}{$0.41 \mathbb{1}$} \\
\hline 5.1 & 5.2 & 5.3 & 5.4 & 5.5 & 5.6 & 5.7 & 5.8 & 5.9 & 5.10 & 5.11 & 5.12 & 5.13 & 5.14 & 5.15 & 5.16 \\
\hline 6.1 & 6.2 & 6.3 & 6.4 & 6.5 & 6.6 & 6.7 & 6.8 & 6.9 & 6.10 & 6.11 & 6.12 & 6.13 & 6.14 & 6.15 & 6.16 \\
\hline \multicolumn{16}{|c|}{$0.41 \uparrow$} \\
\hline 7.1 & 7.2 & 7.3 & 7.4 & 7.5 & 7.6 & 7.7 & 7.8 & 7.9 & 7.10 & 7.11 & 7.12 & 7.13 & 7.14 & 7.15 & 7.16 \\
\hline 8.1 & 8.2 & 8.3 & 8.4 & 8.5 & 8.6 & 8.7 & 8.8 & 8.9 & 8.10 & 8.11 & 8.12 & 8.13 & 8.14 & 8.15 & 8.16 \\
\hline
\end{tabular}

Figure 8. Roof expansion and positioning of 128 PVs type Sxp154Q by Solbian, 16 PVs in the East-West axis and 8 PVs in the North-South axis with 3 corridors with a width of $41 \mathrm{~cm}$ and nominal power $19,712 \mathrm{~W}$.

\section{Proposed Design Methodology for Stand Alone Photovoltaic Panels with Batteries}

\subsection{Basic Goals of Proposed Design Methodology for SAPV with Batteries}

The basic goal of the proposed methodology is to minimize the total cost of construction, operation, and maintenance of the stand-alone photovoltaic panels with batteries that supply the electrode station at the Stachtoroi Island, varying the PVs population and the type and the capacity of batteries, taking into consideration simultaneously:

- The daily operation process of the respective power system with the technical limitations of PVs, inverters, batteries, etc.,

- The seasonal and daily variation of the electrode station load demand with respect to the available temperature (here the average three hours temperature for 15 years are available from the neighboring meteorological station),

- The seasonal and daily variation of PV power production with respect to the available radiation (here the mean monthly irradiation is available in the neighboring area from [11] and its time-scale is properly adjusted through the process of Section 4.3),

- The reliability level from an energy point of view, where the SAPV operation will be failed if the load demand is supplied by the back-up diesel-engine generator sets because of energy deficiency of the PVs-batteries system (the generator sets should operate only in case of forced outages).

- The environmental limitation of $\mathrm{CO}_{2}$ emissions reduction, which is succeeded indirectly as the generator sets are going to operate only for maintenance and SAPV forced outage reasons, not for energy supply systematically, which means that $\mathrm{CO}_{2}$ emissions are nullified practically.

Next, the respective mathematical description will be presented. 


\subsection{Mathematical Formulation of the SAPV Daily OPERATION Process}

Each SAPV configuration, which consists of a specific PVs population $N_{\text {panel }}$, of the battery type (i.e., AGM VRLA, and gel), and of the battery capacity $C_{n o m}$, is studied during its operation. During the time period under study $T_{p}$ for each time step $t$ with a time duration of $d t$ the PVs power production $P_{P V}(t)$ is constant, and is determined by the solar radiation of that time step and the daily hour in Section 4.3 , while the load demand $P_{\text {load }}(t)$ is also constant and its value is calculated with respect to the environmental temperature $T_{\text {temp }}(t)$ taking into consideration the electrical consumptions of Tables 1-3 with emphasis in split-units operation, where the respective load demand $P_{\text {load_split_unit }}$ is formed as:

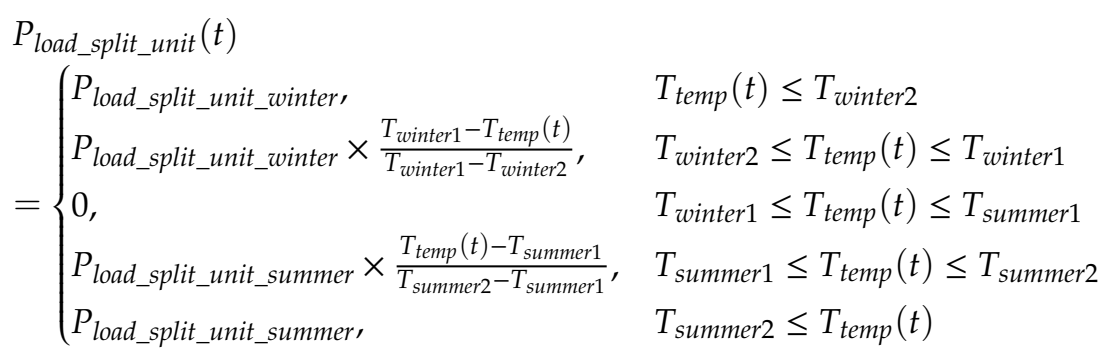

where during the winter period the maximum power load demand by split-unit is $P_{\text {load_split_unit_winter }}$ at temperature $T_{\text {winter } 2}$ and its operation starts under temperature $T_{\text {winter } 1}$, while during the summer period the respective maximum power load demand by split-unit is $P_{\text {load_split_unit_summer }}$ at temperature $T_{\text {summer } 2}$ and its operation starts above temperature $T_{\text {summer } 1}$.

The battery stored energy $E(t)$ at the time step $t$ is formed with respect to the previous time step $(t-1)$ and operation phase (charge, discharge, and no-operation) by:

$$
\begin{gathered}
\text { Charge phase : } E(t)=\left(1-n_{r}\right) \times E(\mathrm{t}-1)+n_{c h} \times P_{c h}(t) \times d t \\
\text { Discharge phase : } E(t)=\left(1-n_{r}\right) \times E(t-1)-\frac{P_{\text {dis }}(t)}{n_{\text {dis }}} \times d t \\
\text { No-operation phase : } E(t)=\left(1-n_{r}\right) \times E(t-1)
\end{gathered}
$$

Under the following conditions:

Power balance for all phases: $P_{c h}(t)+P_{\text {load }}(t)+P_{\text {add }}(t)=P_{\text {dis }}(t)+P_{P V}(t)+P_{L O E}(t)$

Only one phase existence : $P_{d i s}(t) \times P_{c h}(t)=0$

Battery power limitations during the charge phase : $0 \leq P_{c h}(t) \leq P_{c h-\max }$

Battery power limitations during the discharge phase : $0 \leq P_{\text {dis }}(t) \leq P_{\text {dis-max }}$

$$
\text { Battery energy limitations : } 0 \leq S o C j^{\prime} j^{\prime}(t)(t) j^{\prime} j^{\prime}(t)_{\max } \min
$$

Produced PV power loss limitation : $P_{\text {add }}(t) \times u\left(S o C j^{\prime} j^{\prime}(t)(t)_{\max }()\right)$

Load demand power loss limitation : $P_{L O E}(t) \times u\left(E(t)-S o C j^{\prime} j^{\prime}(t)_{\min }()\right)$

Under the following definitions:

$$
\begin{gathered}
\text { State of charge } S o C(t) / \text { Depth of discharge } D o D(t): S o C(t)=1-D o D(t)=\frac{E(t)}{C_{n o m} \times V_{\text {nomESS }}} \\
\text { Produced PV energy loss : } E_{\text {add }}=\sum_{t=1}^{T_{p}} P_{\text {add }}(t) \times d t
\end{gathered}
$$




$$
\text { Load demand energy loss : } E_{L O E}=\sum_{t=1}^{T_{p}} P_{L O E}(t) \times d t
$$

where $P_{c h}(t)$ is the battery charge power, $n_{c h}$ the charge efficiency factor, $P_{d i s}(t)$ the battery discharge power, $n_{\text {dis }}$ the discharge efficiency factor, $n_{r}$ the self-discharge rate (i.e., $2-20 \%$ per month for lead acid batteries), $P_{\text {add }}(t)$ the produced PV power loss in case of maximum state of battery charge and $E_{\text {add }}$ the respective energy, $P_{L O E}(t)$ the load demand power loss in case of the minimum state of battery charge and $E_{L O E}$ the respective energy, $S o C(t)$ the state of battery charge, which is connected with the depth of discharge $D o D(t)$ univocally by Equation (35), $C_{j}{ }^{\prime}$ the remaining capacity of battery for the $j$ th day of the time period under study, $V j /(t)$ the respective battery voltage, $S o C_{\min }$ and $S o C_{\max }$ the minimum and the maximum state of battery charge (i.e., $20 \%$ and $95 \%$ for lead acid batteries) respectively, $P_{c h-m a x}$ the maximum battery charge power (which is determined by the nominal characteristics of charger and the battery nominal current that varies between $1 \%$ and $500 \%$ of the nominal discharge current in $10 \mathrm{~h}$ for lead acid batteries), and $P_{\text {dis-max }}$ the maximum battery discharge power (which is determined by the nominal characteristics of the charger and the maximum battery nominal discharge current. In our case, for 10 days of autonomy the mean discharge current lasts more than $100 \mathrm{~h}$, which is the biggest duration usually listed by manufacturers [61,62]). $u(x)$ is the classical step function.

The aforementioned steps are repeated until either the lifetime of elements (usually of the battery) is exhausted according to the elements ageing process (see Section 4.4 for battery degradation and Equation (63)) or the load demand power loss is not zero, so back-up generators should be operated because of energy inadequacy. The energy deficiency of the PVs-battery system also determines the economic lifetime of crucial elements such as batteries, even if their physical lifetime have not been exhausted, and it will be the alternative stopping criterion of steps repetition. Practically the maximum $T_{p}$ is found, when the multiplicands of Equation (34) are null marginally. Simultaneously, the reliability level of energy adequacy is satisfied as the load demand power loss and the energy loss are ensured to be zero until that time step.

\subsection{Mathematical Formulation of the PV Panels Power Production}

The available solar radiation data is the mean monthly irradiation $H_{m-p a n e l}$ by Table 4 , which gives the daily available solar irradiation $H_{m-\text { panel-day }}$ by Equation (17) easily. In order to find out the PVs power production during $t$ and $t+d t$ hours the respective available solar irradiation $H_{m \text {-panel-day }}(t, t$ $+d t$ ) is calculated based on $H_{m-p a n e l-d a y}$ and the proposed solar radiation modification factor $f_{\text {Hmday }}(t$, $t+\mathrm{d} t)$ :

$$
\begin{aligned}
& H_{m-\text { panel-day }}(t, t+d t)=f_{\text {Hmday }}(t, t+d t) \times H_{m-\text { panel-day }} \\
& f_{\text {Hmday }}(t, t+d t)=\frac{\tan \delta \times \tan \varphi \times(\omega(t+d t)-\omega(t))+(\sin (\omega(t+d t))-\sin (\omega(t)))}{2 \times\left(\tan \delta \cdot \tan \varphi \cdot \omega_{s}+\sin \omega_{s}\right)} \\
& \geq 0
\end{aligned}
$$

Under the conditions for sunrise and sunset hours:

$$
-\omega_{s} \leq \omega(t) \leq \omega_{s} \&-\omega_{s} \leq \omega(t+d t) \leq \omega_{s}
$$

This happens because the sun angle position (altitude) during the day is given by:

$$
\sin \beta=\sin \delta \times \sin \varphi+\cos \delta \times \cos \varphi \times \cos \omega
$$

So, the daily available solar irradiation $H_{m-p a n e l-d a y}$ for the selected $a$ angle inclination with the null shadow angle is calculated based on the solar declination $\delta$ by Equation (7), the $\omega_{s}$ sunset, the $\left(-\omega_{s}\right)$ sunrise, the $M_{m}$ population of days of the mth month, and the $I_{o-m d a y}$ solar radiation intensity and it is:

$$
H_{m-\text { panel-day }}=\frac{H_{m-\text { panel }}}{M_{m}}=I_{o-m d a y} \times \int_{-\omega_{s}}^{\omega_{s}}(\sin \delta \times \sin \varphi+\cos \delta \times \cos \varphi \times \cos \omega) \times d \omega
$$


where the parameters $a_{1}$ and $a_{2}$ are determined as:

$$
\begin{aligned}
& a_{1}=I_{o-m \text { day }} \times \sin \delta \times \sin \varphi \\
& a_{2}=I_{o-\text { mday }} \times \cos \delta \times \cos \varphi
\end{aligned}
$$

From the combination of Equations (43) and (44):

$$
a_{1}=a_{2} \times \tan \delta \times \tan \varphi
$$

From the combination of Equations (41) and (43):

$$
H_{m-\text { panel-day }}=\int_{-\omega_{s}}^{\omega_{s}}\left(a_{1}+a_{2} \times \cos \omega\right) \times d \omega=a_{1} \times 2 \times \omega_{s}+a_{2} \times 2 \times \sin \omega_{s}
$$

From the combination of Equations (45) and (46):

$$
a_{2}=\frac{1}{2} \times \frac{H_{m-\text { panel-day }}}{\sin \omega_{s}+\omega_{s} \times \tan \delta \times \tan \varphi}
$$

Under conditions of Equation (40) the available solar irradiation $H_{m \text {-panel-day }}(t, t+d t)$ between $t$ and $t+d t$ hours is equal to:

$$
\begin{aligned}
H_{m-\text { panel-day }}(t, t+d t) & =I_{o-\text { mday }} \times \int_{\omega(t)}^{\omega(t+d t)}(\sin \delta \times \sin \varphi+\cos \delta \times \cos \varphi \times \cos \omega) \times d \omega \\
\Rightarrow & \\
H_{m-\text { panel-day }}(t, t+d t)= & \int_{\omega(t)}^{\omega(t+\Delta d t)}\left(a_{1}+a_{2} \times \cos \omega\right) \times d \omega \Rightarrow \\
H_{m-\text { panel-day }}(t, t+d t) & =a_{1} \times(\omega(t+d t)-\omega(t))+a_{2} \times(\sin (\omega(t+d t))-\sin (\omega(t))) \Rightarrow \\
H_{m-\text { panel-day }}(t, t+d t) & =I_{o-\text { mday }} \times \frac{\tan \delta \times \tan \varphi \times(\omega(t+d t)-\omega(t))+(\sin (\omega(t+d t))-\sin (\omega(t)))}{2 \times\left(\tan \delta \times \tan \varphi \times \omega_{s}+\sin \omega_{s}\right)}
\end{aligned}
$$

Next, the PVs power production $P_{P V}(t)$ is calculated by:

$$
P_{P V}(t)=\sigma_{\text {TotLoss } P V} \times \sigma_{\text {inv }} \times \sigma_{P V} \times \frac{H_{m-\text { panel-day }}(t, t+d t)}{d t} \times N_{\text {panel }} \times A_{\text {panel }}
$$

Under the condition:

$$
P_{P V}(t) \geq P_{P V \min }
$$

where $\sigma_{i n v}$ is the PV inverter efficiency factor (i.e., typically 0.92), $\sigma_{P V}$ is the PVs efficiency factor (i.e., typically 0.147 for Sxp154Q panel), $A_{\text {panel }}$ the area of one PVs (i.e., $1.041816 \mathrm{~m}^{2}$ for Sxp154Q), and $P_{P V l i m}$ the lowest operational limit for PVs (it usually corresponds to solar irradiance $200 \mathrm{~W} / \mathrm{m}^{2}$ ).

\subsection{Mathematical Formulation of the Battery Capacity Degradation}

The batteries manufacturers advertise a nominal lifetime $T_{\text {bat_life }}$ of 5-20 years for lead acid batteries without mentioning the ageing phenomena because of charge-discharge cycles. In reality the battery storage and usage lead on static and dynamic degradation, respectively [63-65]. The first one is caused by the deterioration of the functional characteristics of the battery materials without any operation (only discharge can exist), mostly the electrodes corrosion and the electrolyte oxidation, while the second one is mainly affected by the electrical and thermal forces due to the battery cycle, environment conditions (especially temperature), and depth of discharge. The battery life loss rate can be divided to static and dynamic ones being formulated in years ${ }^{-1}$ [63]. Here, the mathematical formulation is based on days ${ }^{-1}$ because one battery cycle is practically realized every day, as during 
daylight the battery is charged by PVs, while during night it is discharged. The daily static loss rate $\gamma_{s}{ }^{\prime}$ is calculated by:

$$
\gamma_{s}^{\prime}=\frac{1}{T_{\text {bat_life }}[\text { days }]}
$$

The daily dynamic loss rate $\gamma_{d-j}{ }^{\prime}$ is estimated by:

$$
\gamma_{d-j^{\prime}}=\sum_{i=1}^{n_{j}} \frac{1}{N_{D-j^{\prime}}}
$$

where $N_{D-j}{ }^{\prime}$ indicates the maximum number of cycles allowed for the actual remaining capacity of the battery corresponding to its discharge depth remaining between specific upper and lower limits of the nominal capacity, while $n_{j}$ is the number of cycles during a day. In case of one main cycle per day Equation (53) is simplified as:

$$
\gamma_{d-j}^{\prime}=\frac{1}{N_{D-j^{\prime}}}
$$

The maximum number of cycles $N_{D}$ mainly depends on the depth of discharge $D o D$ [63-65] and secondarily on the environment temperature [64]. Here, only $D o D$ is considered because the temperature effect involves extra laboratory tests. The respective function can be exponential [65], double-exponential [62], simplified hyperbolic [10], hyperbolic, and power one respectively:

$$
\begin{gathered}
N_{D}=a \times \exp (-b \times D o D): a, b>0 \\
N_{D}=a_{1} \times \exp \left(-b_{1} \times D o D\right)+a_{2} \times \exp \left(b_{2} \times D o D\right): a_{1}, a_{2}, b_{1}, b_{2}>0 \\
N_{D}=\frac{V_{N_{D} \cdot D o D}}{D o D}: V_{N_{D} \cdot D o D}>0 \\
N_{D}=\frac{c}{D o D}+d: c, d>0 \\
N_{D}=e \times D o D^{-f}: e, f>0
\end{gathered}
$$

where $a, b, a_{1}, a_{2}, b_{1}, b_{2}, V_{N D \cdot D o D}, c, d, e$, and $f$ can be estimated by the least square errors (LSE) method. The best adaptation for the $N_{D}-D o D$ curves is determined by the criteria of the mean square error $J$ and correlation index $r$ for $n_{d}$ experimental values pairs:

$$
\begin{gathered}
J=\frac{1}{n_{d}} \times \sum_{i=1}^{n_{d}}\left(N_{D i}-N_{D i, \text { real }}\right)^{2} \\
r=\frac{\sum_{i=1}^{n_{d}}\left(N_{D i}-\overline{N_{D}}\right) \times\left(N_{D i, \text { real }}-\overline{N_{D, \text { real }}}\right)}{\sqrt{\sum_{i=1}^{n_{d}}\left(N_{D i}-\overline{N_{D}}\right)^{2} \times \sum_{i=1}^{n_{d}}\left(N_{D i, \text { real }}-\overline{N_{D, \text { real }}}\right)^{2}}}
\end{gathered}
$$

where the parameters with subscript "real" are the experimental data (or from data sheets), the $N_{D i}$ are estimated by LSE method, and the upper line parameter is the respective mean value.

It is noted that the batteries data sheets provide the value of the parameter $V_{N D \cdot D o D}$ as a constant product between the maximum number of cycles $N_{D}$ and the depth of discharge $D o D[10,11,61,62]$, i.e., between 1200 and 1500 for VRLA batteries, while Equation (58) is overwhelmed by Equation (57). Sometimes Equation (56) presents poor behavior in extrapolation, so it will be avoided.

The daily degradation loss rate $\gamma_{a-j}{ }^{\prime}$ is calculated by the sum of the static and dynamic loss ones:

$$
\gamma_{\alpha-j^{\prime}}=\gamma_{s}{ }^{\prime}+\gamma_{d-j^{\prime}}
$$


The battery system must be redrawn, if it loses its total life duration after $N_{B}$ days on operation:

$$
\sum_{j^{\prime}=1}^{N_{B}} \gamma_{\alpha-j^{\prime}}=100 \%
$$

Furthermore, the remaining capacity of battery $C_{j}{ }^{\prime}$ for the $j$ th day is estimated using the daily degradation loss rate $\gamma_{a-j}{ }^{\prime}$ :

$$
C_{j^{\prime}}= \begin{cases}C_{\text {nom }}, & j=1 \\ C_{n o m} \times \prod_{k=2}^{j}\left(1-\gamma_{\alpha-(k-1)}\right), & j>1\end{cases}
$$

\subsection{Mathematical Formulation of the Cost Function}

Each SAPV configuration, which consists of a specific PVs population $N_{\text {panel }}$, of the battery type and of the battery capacity $C_{n o m}$, is checked not only from an operational point of view but also from a financial one taking into consideration the construction, operation, and maintenance costs for the whole life cycle. For this purpose the equivalent annual total cost $T C_{\text {annual }}$ should be minimized given by:

$$
\begin{gathered}
A_{\text {cap }-j}=C_{c a p-j} \times \frac{\left(1+i_{r}\right)^{T_{j}} \times i_{r}}{\left(1+i_{r}\right)^{T_{j}}-1} \\
T C_{\text {annual }}=\sum_{j}\left(A_{\text {cap }-j}+C_{f i x-j}\left(P_{A}\right)+c_{o p-j} \times t_{o p-j}\right)
\end{gathered}
$$

where $C_{\text {cap-j }}$ is the initial capital value of $j$ th equipment with the equivalent withdrawal cost after the economic lifetime, $T_{j}$ the respective economic lifetime (i.e., 10 years for marine PVs, 25 years for building roof, variable for batteries with respect to their ageing, etc.), $A_{\text {cap-j }}$ the equivalent fixed annual capital payment, $i_{r}$ the interest rate without inflation, $C_{f i x-j}$ the fixed annual cost of $j$ th equipment for maintenance, personnel wages, etc., which can depend on the peak load $P_{A}, c_{o p-j}$ the operation cost of $j$ th equipment, which is analog to the annual operation hours $t_{o p-j}$ and depends on maintenance. The operation cost, which depends on fuel and oil cost, is ignored because the back-up diesel generators operate only for maintenance reasons.

\subsection{Basic Steps of Proposed Design Methodology for SAPV with Batteries}

The basic steps of the proposed analytical design methodology for the sizing of the SAPV power system based on the sensitivity analysis regarding PVs population $N_{\text {panel }}$, the battery type, and the battery capacity $C_{\text {nom }}$, are the following:

- Initialization of the range of PVs population: The population of PVs can receive specific values $N_{\text {panel1 }}, N_{\text {panel2 }}, \ldots, N_{\text {panelK}}$. The type of PVs has been preselected as the Sxp154Q panel by Solbian [60] because it is a marine application and this panel is the biggest one. It can be easily modified involving further types of PVs.

- Initialization of the battery type and of the range of battery capacity for specific nominal voltage: The type of battery has been preselected as lead acid AGM and gel VRLA ones because they satisfy maintenance and safety against fire risk criterions, while the constructors choice is based on certificates, capital cost, technical criterions such as the typical life cycle, initial capital cost, etc. Next, the battery capacity can receive specific values $C_{\text {nom } 1}, C_{n o m 2}, \ldots, C_{n o m L}$, with respect to the battery data sheets [61,62].

- Initialization of the interest rate and of other parameters: The interest rate without inflation can receive specific values $i_{r 1}, i_{r 2}, \ldots, i_{r M}$, while other parameters, such as the PV daily energy increment factor $\sigma_{i n_{-} E d a y}$, the battery daily energy increment factor $\sigma_{i n_{-} E d a y \_E S S}$, etc. are predetermined. 
- Determination of the solar radiation modification factor: The solar radiation modification factor $f_{\text {Hmday }}(t, t+d t)$ is calculated by Equation (39) according to the process of Section 4.4 and it has the same value for the same current day of a month for different years and it is calculated once.

- Estimation of the economic lifetime of the battery: For each SAPV configuration (specific PVs population $N_{\text {panel }}$, battery type, and battery capacity $C_{n o m}$ ) the respective economic lifetime of the battery is going to be determined as the other elements (PVs, electrical installations, etc.) have a constant lifetime. Next, the following subroutine is executed:

1. The $j_{\text {initial }}$ th day is set as 1 , the available days with temperatures are $N_{D_{-} \text {Temp }}$, while the best function of Equations (55), (58), and (59) for the $N_{D}-D o D$ curves of the specific battery is chosen with respect to the criterions of the mean square error $J$ and correlation index $r$ from Equations (60) and (61).

2. The $j_{\text {initial }}$ th day is chosen as the initial current day from the 15 years temperature data, while the necessary initialization is realized, i.e., the initial state of the battery charge (i.e., $80 \%$ ), etc.

3. For the $j$ th current day for each time step $t$ the available solar irradiation $H_{m-\text { panel-day }}(t, t+d t)$ is estimated by Equations (38) and (39) and the PVs power production $P_{P V}(t)$ is calculated by Equation (50) with respect to Equation (51). Similarly, the respective load demand $P_{\text {load }}(t)$ is estimated taking into consideration the temperature-dependent load variation by Equation (24). Next, for each time step the investigation of the phase kind is carried out:

$$
\text { If } P_{P V}(t)>P_{\text {load }}(t) \rightarrow \text { charge phase, otherwise discharge phase/no operation phase }
$$

In case of the charge phase Equations (25), (28), (30), (32), (33), and (36) are applied with $P_{\text {dis }}(t)=$ $P_{L O E}(t)=0$. In case of the discharge phase Equations (26), (38), (31), (32), (34), and (37) are applied with $P_{c h}(t)=P_{\text {add }}(t)=0$. The no operation case occurs in the equality condition of Equation (67) and is the same with the discharge phase practically.

At the end of the $j t h$ current day the daily degradation loss rate $\gamma_{a-j}{ }^{\prime}$ is calculated by Equations (52), 4. (54), and (62), the remaining capacity of battery $C_{j}{ }^{\prime}$ by Equation (64) and the depth of discharge $D o D$ by Equation (35) taking into consideration the smallest battery energy $E(t)$ during the $j t h$ current day.

At the end of the $j$ th current day the total life duration of the battery is checked by Equation (63)

5. not to be exhausted and the load demand power loss is checked to be zero by Equation (28). If one of the criterions is not satisfied, the economic battery lifetime $T_{\text {econ_bat }}\left(j_{\text {initial }}\right)$ is determined as $j-j_{\text {initial }}$ because of ageing/reliable energy inadequacy reasons, respectively, and the subroutine goes to step 6. Otherwise the $j$ th current day is increased by one, and the subroutine returns to step 3. It is noted that if the $j$ th current day becomes bigger than $N_{D_{-} T e m p}$ days after the increment, the $j$ th current day becomes 1 , while the difference of the lifetime $\left(j-j_{\text {initial }}\right)$ is modified to $\left(j-j_{\text {initial }}+\right.$ $N_{D_{-} \text {Temp }}$ ).

The $j_{\text {initial }}$ th day is increased by one and the subroutine returns to step 2, except all available days

6. have been examined as initial ones. If all available days have been examined as initial, the total minimum economic battery lifetime $T_{\text {econ_bat_min }}$ is estimated as:

$$
T_{\text {econ_bat_min }}=\min \left\{T_{\text {econ_bat }}\left(j_{\text {initial }}\right)\right\}
$$

- Estimation of the total cost function: For each SAPV configuration (specific PVs population $N_{\text {panel }}$, battery type, and battery capacity $C_{n o m}$ ) the respective equivalent annual total cost $T C_{\text {annual }}$ is calculated by Equations (65) and (66) with respect to the different components costs (i.e., capital, withdrawal, maintenance, etc.) and economic lifetime of elements, where the battery lifetime is determined by Equation (68), while the other ones are constant. From all possible configurations 
the minimum equivalent annual total cost can be determined easily, while a sensitivity analysis can be carried out.

The basic advantage of the proposed methodology is that the optimization process of the SAPV system sizing selects elements (panels and battery elements) from a pool with real technical data at the expense of computational time.

\section{Results and Discussion for the Proposed Design Methodology for Stand Alone Photovoltaic Panels with Batteries}

\subsection{Available Data for the Stand-Alone Photovoltaic with Batteries for the Electrode Station of Stachtoroi Island}

Stachtoroi is a small uninhabited island that presents difficulties of accessibility for humans. Small animals and seagulls are its main population. There is a severe lack of meteorological data forcing the authors to use the three hours temperatures for the last 15 years from a near meteorological station in Attica, which were given by H-IPTSO, while the solar radiation are given free of charge as the mean monthly extraterrestrial solar irradiation at the horizontal sea level by [11]. In Table 5 the solar radiation modification factor $f_{\text {Hmday }}(t, t+d t)$ for the typical day of each month was calculated indicatively. The daily electric energy consumption for electrode station was calculated similarly with the peak load estimation in Section 3.2 taking into consideration Equation (24) and the three hour environmental temperature $T_{\text {temp }}(t)$.

Table 5. Calculation of solar radiation modification factor $f_{\text {Hmday }}(t, t+\mathrm{d} t)$ for the typical current day of the year for the calculation of daily solar irradiation (DoY) of each month.

\begin{tabular}{|c|c|c|c|c|c|c|c|}
\hline & & & & \multicolumn{4}{|c|}{ Solar Time } \\
\hline & & & & $\begin{array}{c}12: 00-15: 00 \\
\text { or 9:00-12:00 }\end{array}$ & $\begin{array}{l}\text { 15:00-18:00 } \\
\text { or 6:00-9:00 }\end{array}$ & $\begin{array}{l}18: 00-21: 00 \\
\text { or 3:00-6:00 }\end{array}$ & $\begin{array}{l}21: 00-24: 00 \\
\text { or } 0: 00-3: 00\end{array}$ \\
\hline & DoY & $a_{1} / I_{o-m d a y}$ & $a_{2} / I_{o-m d a y}$ & \multicolumn{4}{|c|}{$f_{\text {Hmday }}(t, t+\mathrm{d} t)$} \\
\hline Month & $(-)$ & $(-)$ & $(-)$ & & & & \\
\hline January & 15 & -0.264348 & 0.874992 & 0.411095 & 0.088905 & 0.000000 & 0.000000 \\
\hline February & 46 & -0.125742 & 0.685957 & 0.386288 & 0.113712 & 0.000000 & 0.000000 \\
\hline March & 74 & -0.020311 & 0.531517 & 0.359887 & 0.140113 & 0.000000 & 0.000000 \\
\hline April & 105 & 0.053163 & 0.413104 & 0.333863 & 0.162749 & 0.003388 & 0.000000 \\
\hline May & 135 & 0.091095 & 0.344943 & 0.315457 & 0.172577 & 0.011966 & 0.000000 \\
\hline June & 166 & 0.105764 & 0.316209 & 0.306660 & 0.175682 & 0.017657 & 0.000000 \\
\hline July & 196 & 0.100172 & 0.327374 & 0.310163 & 0.174561 & 0.015276 & 0.000000 \\
\hline August & 227 & 0.072280 & 0.379636 & 0.325212 & 0.167962 & 0.006826 & 0.000000 \\
\hline September & 258 & 0.014339 & 0.477263 & 0.348738 & 0.151049 & 0.000213 & 0.000000 \\
\hline October & 288 & -0.081787 & 0.623096 & 0.376360 & 0.123640 & 0.000000 & 0.000000 \\
\hline November & 319 & -0.219714 & 0.815339 & 0.403969 & 0.096031 & 0.000000 & 0.000000 \\
\hline December & 349 & -0.315457 & 0.942198 & 0.418476 & 0.081524 & 0.000000 & 0.000000 \\
\hline
\end{tabular}

The PVs for marine applications are constructed by Solbian indicatively using the biggest panel Sxp154Q with a typical cost of $755 € /$ panel and economic lifetime of 10 years [60]. The inverters are constructed by SMA Solar Technology AG indicatively using different types with respect to the PVs population, i.e., two inverters SMA Sunny Tripower 8000 TL were chosen in case of 100 Sxp154Q with a total cost of $4916 €$ [66]. In Table 6 the inverters cost for different PVs population was registered, while the respective economic lifetime was 20 years for all cases. Next the total cost of PVs and inverters was accreted by $10 \%$ indicatively (usually from $5 \%$ to $15 \%$ ) because of the control system, cables, and switchboards installations. Additionally, if the PVs need more area than the available roof of Figure 6, 
the roof is expanded and the necessary civil construction works cost $250 € / \mathrm{m}^{2}$ (roof area) with a typical lifetime equal to 25 years.

Table 6. Indicative SMA SUNNY TRIPOWER x000 TL inverters total cost Cost $I_{I n v}(€)$ per PVs population $N_{\text {panel }}[66]$.

\begin{tabular}{cllllllllllllllllll}
\hline$N_{\text {panel }}$ & $\mathbf{2 5}$ & $\mathbf{5 0}$ & $\mathbf{7 5}$ & $\mathbf{8 0}$ & $\mathbf{8 5}$ & $\mathbf{9 0}$ & $\mathbf{9 5}$ & $\mathbf{1 0 0}$ & $\mathbf{1 0 5}$ & $\mathbf{1 1 0}$ & $\mathbf{1 1 5}$ & $\mathbf{1 2 0}$ & $\mathbf{1 2 5}$ & $\mathbf{1 3 0}$ & $\mathbf{1 4 0}$ & $\mathbf{1 5 0}$ & $\mathbf{1 7 5}$ & $\mathbf{2 0 0}$ \\
\hline Cost $_{\text {Inv }}[€]$ & 2458 & 2458 & 2817 & 4916 & 4916 & 4916 & 4916 & 4916 & 5634 & 5634 & 5634 & 5634 & 5634 & 5634 & 7374 & 8451 & 8451 & 9832 \\
\hline
\end{tabular}

The battery system can be formed by AGM lead acid elements or by gel form ones. Indicatively in case of AGM elements the AGM VRLA 12 V 100 Ah C20 by Narada [61] was used with a typical cost of $180 € /$ element, nominal lifetime of 6 years, and self-discharge rate of $5 \%$ per month. In case of the gel form series RES SOPzV by Sunlight [62] was used with different capacities of $2 \mathrm{~V}$ elements [62]. In Table 7 the $110 \mathrm{~V}$ RES SOPzV battery system cost for a different total capacity was registered, while the respective nominal lifetime was 10 years and a self-discharge rate of $2 \%$ per month for all cases. It is noted that the economic lifetime was determined by Sections 4.4 and 4.6.

Table 7. Indicative $110 \mathrm{~V}$ Sunlight RES SOPzV battery system total cost $\operatorname{Cost}_{R E S}(€)$ and configuration (parallel branches $N_{\text {par }}$ and series elements $N_{\text {ser }}$ ) with respect to the total capacity $C_{\text {nom }}(\mathrm{Ah})$ [62].

\begin{tabular}{|c|c|c|c|c|c|c|c|c|c|}
\hline$C_{n o m}(\mathrm{Ah})$ & Type & $N_{p a r}$ & $N_{s e r}$ & $\operatorname{Cost}_{\text {RES }}(\boldsymbol{(})$ & $C_{n o m}(\mathrm{Ah})$ & Type & $N_{p a r}$ & $N_{s e r}$ & $\operatorname{Cost}_{R E S}(\boldsymbol{\epsilon})$ \\
\hline 290 & $\begin{array}{c}\text { Res } 2 \\
\text { SOPZV150 }\end{array}$ & 2 & 55 & 9350 & 2676 & $\begin{array}{c}\text { Res8 } \\
\text { SOPZV1360 }\end{array}$ & 2 & 55 & 43,670 \\
\hline 436 & $\begin{array}{c}\text { Res } 3 \\
\text { SOPZV225 }\end{array}$ & 2 & 55 & 12,320 & 2931 & $\begin{array}{c}\text { Res } 7 \\
\text { SOPZV990 }\end{array}$ & 3 & 55 & 52,800 \\
\hline 558 & $\begin{array}{c}\text { Res } 2 \\
\text { SOPZV180 }\end{array}$ & 2 & 55 & 13,970 & 3348 & $\begin{array}{c}\text { Res8 } \\
\text { SOPZV1135 }\end{array}$ & 3 & 55 & 58,575 \\
\hline 838 & $\begin{array}{c}\text { Res } 3 \\
\text { SOPZV425 }\end{array}$ & 2 & 55 & 19,250 & 3513 & $\begin{array}{c}\text { Res } 7 \\
\text { SOPZV1190 }\end{array}$ & 3 & 55 & 61,050 \\
\hline 1116 & $\begin{array}{c}\text { Res } 4 \\
\text { SOPZV565 }\end{array}$ & 2 & 55 & 22,550 & 4014 & $\begin{array}{c}\text { Res8 } \\
\text { SOPZV1360 }\end{array}$ & 3 & 55 & 65,505 \\
\hline 1396 & $\begin{array}{c}\text { Res } 5 \\
\text { SOPZV710 }\end{array}$ & 2 & 55 & 26,950 & 4464 & $\begin{array}{c}\text { Res8 } \\
\text { SOPZV1135 }\end{array}$ & 4 & 55 & 78,100 \\
\hline 1676 & $\begin{array}{c}\text { Res } 6 \\
\text { SOPZV850 }\end{array}$ & 2 & 55 & 30,030 & 4684 & $\begin{array}{c}\text { Res } 7 \\
\text { SOPZV1190 }\end{array}$ & 4 & 55 & 81,400 \\
\hline 1954 & $\begin{array}{c}\text { Res } 7 \\
\text { SOPZV990 }\end{array}$ & 2 & 55 & 35,200 & 5352 & $\begin{array}{c}\text { Res8 } \\
\text { SOPZV1360 }\end{array}$ & 4 & 55 & 87,340 \\
\hline 2232 & $\begin{array}{c}\text { Res8 } \\
\text { SOPZV1135 }\end{array}$ & 2 & 55 & 39,050 & 5855 & $\begin{array}{c}\text { Res } 7 \\
\text { SOPZV1190 }\end{array}$ & 5 & 55 & 101,750 \\
\hline
\end{tabular}

It is noted that for every battery element the adaptation between the maximum number of cycles $N_{D}$ and the depth of discharge $D o D$ was realized through the process of Section 4.4. Indicatively the experimental data of the respective $N_{D}-D o D$ is given in Table 8. If the LSE method is applied with the exponential function of Equation (55), the hyperbolic one of Equation (58), and the power one of Equation (59), the mean square error $J$ and correlation index $r$ will be calculated by Equations (60) and (61) in Table 8, from which it is obvious the inferiority of the exponential one, while the others have similar values with a slight dominance of the hyperbolic function.

The batteries chargers were constructed by GSA Industries indicatively using different types with respect to the battery capacities [67], i.e., the total cost of two chargers for a battery capacity of 2600-3800 Ah was $22 \mathrm{k} €$, for 1800-2400 Ah was $18 \mathrm{k} €$, for 1400-1700 Ah was $15 \mathrm{k} €$, and for smaller than 1300 Ah was $12 \mathrm{k} €$, respectively. The economic lifetime was 20 years.

The constant maintenance cost per year for photovoltaic panels and batteries amounts to $1200 €$, while the operation cost was equal to zero (back-up generators' operation for service reasons and for forced outages of the SAPV system is ignored because it is very small and practically constant in all cases, if the energy adequacy is satisfied by SAPV system). 
Table 8. Experimental values between the maximum number of cycles $N_{D}$ and the depth of discharge $D o D$ for AGM VRLA battery system (see Table 6.7 in [11]), the functions between cycles $N_{D}-D o D$ adapted by LSE method and the respective values of the mean square error $J$ and the correlation index $r$.

\begin{tabular}{|c|c|c|c|c|c|c|c|c|}
\hline$N_{D}(-)$ & 18000 & 8100 & 5200 & 3750 & 2800 & 2200 & 1800 & 1500 \\
\hline$D o D(\%)$ & 10 & 20 & 30 & 40 & 50 & 60 & 70 & 80 \\
\hline Function & \multicolumn{3}{|c|}{$N_{D}=17015 \cdot \exp (-3.308 \cdot D o D)$} & \multicolumn{3}{|c|}{$N_{D}=1822.9 / D o D-811.9$} & \multicolumn{2}{|c|}{$N_{D}=12017 \cdot D o D^{-1.189}$} \\
\hline$J(-)$ & \multicolumn{3}{|c|}{$4,500,224$} & \multicolumn{3}{|c|}{48,500} & \multicolumn{2}{|c|}{49,540} \\
\hline$r(-)$ & \multicolumn{3}{|c|}{0.94905} & \multicolumn{3}{|c|}{0.99960} & \multicolumn{2}{|c|}{0.99972} \\
\hline
\end{tabular}

\subsection{Determination of the Range for the Crucial Parameters of the Proposed Design Methodology}

The preliminary idea is that the range of its crucial parameter should be expanded from zero (or almost zero) to a big value, bigger than the preliminary study one by a multiplier factor of 1.5-2.0. In the area of the preliminary study one the proposed values should be thicker. From the sensitivity analysis the values can change repeating the process. Taking into consideration the results of the preliminary study, where the PVs population should be 128 and the $110 \mathrm{~V}$ battery capacity should be $3724 \mathrm{Ah}$, the following ranges of the crucial parameters were proposed:

- PVs population: The population of PVs $N_{\text {panel }}$ could be 25, 50, 75, 80, 85, 90, 95, 100, 105, 110, 115, $120,125,130,135,140,145,150,155,160,165,175$, and 200, which means 23 values.

- Capacity for the 108 V AGM VRLA battery system by Narada: The capacity could be 200, 400, 600, $800,1000,1200,1400,1600,1800,2000,2200,2400,2600,2800,3000,3200,3400,3600,3800,4000$, 4200, 4400, 4700, and $6000 \mathrm{Ah}$, which means 25 values.

- Capacity for 110 V gel RES SOPzV battery system by Sunlight: The capacity could be 290, 436, $558,838,1116,1396,1676,1954,2232,2342,2676,2931,3348,3513,4014,4464,4684,5352,5855$, and $6690 \mathrm{Ah}$, which means 20 values.

- Interest rate without inflation: It could be $0 \%, 0.5 \%, \ldots$, and $10 \%$ with a typical value of $3 \%$ and 21 values.

\subsection{Estimation of the Economic Lifetime of the Battery}

For each combination of PVs and the battery system the economic lifetime was calculated examining different scenarios of an initial day and choosing the most unfavorable one by Equation (68). Here, the historical temperature data of 15 years were given analytically, so $5478(=12 \times 365+3 \times 366)$ different initial days were available forming 5478 cases per combination. Indicatively six combinations are shown in Figure 9, where the progress of the remaining capacity is presented with respect to the current days. The remaining capacity curve stopped to be traced and either the total life duration of the battery was exhausted or the load demand power loss was not zero satisfying the reliability criterion of energy adequacy. Simultaneously, the economic lifetime of the battery was determined. It is obvious that the increase of PVs and of the battery capacity improved the battery lifetime, while there was a slight superiority of gel RES SOPzV battery against AGM VRLA one. In Table 9 the respective arithmetic results were registered, where it was found out that the increase of PVs and the decrease of the battery capacity resulted in bigger mean daily produced PV energy loss $E_{\text {add-day, }}$, while the initial and the last day for the most unfavorable scenario were not the same for the different combinations. 


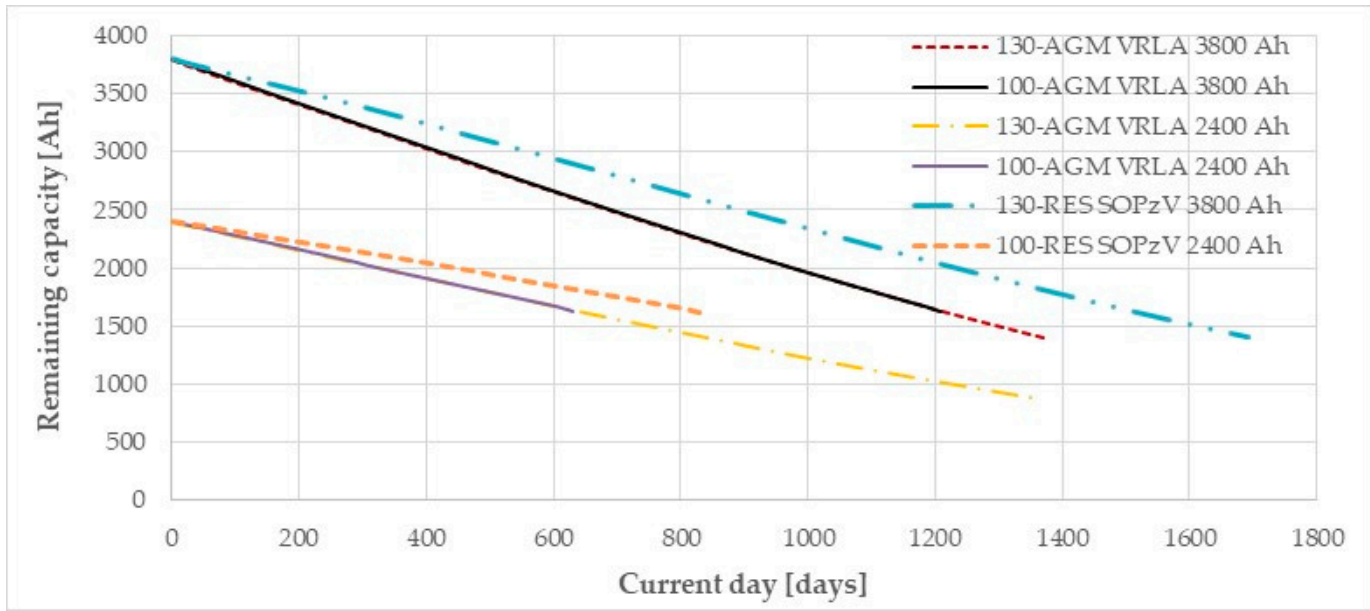

Figure 9. Remaining capacity of the battery with respect to the current days on operation for different combinations of PVs (100 or 130), battery type (AGM VRLA or gel RES SOPzV), and capacities (2400 or $3800 \mathrm{Ah})$.

Table 9. Battery economic lifetime, initial and last day for the worst scenario, remaining capacity at the end of the battery economic lifetime, the total produced PV energy loss $E_{\text {add }}$ for the all economic lifetime, and the mean daily produced PV energy loss $E_{a d d-d a y}$ for indicative different combinations of PVs (100 or 130), battery type (absorbed glass mat (AGM) valve regulated lead acid (VRLA) or gel RES SOPzV), and capacities (2400 or $3800 \mathrm{Ah}$ ).

\begin{tabular}{cccccccc}
\hline$N_{\text {panel }}$ & $\begin{array}{c}\text { Battery } \\
\text { Type }\end{array}$ & $C_{\text {nom }}$ (Ah) & $\begin{array}{c}\text { Battery } \\
\text { Lifetime } \\
\text { (Years) }\end{array}$ & $\begin{array}{c}\text { Initial and Last } \\
\text { Day for the Worst } \\
\text { Scenario }\end{array}$ & $\begin{array}{c}\text { Remaining Capacity } \\
\text { (Ah-\% with Respect } \\
\text { to } C_{\text {nom }} \text { ) }\end{array}$ & $\begin{array}{c}E_{\text {add }} \\
\text { (kWh) }\end{array}$ & $\begin{array}{c}E_{\text {add-day }} \\
\text { (kWh) }\end{array}$ \\
\hline 130 & VRLA & 3800 & 3.75 & $2167-3536$ & $1396.97-36.76 \%$ & 66,701 \\
\hline 100 & VRLA & 3800 & 3.30 & $986-2193$ & $1622.00-42.68 \%$ & 39,549 & 32.77 \\
\hline 130 & VRLA & 2400 & 3.69 & $1280-2626$ & $882.54-36.77 \%$ & 61,717 & 45.78 \\
\hline 100 & VRLA & 2400 & 1.71 & $1565-2193$ & $1625.88-67.74 \%$ & 234,94 & 37.59 \\
\hline 128 & $\begin{array}{l}\text { RES } \\
\text { SOPzV }\end{array}$ & 3800 & 4.63 & $2167-3857$ & $1396.45-36.75 \%$ & 81,128 \\
\hline 100 & RES & 2400 & 2.26 & $1367-2193$ & $1608.74-67.03 \%$ & 26,388 \\
\hline
\end{tabular}

The improvement of the battery economic lifetime was assertive not as a linear phenomenon as it can be seen in Figure 10 with the PVs variation for AGM VRLA battery with capacity of 2400 Ah and in Figure 11 with the capacity variation with 120 PVs. In Figure 10 the lifetime is stabilized at 3.7 years for a PVs population equal to 125, while in Figure 11 it was stabilized at 3.7 years for a capacity equal to $2600 \mathrm{Ah}$ with a very small increase until 3.77 years at a capacity of $6000 \mathrm{Ah}$.

By studying the $23 \times 25=575$ combinations the respective results can be generalized in three-dimension Figure 12, where the economic lifetime for SAPV system is presented with respect to the capacity of 108 V AGM VRLA battery system $(200,400, \ldots, 4200,4400,4700$, and 6000 Ah) and PVs population $(80,85, \ldots$, and 165$)$. It is obvious that the SAPV system presents energy inadequacy for battery capacities of $1400 \mathrm{Ah}$ and smaller. Afterwards, significant improvement is presented reaching the "saturated" value of 3.75 years, which can be succeeded for a big population of PVs (above 145) with a capacity equal to $1600 \mathrm{Ah}$, for big capacities (above $4400 \mathrm{Ah}$ ) with a PV population equal to 95, and for value pairs (PV population and battery capacity) that were located in the imaginary line between points $(145,1600)$ and $(100,4000)$. 


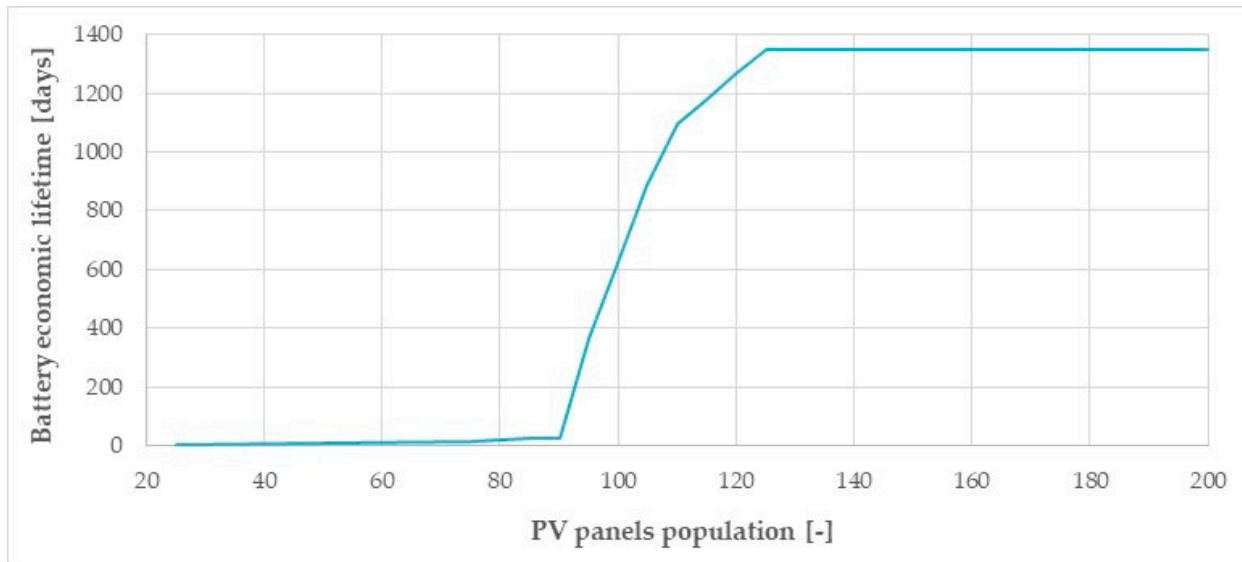

Figure 10. Battery economic lifetime for the SAPV system with respect to the PV population while the capacity of the $108 \mathrm{~V}$ AGM VRLA battery system is $2400 \mathrm{Ah}$.

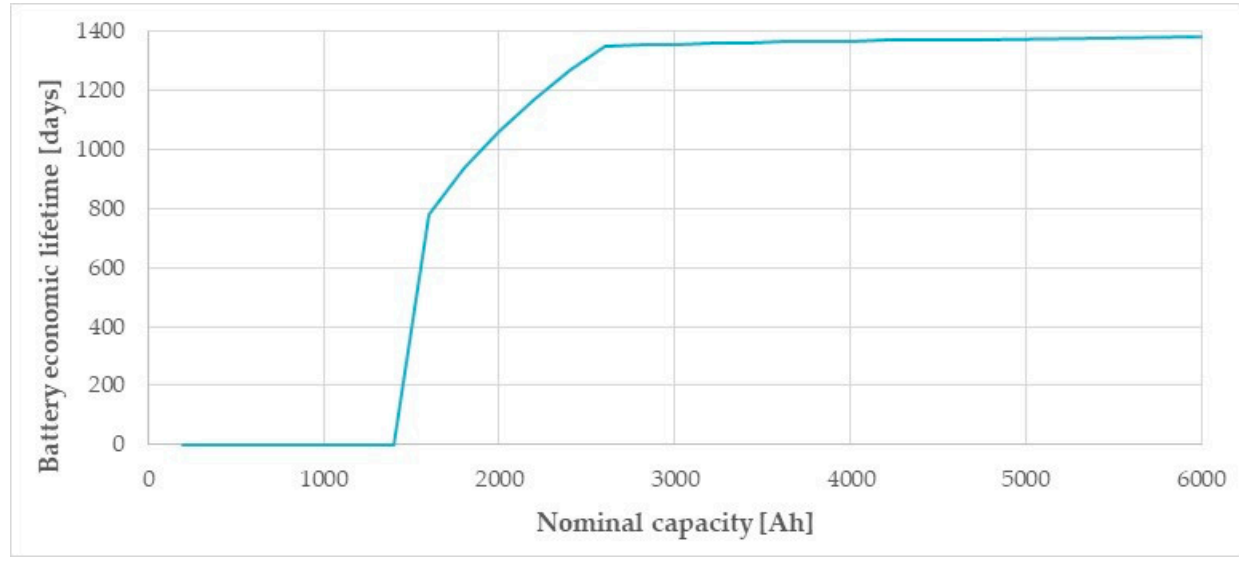

Figure 11. Battery economic lifetime for the SAPV system with respect to the capacity of the $108 \mathrm{~V}$ AGM VRLA battery system while the PV population is 120.

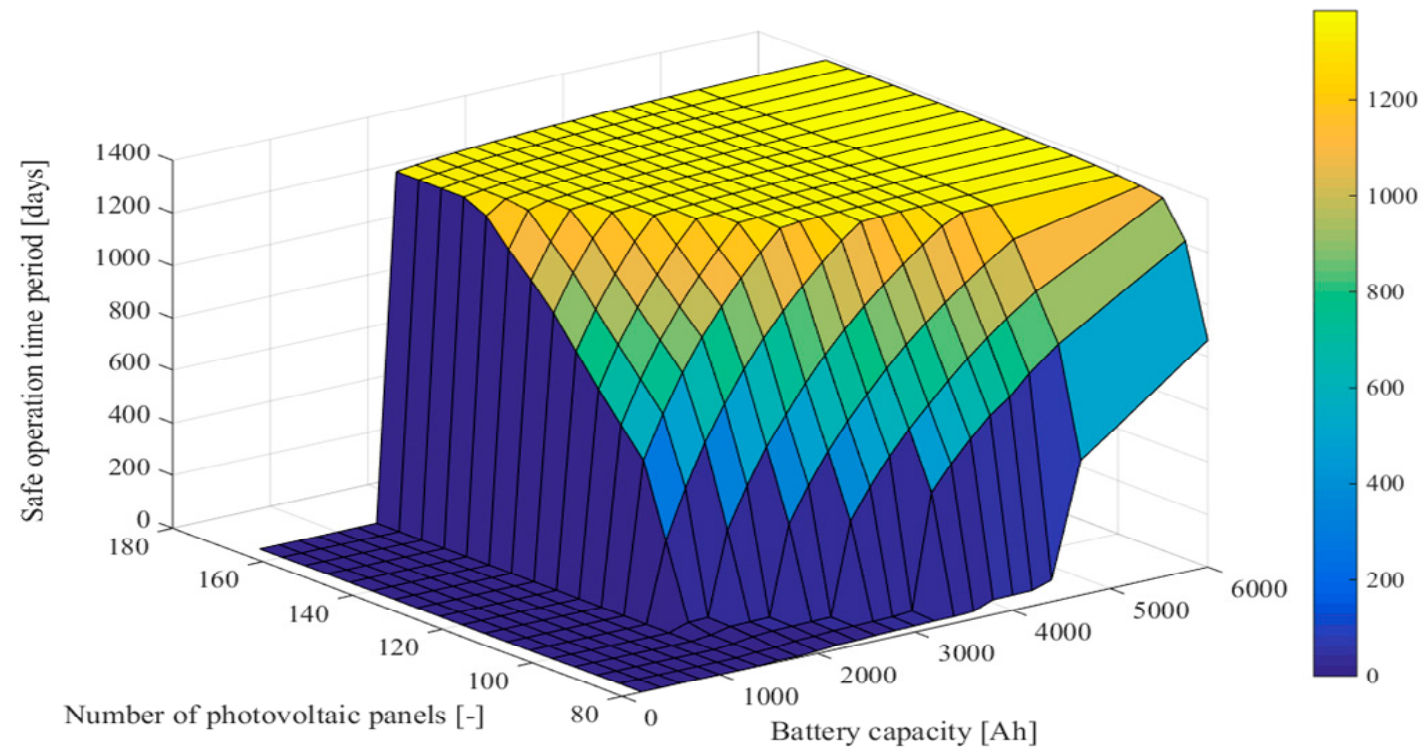

Figure 12. Battery economic lifetime for the SAPV system with respect to the capacity of the $108 \mathrm{~V}$ AGM VRLA battery system $(200,400, \ldots, 4200,4400,4700$, and 6000 Ah) and PV population (80, 85, $\ldots$, and 165). 
The same conclusion for the improvement of the battery economic lifetime could be drawn in case of the gel RES SOPzV battery where $23 \times 20=460$ combinations were carried out. The respective results were generalized in three-dimensions in Figure 13, where the economic lifetime for SAPV system is presented with respect to the capacity of the $110 \mathrm{~V}$ RES SOPzV battery system (see Table 7) and PV population $(80,85, \ldots$, and 165$)$. The SAPV system presents energy inadequacy for battery capacities of $1400 \mathrm{Ah}$ and smaller again. Afterwards, significant improvement is presented reaching the "saturated" value of 4.7 years, which it can be succeeded for a big population of PVs (above 145) with a capacity equal to $1600 \mathrm{Ah}$, for big capacities (above $4464 \mathrm{Ah}$ ) with a PV population equal to 90, and for value pairs (PVs population and battery capacity) that were located in the imaginary line between points $(145,1600)$ and $(90,6000)$.

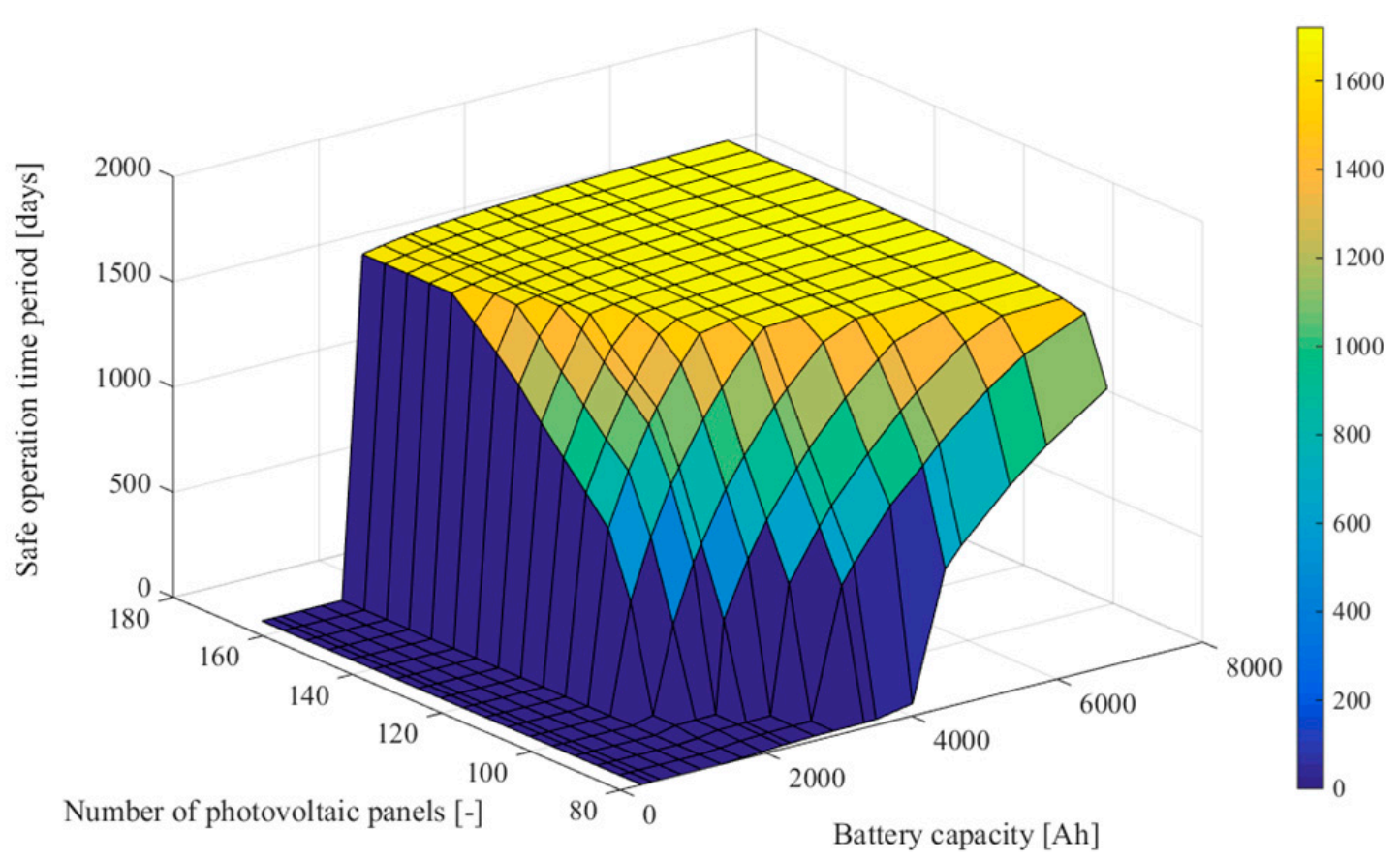

Figure 13. Battery economic lifetime for the SAPV system with respect to the capacity of the $110 \mathrm{~V}$ gel RES SOPzV battery system (see Table 7 ) and PV population $(80,85, \ldots$, and 165$)$.

The area limitations of a big battery economic lifetime for both battery types were quite similar, but the gel RES SOPzV battery presents more improved behavior than the AGM VRLA significantly, as the respective lifetime was increased by $25 \%$. However, this as not sufficient for battery selection, as the gel RES SOPzV had significantly bigger capital cost and the criterion of an equivalent annual total cost must be applied for all combinations.

\subsection{Estimation of the Equivalent Annual Total Cost and Selection of the Optimized Configuration}

For each combination of PVs and the battery system the equivalent annual total cost was calculated by Equations (65) and (66) for different values of interest rate without inflation. Indicatively the connection between this cost and the interest rate is presented in Figure 14 for the six combinations of Figure 9 and Table 9. In all cases the equivalent annual total cost was increased with the interest rate increment almost linearly. However, the respective slope was not the same, as it got bigger when the nominal capacity enlarged, while the slope for gel RES SOPzV battery was bigger than AGM VRLA one because of its bigger capital cost for the same nominal capacity. Additionally, the increase of PVs and the decrease of the battery capacity result for the same type battery could decrease the total cost. 


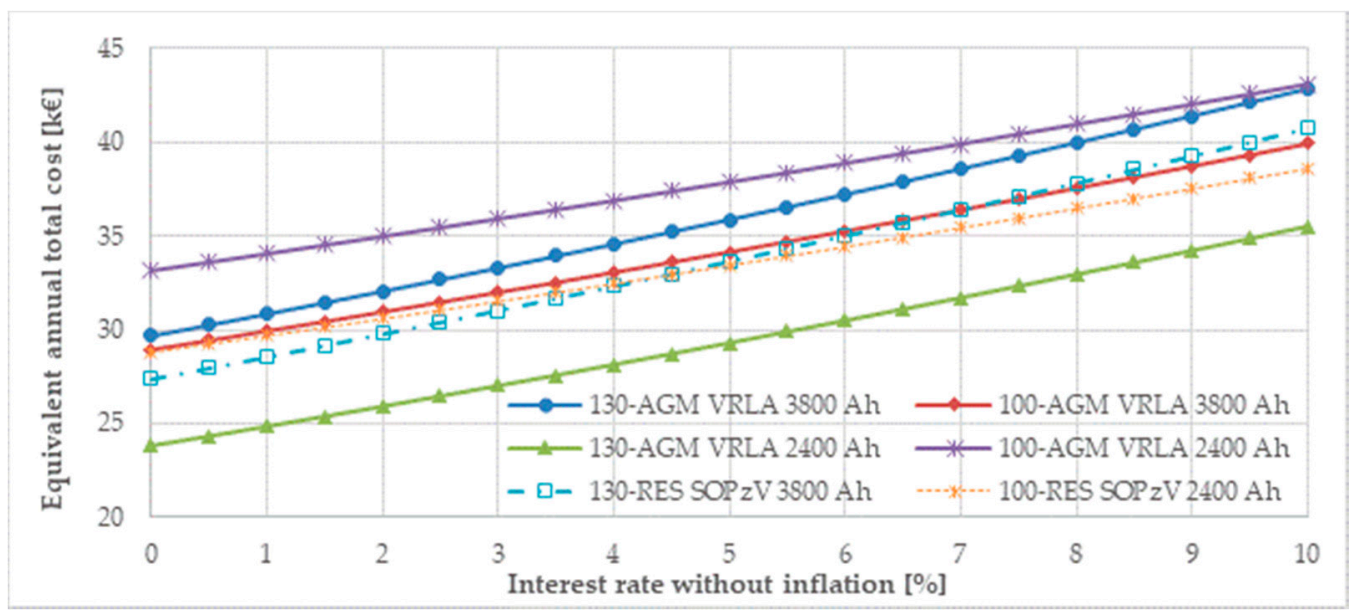

Figure 14. Equivalent annual total cost with respect to the interest rate without inflation combinations of PVs (100 or 130), battery type (AGM VRLA or gel RES SOPzV), and capacities (2400 or 3800 Ah).

The equivalent annual total cost had no-linear behavior as it could be seen in the three-dimensions in Figure 15 with the PV variation for the AGM VRLA battery with a capacity of 2400 Ah and in the three-dimensions in Figure 16 with the capacity variation with 120 PVs. In Figure 15 the minimum cost was succeeded for 120 panels if the interest rate was $0.5 \%$ and above, while in Figure 16 it was achieved at a capacity of $2000 \mathrm{Ah}$ in the case of an interest rate of $2 \%$ and above and at $2200 \mathrm{Ah}$ in the case of an interest rate of $1.5 \%$ and below. Alternatively, all possible 575 combinations for PV population and for a battery capacity of the $108 \mathrm{~V}$ AGM VRLA battery system were examined for a specific interest rate. Indicatively in the three-dimensions in Figure 17 the annual equivalent annual total cost is presented with respect to the capacity of the 108 V AGM VRLA battery system $(200,400, \ldots, 4400,4700$, and $6000 \mathrm{Ah})$ and $\mathrm{PV}$ population $(80,85, \ldots$, and 165$)$ for an interest rate equal to $3 \%$ and the minimum value occurred for a capacity of $1600 \mathrm{Ah}$ and $140 \mathrm{PVs}$.

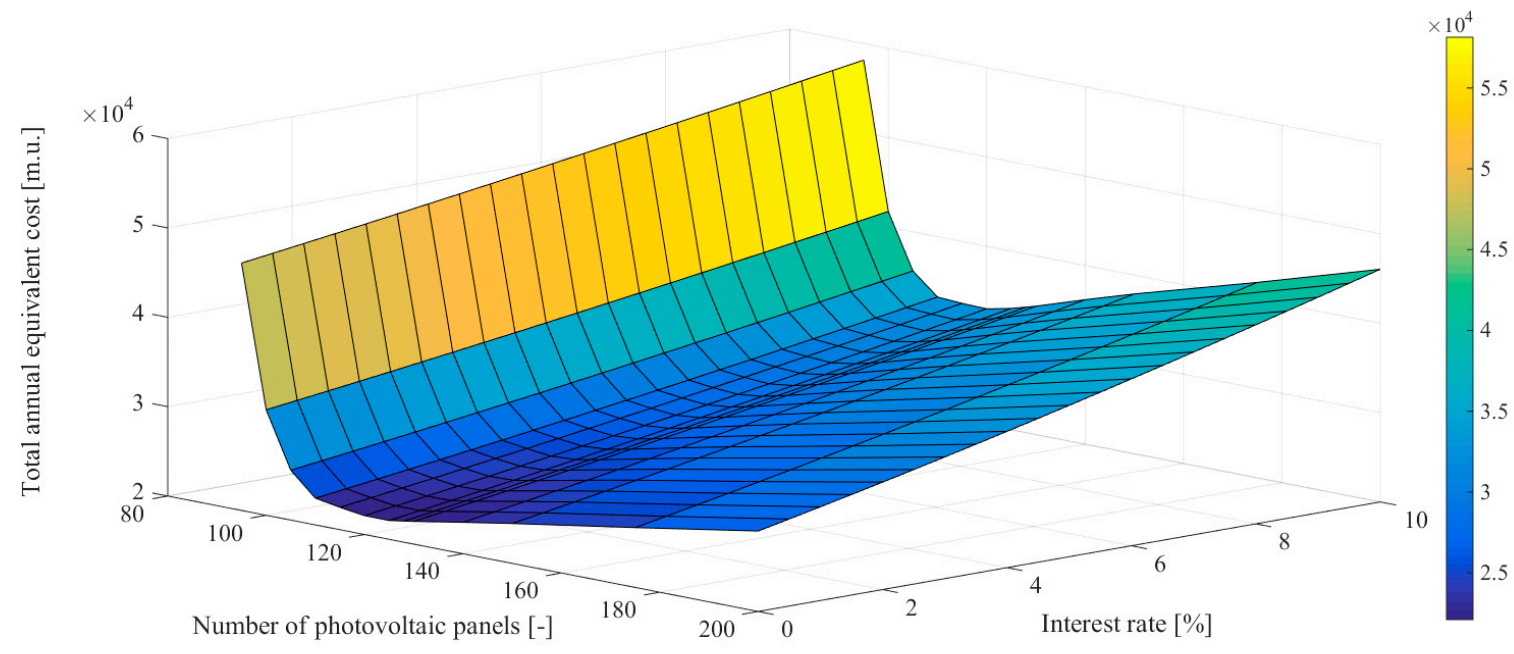

Figure 15. Equivalent annual total cost with respect to the interest rate without inflation and to the PVs population while the capacity of the 108 V AGM VRLA battery system is 2400 Ah. 


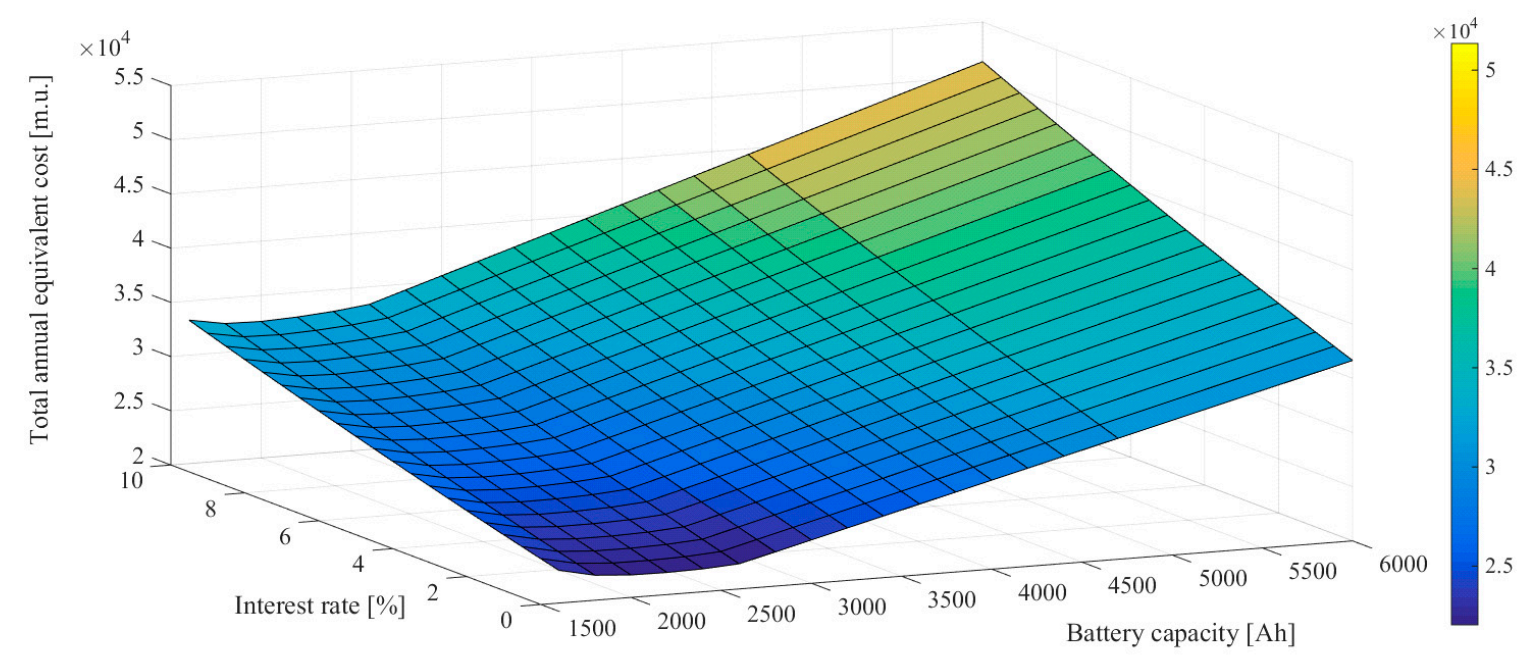

Figure 16. Equivalent annual total cost with respect to the interest rate without inflation and to the capacity of the 108 V AGM VRLA battery system while the PVs population is 120.

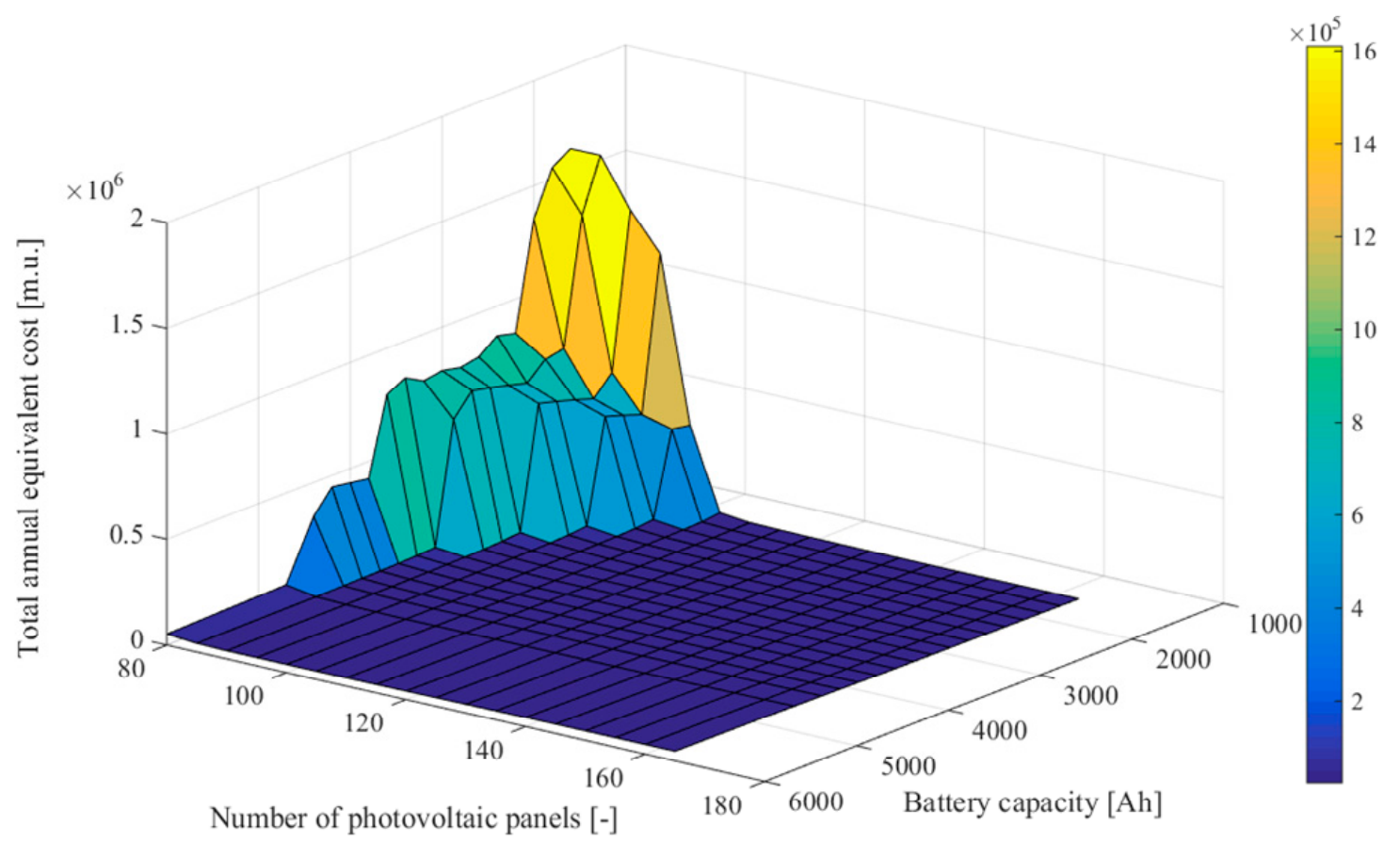

Figure 17. Equivalent annual total cost with respect to the capacity of the $108 \mathrm{~V}$ AGM VRLA battery system $(200,400, \ldots, 4200,4400,4700$, and 6000 Ah) and PV population $(80,85, \ldots$, and 165$)$ for an interest rate without inflation at $3 \%$.

In Table 10 the best selection of the SAPV system with AGM VRLA batteries is presented with respect to the equivalent annual total cost, where the battery capacity was equal to $1600 \mathrm{Ah}$ in all cases, while the population of PVs should be 145 for an interest rate of $2.5 \%$ and below, 140 between $3 \%$ and $5.5 \%$, and 130 between $6 \%$ and $10 \%$. This means that the proposed configuration varied, because the population of PVs decreased as the interest rate increased, while the battery capacity was stable in the case of the AGM VRLA battery type. Additionally, the proposed configuration was different from the preliminary study one, as more PVs were required (an increase of $13 \%$ ), while battery capacity was decreased by $57 \%$. 
Table 10. Proposed configuration of the SAPV system with a battery system (PV population $N_{\text {panel }}$, battery nominal capacity $C_{\text {nom }}$ ) with respect to equivalent total equivalent $\operatorname{cost} T C_{\text {annual }}$ for a different interest rate without inflation $i_{r}$, for the $108 \mathrm{~V}$ Narada AGM VRLA battery and for the $110 \mathrm{~V}$ Sunlight gel RES SOPzV battery system.

\begin{tabular}{|c|c|c|c|c|c|c|}
\hline \multirow[b]{2}{*}{$i_{r}(-)$} & \multicolumn{3}{|c|}{108 V Narada AGM VRLA Battery System } & \multicolumn{3}{|c|}{110 V Sunlight Gel Res SOPzV Battery System } \\
\hline & $N_{\text {panel }}(-)$ & $C_{\text {nom }}(\mathrm{Ah})$ & $T C_{\text {annual }}(\boldsymbol{€})$ & $N_{\text {panel }}(-)$ & $C_{\text {nom }}(\mathrm{Ah})$ & $T C_{\text {annual }}(€)$ \\
\hline $0.00 \%$ & 145 & 1600 & 22,089 & 140 & 1676 & 21,387 \\
\hline $0.50 \%$ & 145 & 1600 & 22,619 & 140 & 1676 & 21,908 \\
\hline $1.00 \%$ & 145 & 1600 & 23,157 & 140 & 1676 & 22,438 \\
\hline $1.50 \%$ & 145 & 1600 & 23,705 & 140 & 1676 & 22,978 \\
\hline $2.00 \%$ & 145 & 1600 & 24,263 & 115 & 2676 & 23,499 \\
\hline $2.50 \%$ & 140 & 1600 & 24,821 & 115 & 2676 & 24,000 \\
\hline $3.00 \%$ & 140 & 1600 & 25,378 & 115 & 2676 & 24,509 \\
\hline $3.50 \%$ & 140 & 1600 & 25,943 & 115 & 2676 & 25,025 \\
\hline $4.00 \%$ & 140 & 1600 & 26,517 & 115 & 2676 & 25,547 \\
\hline $4.50 \%$ & 140 & 1600 & 27,099 & 115 & 2676 & 26,077 \\
\hline $5.00 \%$ & 140 & 1600 & 27,689 & 115 & 2676 & 26,613 \\
\hline $5.50 \%$ & 140 & 1600 & 28,287 & 115 & 2676 & 27,156 \\
\hline $6.00 \%$ & 130 & 1600 & 28,890 & 110 & 2676 & 27,695 \\
\hline $6.50 \%$ & 130 & 1600 & 29,463 & 110 & 2676 & 28,234 \\
\hline $7.00 \%$ & 130 & 1600 & 30,042 & 110 & 2676 & 28,778 \\
\hline $7.50 \%$ & 130 & 1600 & 30,629 & 110 & 2676 & 29,328 \\
\hline $8.00 \%$ & 130 & 1600 & 31,222 & 110 & 2676 & 29,883 \\
\hline $8.50 \%$ & 130 & 1600 & 31,821 & 110 & 2676 & 30,445 \\
\hline $9.00 \%$ & 130 & 1600 & 32,426 & 110 & 2676 & 31,011 \\
\hline $9.50 \%$ & 130 & 1600 & 33,038 & 110 & 2676 & 31,583 \\
\hline $10 \%$ & 130 & 1600 & 33,655 & 110 & 2676 & 32,161 \\
\hline
\end{tabular}

In the case of the gel RES SOPzV battery the same process for the selection of the best configuration was applied examining 460 combinations for each value of interest rate without inflation. Indicatively in three-dimensions in Figure 18 the equivalent annual total cost is presented with respect to the capacity of the $110 \mathrm{~V}$ gel RES SOPzV battery system (see Table 7 ) and PV population $(80,85, \ldots$, and 165 ) for an interest rate equal to $3 \%$ and the minimum value occurred for a capacity of $2676 \mathrm{Ah}$ and 115 PVs.

In Table 10 the best selection of the SAPV system with gel RES SOPzV batteries was also registered with respect to the equivalent annual total cost. Now the behavior was more complicated, because the battery capacity was equal to $1676 \mathrm{Ah}$ for an interest rate of $1.5 \%$ and below and $2676 \mathrm{Ah}$ for an interest rate of $2.0 \%$ and above, while the population of PVs should be 140 for an interest rate of $1.5 \%$ and below, 115 between $2.0 \%$ and $5.5 \%$, and 110 between $6 \%$ and $10 \%$. This means that the proposed configuration varied, because the population of PVs decreased as the interest rate increased, while the battery capacity increased as the interest rate increased. Furthermore, the proposed configuration was different from the preliminary study one, as battery capacity decreased until $55 \%$, while the behavior of the PV population was more complicated, as it varied from $86 \%$ to $109 \%$ during the interest rate decrease.

Comparing the two types of batteries with respect to the equivalent annual total cost in Table 10 it was found out that the best configuration using gel RES SOPzV batteries was superior than the respective one of the AGM VRLA battery for every interest rate, while the proposed configurations by the application of the proposed methodology were not the same for both battery types.

Additionally, the SAPV system with RES SOPzV batteries needs a smaller population of PVs and a bigger battery capacity than the respective configuration for the AGM VRLA battery at the same interest rate. 


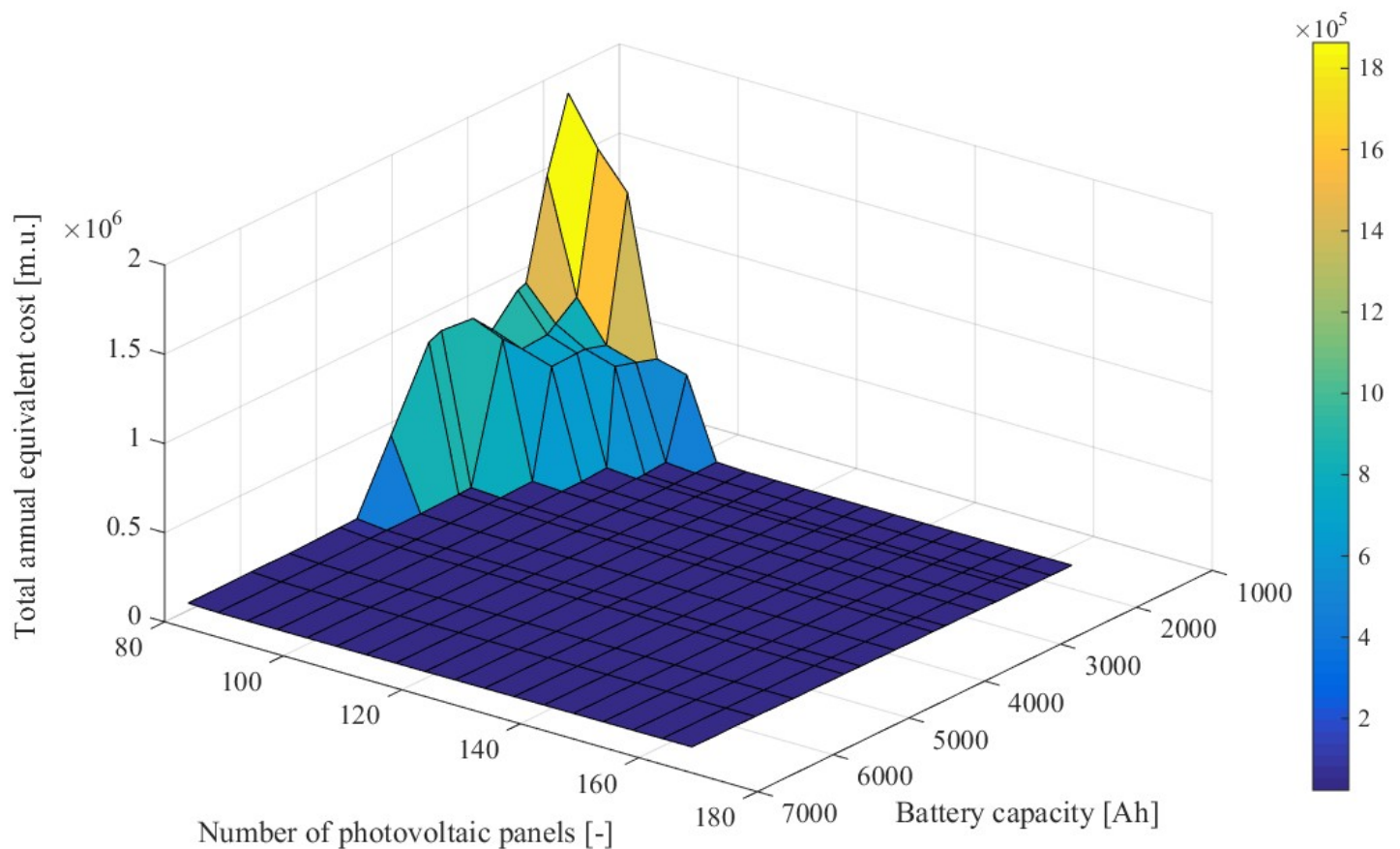

Figure 18. Equivalent annual total cost with respect to the capacity of the $110 \mathrm{~V}$ gel RES SOPzV battery system (see Table 7 ) and PV population $(80,85, \ldots$, and 165$)$ for an interest rate without inflation at $3 \%$.

5.5. Comparison of the Proposed SAPV System with a Battery against the Medium Voltage Submarine Connection with the Aegina Island

The proposed design methodology discovered a superior solution to the preliminary design method for the SAPV system with batteries. However, is this solution better than the classical one, which involves a medium voltage (MV) feeder of $20 \mathrm{kV}$ power supply of the off-site electrode station from the Greek distribution network by the Aegina island according to the guidelines by CIGRE ([45], chapter 7), as presented in Section 2.2. This power supply demands the construction of an MV submarine cable with a length of $8 \mathrm{~km}$ approximately, a transformer between 25 and $30 \mathrm{kVA}$ with the respective MV and low voltage (LV) switchboards, as it has been shown in Figures 2 and 5, where the feeder was one, the respective back-up diesel generator was only one, and the battery system could supply the vital loads for $48 \mathrm{~h}$. The submarine cable was the most expensive element, as its installation cost varied between 200 and $350 \mathrm{k} / \mathrm{km}$ with a typical value of $250 \mathrm{k} € / \mathrm{km}$, while other materials, such as concrete matrix blocks and uraducts for submarine cables crossings, transformers, switchboards, building expansion, etc., amounted to $80 \mathrm{k} €$ approximately, which means that the respective capital investment was about $2080 \mathrm{k} €$ according to the H-IPTSO data. The maintenance cost was $300 €$ per year because of the transformer service, while the power and the electricity charges could be ignored as it might not be evaluated by H-EDNO separately as the public benefit service. The respective economic life was 50 years.

Next, the equivalent annual total cost for the submarine cable connection between Aegina-Stachtoroi was carried out by Equations (65) and (66) for a different interest rate without inflation and it was compared with the respective cost of SAPV system with a battery in Figure 19. It was obvious that the proposed autonomous system for both battery types was superior for all rates with significant divergence, which increased no-linearly as the interest rate increased from $0 \%$ to $10 \%$. This means that the SAPV system with gel RES SOPzV batteries could be used if the respective interest rate was provided. 


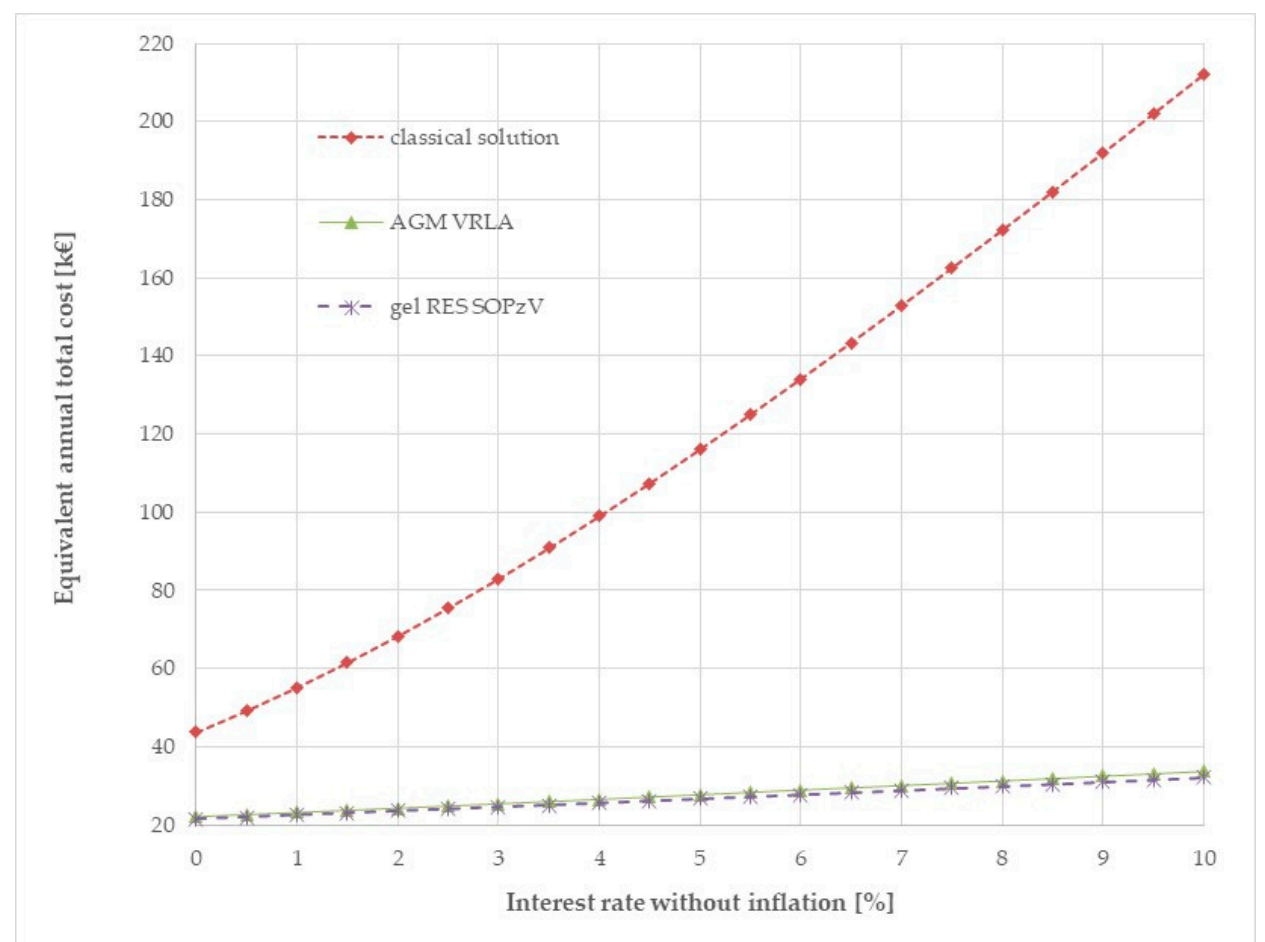

Figure 19. Equivalent annual total cost with respect to the interest rate without inflation for the best combinations of PVs, battery type (AGM VRLA or gel RES SOPzV), and capacities (according to Table 10) against the medium voltage submarine connection with the Aegina Island (classical solution).

\section{Conclusions}

In this paper, a numerical iterative techno-economic optimization methodology based on a sensitivity analysis is presented for the formation of an autonomous power system with PVs and battery, which is going to supply an isolated shoreline electrode station of the HVDC link. The basic advantages of the proposed methodology are:

- $\quad$ The optimization process of the SAPV system sizing selects elements (panels, battery modules) from a pool with real technical data at the expense of computational time.

- The optimized solution is realized through the modification of the PVs type and population and of the battery type and capacity based on a sensitivity analysis.

- Scarcely available meteorological data is used introducing the solar radiation modification factor $f_{\text {Hmday }}(t, t+d t)$ for the calculation of the available solar irradiation $H_{m \text {-panel-day }}(t, t+d t)$ for the time interval $(t, t+d t)$, so the PV produced power is estimated during the respective time interval.

- The daily electric energy consumption for the shoreline electrode station is carried out for each season (winter, summer, and autumn-spring) and different operation modes (stand-alone one and maintenance one) taking into consideration all electrical consumers of the station analytically with high precision.

- Many significant issues are taken into consideration by the proposed methodology, which are ignored or simplified by the classical ones [10], such as:

$>$ The lifetime, the capital, installation, maintenance, operation, and withdrawal costs for system elements (i.e., inverters, PVs, chargers, etc.),

$>$ The operation of PVs-battery charging cycle,

$>$ The battery ageing based on the relationship between battery cycles and depth of discharge,

$>$ The remaining capacity because of the battery degradation,

$>$ The battery auto-discharge rate, 
$>\quad$ The adoption of hyperbolic, exponential, and power functions for the battery cycles-depth of discharge curves for each battery with respect to the criteria of the mean square error and correlation index,

$>\quad$ The determination of the battery economic lifetime based on ageing/reliable energy inadequacy reasons,

$>$ The technical limitations of the system's elements (i.e., maximum power of chargers/inverters), etc.

- The SAPV system operation is simulated from an energy point of view for every day during the under study period satisfying the reliability criterion directly, where the SAPV operation will be failed, if the load demand is supplied by the back-up diesel-engine generator sets because of energy deficiency of the PVs-batteries system.

- The environmental limitation of $\mathrm{CO}_{2}$ emissions reduction is succeeded indirectly, as the generator sets are going to operate only for maintenance and SAPV forced outage reasons, not for energy supply systematically, which means that $\mathrm{CO}_{2}$ emissions are nullified practically.

- The result comparison proves its superiority against the classical one with respect to the equivalent annual total cost.

Additionally, the configuration of the electrical installation for lighting and auxiliary services of the electrode station was analyzed facing the shortages of the general guidelines of the CIGRE [45] and of the IEC [46] for the power system of the electrode stations of HVDC links. These guidelines imposed the power supply by the MV/LV distribution network and not by the autonomous system. Taking into consideration HVDC interconnections with high reliability levels and isolated/off-grid power supply for electrode stations new electrical installation configurations were proposed including renewable energy sources and energy storage systems and remote control. A dedicated electrode station building design is recommended for:

- The limitation of the energy consumption,

- The prevention of the danger for electrochemical corrosion of metallic structures by the direct current flow between electrode stations with no use of structural steel and metallic mechanical settlements,

- The protection with the highest significance factor against environmental dangers,

- The reduction of fire risk by the increment of fire-resistance and by supplementation of a fire-fighting system because of ESSs existence and electrode station isolation, etc.

Finally, a design process for the electrode station building was proposed with five steps, as it was presented in Section 2.3.

The aforementioned methodology was applied for the shoreline electrode station, which will be constructed on the small island of Stachtoroi for the new HVDC link of Attica-Crete in Greece. The proposed autonomous system can involve PVs, two batteries, and two back-up diesel generators for reliability reasons. Wind generators could not be used, because Stachtoroi is a protected sanctuary for seagulls. The PVs should be suitable for marine applications because of the short distance from the seaside $(5-10 \mathrm{~m})$. The batteries can be AGM VRLA ones or gel VRLA ones, but not classical flooded lead acid ones because of the maintenance issues or lithium-ion ones or hydrogen tanks because of serious difficulties in case of fire, while hydro-pumped storage plant cannot be placed because of a small height difference in island. The respective architecture solution is presented in Figure 6, which includes the main electrode station room, a control/accommodation room, two back-up diesel generator rooms, two battery rooms, a storage room, a water and pump room, a W.C., etc.

Following this, the population of PVs (23 values), the type (Narada AGM VRLA, SunLight gel RES $\mathrm{SOPzV}$ ), and the capacity of the battery ( 25 and 20 respectively) were modified and 1035 combinations were examined determining the battery economic lifetime by examining for each combination with 5478 different scenarios of an initial day and by choosing the most unfavorable one. From the sensitivity 
analysis, it was found out that for each battery type the capacity reached a "saturated" value, which it could be succeeded for a big population of PVs with constant capacity, for big capacities with a constant PV population, while an imaginary border line could be expanded between them. Finally, for each combination of PVs and the battery system the equivalent annual total cost was calculated for 21 different values of an interest rate without inflation (i.e., $0 \%, 0.5 \%, \ldots$, and $10 \%$ ). For both battery types the proposed configuration was different than the preliminary study one, while the battery capacity and $\mathrm{PV}$ population changed significantly, as the interest rate varied. The best configuration using gel RES SOPzV batteries was superior to the respective one of the AGM VRLA battery for every interest rate. The first one needed a smaller population of PVs and a bigger battery capacity than the second one for the same interest rate (see Table 10). At the end, the shoreline electrode station on the Stachtoroi island was proposed to be supplied by an autonomous power system with 115 PVs type Sxp154Q by Solbian, with two inverters SMA SUNNY TRIPOWER 10,000 TL, and two 110 V SunLight gel RES 6 SOPzV 850 battery systems (one parallel branch-55 elements in series per system) with two respective GSA industries chargers for the typical interest rate 3\%. Additionally, if the SAPV system is compared with the classical solution, which involves an MV feeder of $20 \mathrm{kV}$ of power supply with a $25 \mathrm{kVA}, 20$ $\mathrm{kV} / 400 \mathrm{~V}$ three-phase transformer for the off-site electrode station from the Greek distribution network by Aegina Island according to the guidelines by CIGRE ([45], chapter 7), the proposed system for both batteries types is superior for all rates with significant divergence, which increases non-linearly as the interest rate increases.

Author Contributions: Conceptualization, P.M.D., G.J.T. and C.D.T.; methodology, P.M.D., G.J.T. and V.T.K.; software, P.M.D., G.J.T. and F.D.K.; validation, P.M.D., G.J.T. and P.A.K.; formal analysis, P.M.D., G.J.T. and V.T.K.; investigation, P.M.D.; resources, P.M.D., G.J.T. and P.A.K.; data curation, C.D.T.; writing-original draft preparation, P.M.D., G.J.T., V.T.K. and P.A.K.; writing-review and editing, P.M.D., G.J.T. and F.D.K.; visualization, P.M.D., G.J.T. and V.T.K.; supervision, G.J.T. and C.D.K.; project administration, G.J.T.; funding acquisition, C.D.K. All authors have read and agreed to the published version of the manuscript.

Funding: This research was funded by H-IPTSO, grant number 191102.

Acknowledgments: The authors would like to thank the H-IPTSO for the meteorological and economic data availability.

Conflicts of Interest: The authors declare no conflict of interest. The funders (H-IPTSO) had no role in the design of the study; in the collection, analyses, or interpretation of data; in the writing of the manuscript, or in the decision to publish the results.

\section{Nomenclature}

$\begin{array}{ll}\text { Abbreviation } & \text { Explanation } \\ \text { AC } & \text { Alternating Current } \\ \text { AGM } & \text { Absorbed Glass Mat (for batteries) } \\ \text { CIGRE } & \text { International council on large electric systems } \\ \text { DC } & \text { Direct Current } \\ \text { DoD } & \text { Depth of Discharge (for battery) } \\ \text { ESS(s) } & \text { Energy Storage System(s) } \\ & \text { 1,1,1,2,3,3,3-Heptafluoropropane, also called heptafluoropropane, HFC-227ea (ISO } \\ \text { FM200 } & \text { name), HFC-227, apaflurane (INN), which is a colorless, odorless gaseous } \\ & \text { halocarbon, commonly used as a gaseous fire suppression agent. } \\ \text { GIS } & \text { Gas Insulated Substation } \\ \text { H-EDNO } & \text { Hellenic Electricity Distribution Network Operator } \\ \text { H-IPTSO } & \text { Hellenic Independent Power Transmission Operator } \\ \text { HVAC } & \text { High Voltage Alternative Current } \\ \text { HVAc } & \text { Heating-Ventilation-Air condition } \\ \text { HVDC } & \text { High Voltage Direct Current } \\ \text { ICAO } & \text { International Aviation Organization } \\ \text { IEC } & \text { International Electrotechnical Committee } \\ \text { LV } & \text { Low Voltage }\end{array}$




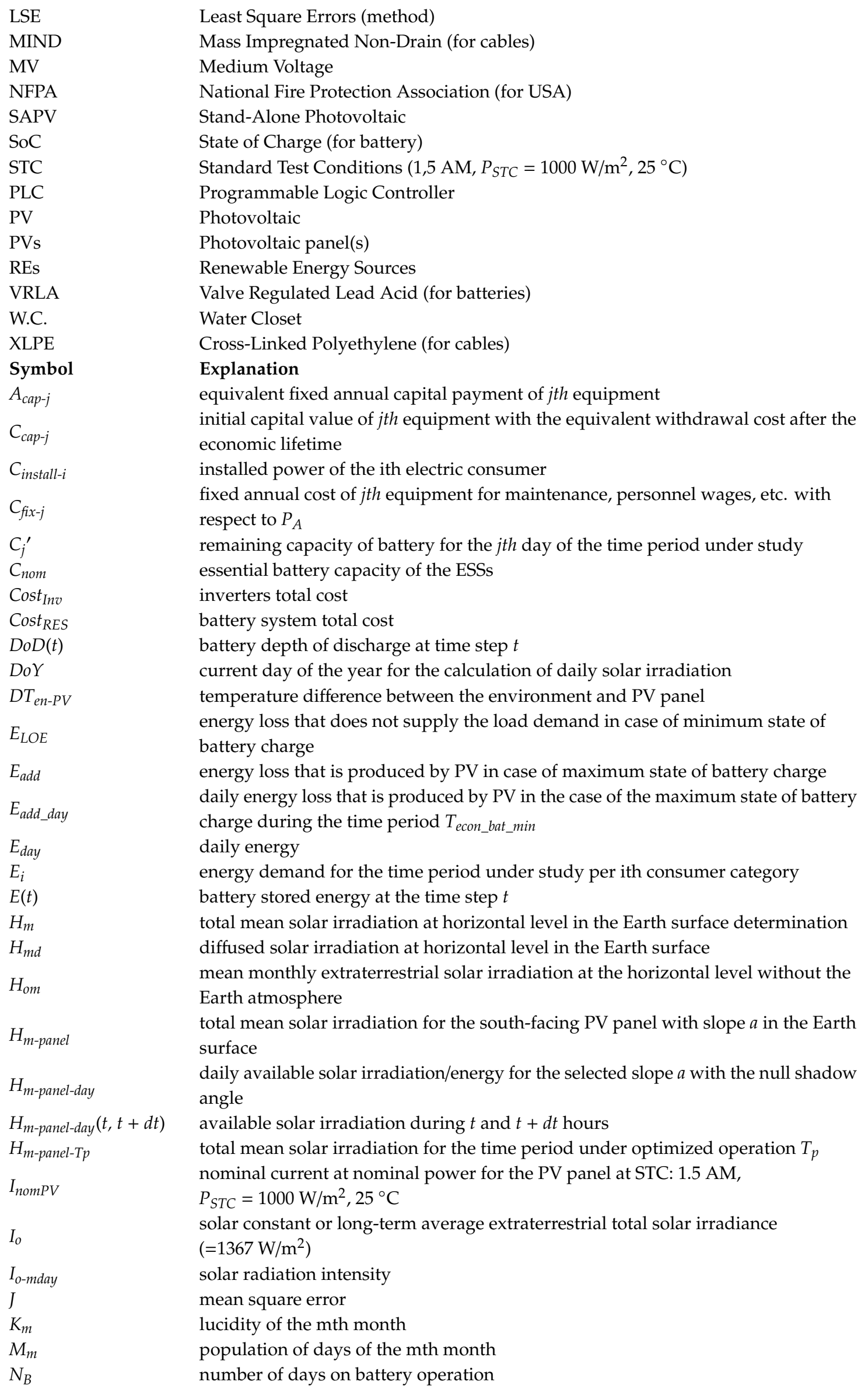




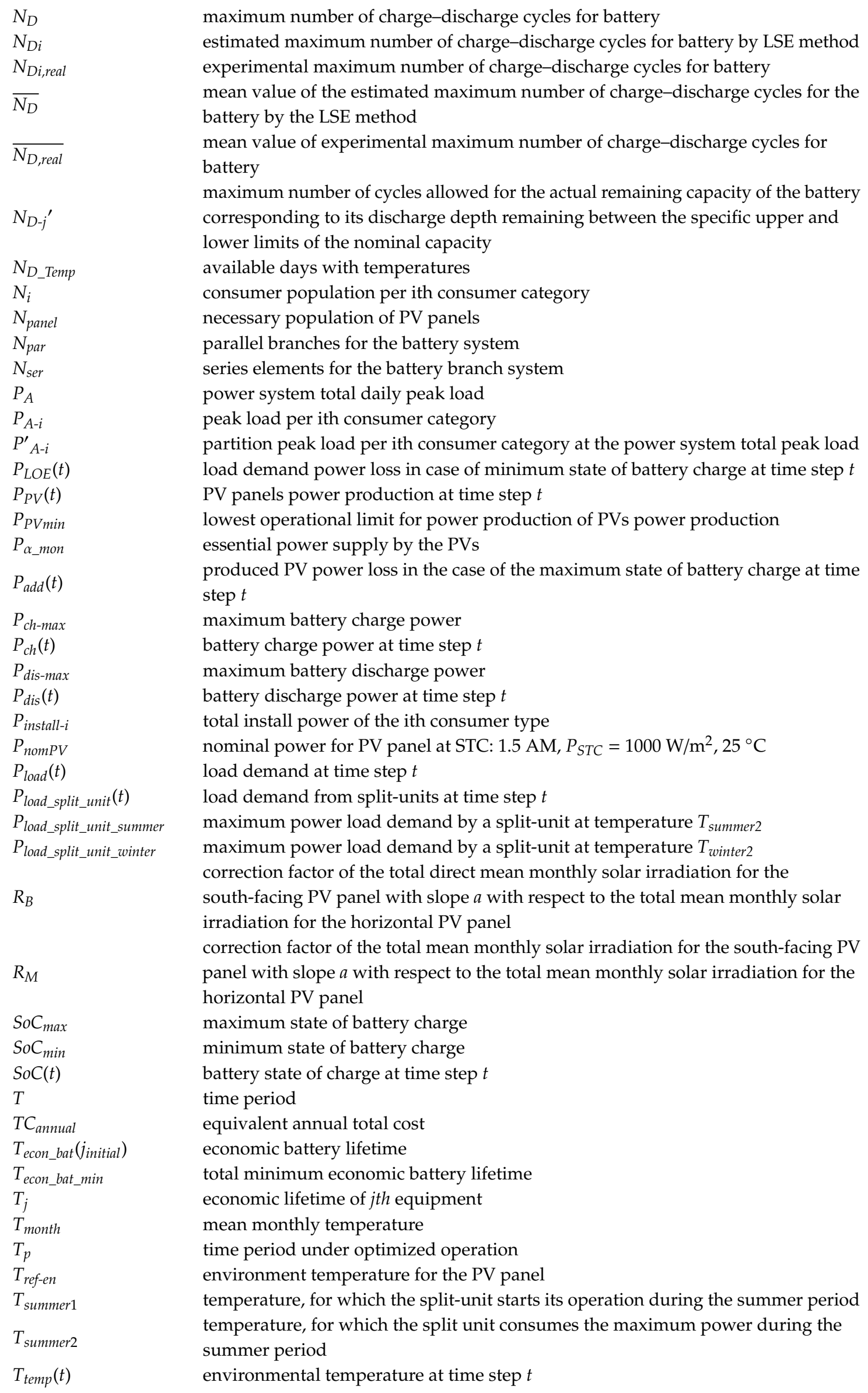




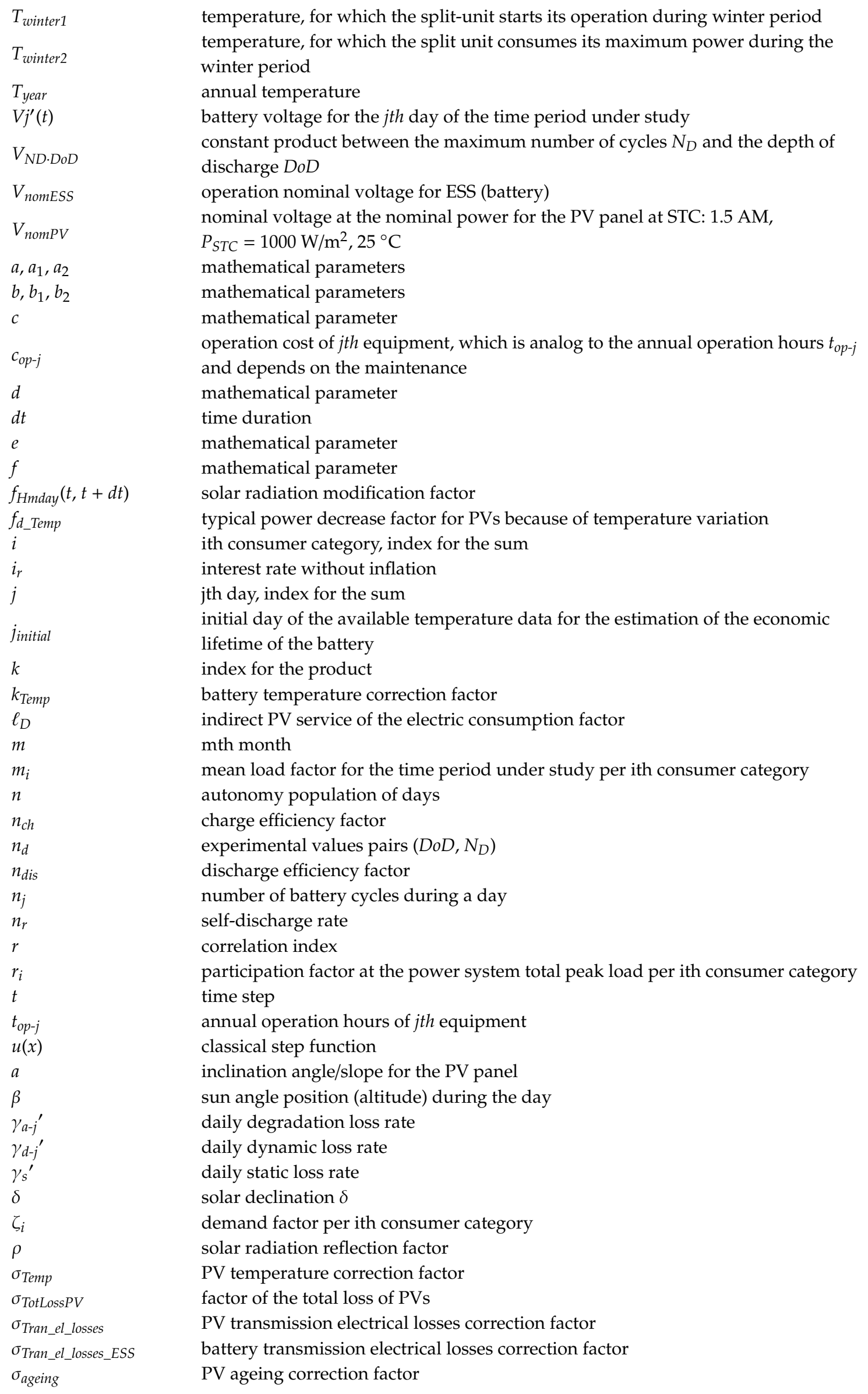




$\begin{array}{ll}\sigma_{\text {ageing_ESS }} & \text { battery ageing correction factor } \\ \sigma_{\text {blocking_diode }} & \text { blocking diode losses correction factor } \\ \sigma_{\text {cables }} & \text { PV cables losses factor } \\ \sigma_{i} & \text { coincidence factor per ith consumer category } \\ \sigma_{\text {in_Eday }} & \text { PV daily energy increment factor } \\ \sigma_{\text {in_Eday_ESS }} & \text { battery daily energy increment factor } \\ \sigma_{\text {no_homogeneity }} & \text { PV lack of homogeneity factor } \\ \sigma_{\text {pollution }} & \text { PV pollution correction factor } \\ \varphi & \text { latitude } \\ \omega_{S} & \text { time sunset } \\ \omega_{s}{ }^{\prime} & \text { hourly sunset angle for the day DoY for the south-facing PV panel with slope } a\end{array}$

\section{References}

1. Huang, B.J.; Hou, T.F.; Hsu, P.C.; Lin, T.H.; Chen, Y.T.; Chen, C.W.; Li, K.; Lee, K.Y. Design of direct solar PV driven air conditioner. Renew. Energy 2016, 88, 95-101. [CrossRef]

2. Kazem, H.A.; Khatib, T.; Sopian, K. Sizing of a standalone photovoltaic photovoltaic/battery system at minimum cost for remote housing electrification in Sohar, Oman. Energy Build. 2013, 61, 108-115. [CrossRef]

3. Benavente, F.; Lundlad, A.; Campana, P.E.; Zhang, Y.; Cabrera, S.; Lindbergh, G. Photovoltaic/battery system sizing for rural electrification in Bolivia: Considering the suppressed demand effect. Appl. Energy 2019, 235, 519-528. [CrossRef]

4. Tsai, C.T.; Beza, T.M.; Molla, E.M.; Kuo, C.C. Analysis and sizing of mini-grid hybrid renewable energy systems for islands. IEEE Access 2020, 8, 70013-70029. [CrossRef]

5. Sato, S.; Weidlich, A. Analysis of avoided transmission through decentralized photovoltaic and battery storage systems. IEEE Trans. Sustain. Energy 2020, 11, 1922-1929. [CrossRef]

6. Achiluzzi, E.; Kobikrishna, K.; Sivabalan, A.; Sabillon, C.; Venkatesh, B. Optimal asset planning for prosumers considering energy storage and photovoltaic (PV) units: A stochastic approach. Energies 2020, 13, 1813. [CrossRef]

7. Alnaser, S.W.; Althaher, S.Z.; Long, C.; Zhou, Y.; Wu, J. Residential community with PV and batteries: Reserve provision under grid constraints. Int. J. Electr. Power Energy Syst. 2020, 119, 105856. [CrossRef]

8. Ridha, H.M.; Gomes, C.; Hizam, H.; Ahmadipour, M. Sizing and implementing off-grid stand-alone photovoltaic/battery systems based on multi-objective optimization and techno-economic (MADE) analysis. Energy 2020, 207, 118163. [CrossRef]

9. Rahman, M.M.; Islam, A.K.M.S.; Salehin, S.; Al-Matin, M.A. Development of a model for techno-economic assessment of a stand-alone off-grid solar photovoltaic system in Bangladesh. Int. J. Renew. Energy Res. 2016, 6, 140-149.

10. Dervos, C.T. Photovoltaic Systems_From Theory to Practice, 1st ed.; University Press NTUA: Athens, Greece, 2013; pp. 1-526. (In Greek)

11. Mpizionis, V.D.; Mpizionis, D.V. Alternative Power Sources, 1st ed.; Tziolas Press: Thessaloniki, Greece, 2011; pp. 1-744. (In Greek)

12. Sarhan, A.; Hizam, H.; Mariun, N.; Ya'acob, M.E. An improved numerical optimization algorithm for sizing and configuration of stand-alone photo-voltaic system components in Yemen. Renew. Energy 2019, 134, 1434-1446. [CrossRef]

13. Katsaprakakis, D.E. Energy Systems Synthesis, 1st ed.; Hellenic Academic Books: Athens, Greece, 2015; pp. 1-398. (In Greek)

14. Rossi, F.; Heleno, M.; Basosi, R.; Sinicropi, A. Environmental and economic optima of solar home systems design: A combined LCA and LCC approach. Sci. Total Environ. 2020, 744, 140569. [CrossRef] [PubMed]

15. Cabral, C.V.T.; Filho, D.O.; Diniz, A.S.A.C.; Martins, J.H.; Toledo, O.M.; Neto, L.V.B.M. A stochastic method for stand-alone photovoltaic sizing. Sol. Energy 2010, 84, 1628-1636. [CrossRef]

16. Khatib, T.; Elmenreich, W. An improved method for sizing stand-alone photovoltaic systems using reneralized regression neural network. Int. J. Photoenergy 2014, 2014. [CrossRef] 
17. Ridha, H.M.; Gomes, C.; Hizam, H.; Ahmadipour, M.; Muhsen, D.H.; Ethaib, S. Optimum design of a stand-alone solar photovoltaic system based on novel integration of iterative-PESA-II and AHP-VIKOR methods. Processes 2020, 8, 367. [CrossRef]

18. Mandelli, S.; Barbieri, J.; Mereu, R.; Colombo, E. Off-grid systems for rural electrification in developing countries: Definitions, classification and a comprehensive literature review. Renew. Sustain. Energy Rev. 2016, 58, 1621-1646. [CrossRef]

19. Goel, S.; Sharma, R. Performance evaluation of stand-alone, grid connected and hybrid renewable energy systems for rural population: A comparative review. Renew. Sustain. Energy Rev. 2017, 78, 1378-1389. [CrossRef]

20. Luna-Rubio, R.; Trejo-Perea, M.; Vargas-Vazquez, D.; Rios-Moreno, G.J. Optimal sizing of renewable hybrids energy systems: A review of methodologies. Sol. Energy 2012, 86, 1077-1088. [CrossRef]

21. Al-falahi, M.D.A.; Jayasinghe, S.D.G.; Enshaei, H. A review on recent size optimization methodologies for standalone solar and wind hybrid renewable energy system. Energy Convers. Manag. 2017, 143, $252-274$. [CrossRef]

22. Fadaee, M.; Radzi, M.A.M. Multi-objective optimization of a stand-alone hybrid renewable energy system by using evolutionary algorithms: A review. Renew. Sustain. Energy Rev. 2012, 16, 3364-3369. [CrossRef]

23. Ridha, H.M.; Gomes, C.; Hizam, H.; Ahmadipour, M.; Heidari, A.A.; Chen, H. Multi-objective optimization and multi-criteria decision-making methods for optimal design of standalone photovoltaic system: A comprehensive review. Renew. Sustain. Energy Rev. 2021, 135, 110202. [CrossRef]

24. Khan, F.A.; Pal, N.; Saeed, S.H. Review of solar photovoltaic and wind hybrid energy systems for sizing strategies optimization and cost analysis methodologies. Renew. Sustain. Energy Rev. 2018, 52, 937-947. [CrossRef]

25. Khatib, T.; Ibrahim, I.A.; Mohamed, A. A review on sizing methodologies of photovoltaic array and storage battery in a standalone photovoltaic system. Energy Convers. Manag. 2016, 120, 430-448. [CrossRef]

26. Singh, G.K. Solar power generation by PV (photovoltaic) technology: A review. Energy 2013, 53, 1-13. [CrossRef]

27. Lian, J.; Zhang, Y.; Ma, C.; Yanga, Y.; Chaima, E. A review on recent sizing methodologies of hybrid renewable energy systems. Energy Convers. Manag. 2019, 199, 112027. [CrossRef]

28. Banik, R.; Das, P. A Review on Architecture, Performance and Reliability of Hybrid Power System. J. Inst. Eng. Series B 2020, 101, 527-539. [CrossRef]

29. Siddaiah, R.; Saini, R.P. A review on planning, configurations, modeling and optimization techniques of hybrid renewable energy systems for off grid applications. Renew. Sustain. Energy Rev. 2016, 58, 376-396. [CrossRef]

30. Mahesh, A.; Sandhu, K.S. Hybrid wind/photovoltaic energy system developments: Critical review and findings. Renew. Sustain. Energy Rev. 2015, 52, 1135-1147. [CrossRef]

31. Bullich-Massagué, E.; Cifuentes-García, F.J.; Glenny-Crende, I.; Cheah-Mañé, M.; Aragüés-Peñalba, M.; Díaz-González, F.; Gomis-Bellmunt, O. A review of energy storage technologies for large scale photovoltaic power plants. Appl. Energy 2020, 274, 115213. [CrossRef]

32. Katsaprakakis, D.A.; Dakanali, I.; Condaxakis, C.; Christakis, D.G. Comparing electricity storage technologies for small insular grids. Appl. Energy 2019, 251, 113332. [CrossRef]

33. Gutierrez-Martin, F.; Calcerrada, A.B.; de Lucas-Consuerga, A.; Dorado, F. Hydrogen storage for off-grid power supply based on solar PV and electrochemical reforming of ethanol-water solutions. Renew. Energy 2020, 147, 639-649. [CrossRef]

34. Leon, D.R.F.; Cavaliero, C.K.N.; da Silva, E.P. Technical and economical design of PV system and hydrogen storage including a sodium hypochlorite plant in a small community: Case of study of Paraguay. Int. J. Hydrog. Energy 2020, 45, 5474-5480. [CrossRef]

35. Hassani, H.; Zaouche, F.; Rekioua, D.; Belaid, S.; Rekioua, T.; Bacha, S. Feasibility of a standalone photovoltaic/battery system with hydrogen production. J. Energy Storage 2020, 31, 101644. [CrossRef]

36. Dawood, F.; Shafiullah, G.M.; Anda, M. Stand-alone microgrid with $100 \%$ renewable energy: A case study with hybrid solar PV-battery-hydrogen. Sustainability 2020, 12, 2047. [CrossRef]

37. Ma, T.; Yang, H.; Lu, L.; Peng, J. Pumped storage-based standalone photovoltaic power generation system: Modeling and techno-economic optimization. Appl. Energy 2015, 137, 649-659. [CrossRef] 
38. Zhao, P.; Xu, W.; Zhang, S.; Wang, J.; Dai, Y. Technical feasibility assessment of a standalone photovoltaic/wind/adiabatic compressed air energy storage based hybrid energy supply system for rural mobile base station. Energy Convers. Manag. 2020, 206, 112486. [CrossRef]

39. Bhayo, B.A.; Al-Kayiem, H.H.; Gilani, S.I.U.; Ismail, F.B. Power management optimization of hybrid solar photovoltaic-battery integrated with pumped-hydro-storage system for standalone electricity generation. Energy Convers. Manag. 2020, 215, 112942. [CrossRef]

40. Loubna, A.; Riad, T.; Salima, M. Standalone photovoltaic array fed induction motor driven water pumping system. Int. J. Electr. Comput. Eng. 2020, 10, 4534-4542. [CrossRef]

41. Sidney, S.; Thomas, J.; Dhasan, M.L. A standalone PV operated DC milk chiller for Indian climate zones. Sadhana 2020, 45, 110. [CrossRef]

42. Baaqeel,H.; Abdelhady, F.; Alghamdi, A.; El-Halwagi, M.M. Optimal design and scheduling of a solar-assisted domestic desalination systems. Comput. Chem. Eng. 2020, 132, 106605. [CrossRef]

43. Shan, C.; Lv, M.; Sun, K.; Gao, J. Analysis of energy system configuration and energy balance for stratospheric airship based on position energy storage strategy. Aerosp. Sci. Technol. 2020, 101, 105844. [CrossRef]

44. Ariadni Interconnection. Technical Description of Shoreline Electrodes for HVDC Link Attica-Crete, 1st ed.; Ariadni Interconnection: Athens, Greece, 2019; pp. 1-30.

45. CIGRE Working Group B4.61. General Guidelines for HVDC Electrode Design, 1st ed.; CIGRE: Paris, France, 2017; Volume 675, pp. 1-150.

46. International Electrotechnical Commission. IEC/TS 62344-Design of Earth Electrode Stations for High Voltage Direct Current (HVDC) Links-General Guidelines, 1st ed.; IEC: Geneva, Switzerland, 2013; pp. 1-91.

47. Lupangu, C.; Bansal, R.C. A review of technical issues on the development of solar photovoltaic systems. Renew. Sustain. Energy Rev. 2017, 73, 950-965. [CrossRef]

48. Kabouris, J.; Karystianos, M.; Nomikos, B.; Tsourakis, G.; Mantzaris, J.; Sakellaridis, N.; Voumvoulakis, E. Power system static and dynamic security studies for the 1st phase of Crete Island Interconnection. J. Energy 2018, 67, 33-43.

49. Woud, H.K.; Stapersma, D. Design of Propulsion and Electric Power Generation Systems, 1st ed.; IMarEST Publications: London, UK, 2002; pp. 1-494.

50. ABB. Switchgear Manual, 11th ed.; ABB AG: Berlin, Germany, 2008; pp. 1-896.

51. Official Gazette. Building Energy Saving Regulations, 2nd ed.; Ministerial Decree; B.2367/12.7.2017; Official Gazette: Elláda, Greece, 2017.

52. National Fire Protection Association. NFPA 72, National Fire Alarm Code; NFPA: Quincy, MA, USA, 2007; p. 272.

53. National Fire Protection Association. NFPA 855, Standard for the Installation of Stationary Energy Storage Systems; NFPA: Quincy, MA, USA, 2020.

54. National Fire Protection Association. NFPA 75, Standard for the Protection of Electronic Computer/Data Processing Equipment; NFPA: Quincy, MA, USA, 1999; p. 18.

55. Rajput, S.; Saikia, P.P. Fire Extinguishing Agents: Sort and Comparison. Int. J. Res. Appl. Sci. Eng. Technol. 2018, 6, 557-567. [CrossRef]

56. National Fire Protection Association. NFPA 2001, Standard on Clean Agent Fire Extinguishing Systems; NFPA: Quincy, MA, USA, 2000; p. 106.

57. National Fire Protection Association. NFPA 13, Standard for the Installation of Sprinkler Systems; NFPA: Quincy, MA, USA, 2000; p. 746.

58. The Impulse Firefighting Gun and Its Supply Units. Available online: https://www.ifex3000.com/en/impulsefirefighting-gun/ (accessed on 2 August 2020).

59. Map of Attica Greece. Available online: https://www.in2greece.com/mappages/stereaellada/attica.htm (accessed on 2 August 2020).

60. SOLBIAN SXp154L Panel. Available online: https://solbian.gr/index.php?route=product/product\&path=20_ 62\&product_id=74 (accessed on 1 May 2020).

61. Technologies. Available online: http://en.naradapower.com/index.php/technologies?ctype=75 (accessed on 1 May 2020).

62. Reserve Power Batteries. Available online: https://www.systems-sunlight.com/product/applications/ups/ spb-agm-batteries/\# (accessed on 1 May 2020). 
63. Yang, Y.; Lian, C.; Ma, C.; Zhang, Y. Research on Energy Storage Optimization for Large-Scale PV Power Stations under Given Long-Distance Delivery Mode. Energies 2019, 13, 27. [CrossRef]

64. Wang, S.; Liu, S.; Yang, F.; Bai, X.; Yue, C. Novel Power Allocation Approach in a Battery Storage Power Station for Aging Minimization. Front. Energy Res. 2020, 7, 166. [CrossRef]

65. Hein, K.; Yan, X.; Wilson, G. Optimal multi-objective scheduling of hybrid ferry with shore to shore power supply considering energy storage degradation. Electronics 2020, 9, 849. [CrossRef]

66. SMA Sunny Tripower 8000 TL. Available online: http://www.europe-solarshop.com/inverters/sma/smasunny-tripower-8000tl.html (accessed on 1 May 2020).

67. GSA 110 VDC Battery Charger. Available online: https://www.indiamart.com/proddetail/110-vdc-batterycharger-10100011155.html (accessed on 1 May 2020).

Publisher's Note: MDPI stays neutral with regard to jurisdictional claims in published maps and institutional affiliations.

(C) 2020 by the authors. Licensee MDPI, Basel, Switzerland. This article is an open access article distributed under the terms and conditions of the Creative Commons Attribution (CC BY) license (http://creativecommons.org/licenses/by/4.0/). 